\title{
Clinical practice guideline for endoscopic resection of early gastrointestinal cancer
}

\author{
Chan Hyuk Park ${ }^{1 *}$, Dong-Hoon Yang ${ }^{2 *}$, Jong Wook Kim ${ }^{3}$, Jie-Hyun Kim ${ }^{4}$, Ji Hyun Kim ${ }^{5}$, Yang Won Min ${ }^{6}$,
} Si Hyung Lee ${ }^{7}$, Jung Ho Bae ${ }^{8}$, Hyunsoo Chung ${ }^{9}$, Kee Don Choi ${ }^{2}$, Jun Chul Park ${ }^{10}$, Hyuk Lee ${ }^{6}$, Min-Seob Kwak ${ }^{11}$, Bun Kim ${ }^{12}$, Hyun Jung Lee ${ }^{9}$, Hye Seung Lee ${ }^{13}$, Miyoung Choi ${ }^{14}$, Dong-Ah Park ${ }^{14}$, Jong Yeul Lee ${ }^{15}$, Jeong-Sik Byeon ${ }^{2}$, Chan Guk Park ${ }^{16}$, Joo Young Cho ${ }^{17}$, Soo Teik Lee ${ }^{18}$, Hoon Jai Chun ${ }^{19}$

\begin{abstract}
${ }^{1}$ Department of Gastroenterology, Hanyang University Guri Hospital, Guri; ${ }^{2}$ Department of Gastroenterology, Asan Medical Center, Seoul; ${ }^{3}$ Department of Gastroenterology, Inje University Ilsan Paik Hospital, Goyang; ${ }^{4}$ Department of Gastroenterology, Yonsei University Gangnam Severance Hospital, Seoul; ${ }^{5}$ Department of Gastroenterology, Inje University Busan Paik Hospital, Busan; ${ }^{6}$ Department of Gastroenterology, Samsung Medical Center, Seoul; ${ }^{7}$ Department of Gastroenterology, Yeungnam University Medical Center, Daegu; ${ }^{8}$ Department of Gastroenterology, Seoul National University Hospital Healthcare System Gangnam Center, Seoul; ${ }^{9}$ Department of Gastroenterology, Seoul National University Hospital, Seoul; ${ }^{10}$ Department of Gastroenterology, Yonsei University Severance Hospital, Seoul; ${ }^{11}$ Department of Gastroenterology, Kyung Hee University Hospital at Gangdong, Seoul, ${ }^{12}$ Center for Colorectal Cancer, National Cancer Center, Goyang; ${ }^{13}$ Department of Pathology, Seoul National University Bundang Hospital, Seongnam; ${ }^{14}$ National Evidence-based Healthcare Collaborating Agency, Seoul; ${ }^{15}$ Center for Gastric Cancer, National Cancer Center, Goyang; ${ }^{16}$ Department of Gastroenterology, Chosun University Hospital, Gwangju; ${ }^{17}$ Department of Gastroenterology, Cha University Bundang Medical Center, Seongnam; ${ }^{18}$ Department of Gastroenterology, Jeonbuk National University Hospital, Jeonju; ${ }^{19}$ Department of Gastroenterology, Korea University Anam Hospital, Seoul, Korea
\end{abstract}

Although surgery was the standard treatment for early gastrointestinal cancers, endoscopic resection is now a standard treatment for early gastrointestinal cancers without regional lymph node metastasis. High-definition white light endoscopy, chromoendoscopy, and image-enhanced endoscopy such as narrow band imaging are performed to assess the edge and depth of early gastrointestinal cancers for delineation of resection boundaries and prediction of the possibility of lymph node metastasis before the decision of endoscopic resection. Endoscopic mucosal resection and/or endoscopic submucosal dissection can be performed to remove early gastrointestinal cancers completely by en bloc fashion. Histopathological evaluation should be carefully made to investigate the presence of risk factors for lymph node metastasis such as depth of cancer invasion and lymphovascular invasion. Additional treatment such as radical surgery with regional lymphadenectomy should be considered if the endoscopically resected specimen shows risk factors for lymph node metastasis. This is the first Korean clinical practice guideline for endoscopic resection of early gastrointestinal cancer. This guideline was developed by using mainly de novo methods and encompasses endoscopic management of superficial esophageal squamous cell carcinoma, early gastric cancer, and early colorectal cancer. This guideline will be revised as new data on early gastrointestinal cancer are collected. (Intest Res 2021;19:127-157)

Key Words: Superficial esophageal squamous cell carcinoma; Early gastric cancer; Early colorectal cancer; Endoscopic resection; Guideline 


\section{INTRODUCTION}

Endoscopic resection is a minimally invasive procedure for the treatment of early gastrointestinal cancers including esophageal, gastric, and colorectal cancers. ${ }^{1}$ In South Korea, the widespread use of upper gastrointestinal and colorectal endoscopies for screening purposes has increased the rate of early diagnosis of gastrointestinal cancers and, subsequently, the number of endoscopic resections performed for early gastrointestinal cancers. ${ }^{2,3}$ The popularity of endoscopic submucosal dissection (ESD) has rapidly increased with over thousands of ESD procedures performed per year as the procedure allows the en bloc resection of a lesion regardless of its size and location. ${ }^{3,4}$ ESD was first introduced in South Korea in 1999 and has been widely accepted as a treatment method for early gastric cancer since 2003. It was performed in 45 tertiary medical institutions in 2014 and is being performed in $44 \%$ of the total 287 general hospitals in South Korea. ${ }^{5}$

Endoscopic resection does not require general anesthesia, has fast recovery time relative to the extent of resection, requires a short hospital stay, and is cost-friendly. ${ }^{6}$ However, since the procedure only resects primary local lesions and not the lymph nodes, it is important to screen patients for early gastrointestinal cancer without a possibility of lymph node metastasis before endoscopic resection. ${ }^{1,7,8}$ Additionally, even if endoscopic resection of a local lesion is successful, surgical resection must still be considered to minimize the possibility of cancer recurrence and metastasis when histopathological risk factors associated with cancer recurrence in the lymph nodes are detected in the endoscopic resection specimen. High-resolution endoscopy, image-enhanced endoscopy, chromoscopy, magnification endoscopy, endoscopic ultrasound, and computed tomography (CT) are used in making the clinical decision of whether to perform endoscopic resections, ${ }^{9-15}$ and models have been developed that can predict patients with high likelihoods of lymph node metastasis. ${ }^{1,7,8,16,17}$ Evidence-based guidelines published from other countries help clinicians with decision-making regarding the examination and treatment of gastrointestinal cancers. ${ }^{1}$ However, since the incidence of gastrointestinal cancers and available medical resources vary greatly depending on the target organs (esophagus, stomach, and colon), countries, and regions, direct application of foreign guidelines to the medical situations of South Korea would be inadequate. South Korea still has no clinical practice guidelines for endoscopic resection of early gastrointestinal cancers despite the high need for it, forcing physicians to refer to foreign clinical practice guidelines or review domestic literatures and apply their results in clinical practice. The present clinical practice guideline comprehensively reviews studies on endoscopic resection of early gastrointestinal cancers conducted in and outside Korea and proposes recommendations for the examination and treatment of early gastrointestinal cancers after considering the epidemiological and clinical characteristics of early gastrointestinal cancers and medical environments in the country. This guideline consists of three sections, each discussing superficial esophageal squamous cell carcinoma (SESCC), early gastric cancer, and early colorectal cancer, and will be subject to revisions and modifications based on future research findings.

\section{METHODS}

\section{Purpose and Scope of Developing Clinical Practice Guideline}

We aimed to develop a treatment guideline for endoscopic resection of early gastrointestinal cancers that caters to the current medical situations in Korea and can be used in clinical settings. The target population for this guideline included male and female adults with SESCC, early gastric cancer, and early colorectal cancer requiring endoscopic resection. The users of this clinical guideline are gastroenterologists who perform gastrointestinal endoscopy in primary, secondary, and tertiary medical institutions. To facilitate the understanding of gastroenterologists, the definitions of terms regarding endoscopic resection were presented in Table 1. The purpose of the guideline is to help these physicians make decisions regarding patient diagnosis, preoperative evaluation, method of resection, and postoperative management. It also aims to guide resident physicians and hospital employees in these aspects and provide patients and healthy persons with realistic and standard medical information.

\section{Formation of the Clinical Practice Guideline Com- mittee and Development Process}

The Clinical Practice Guideline Committee consisted of the president (Hoon Jai Chun), congress chairman (Soo Teik Lee), and committee members of Korean Society of Gastrointestinal Endoscopy (KSGE) in November 2017. The members of the committee established a development strategy, elected a director of clinical practice guideline project, and reviewed and approved budgets regarding the project. In addition, they reviewed proposed recommendations and ensured editorial 
Table 1. Definition of Terms Related to Endoscopic Resection

\begin{tabular}{ll}
\hline Term & \multicolumn{1}{c}{ Definition } \\
\hline En bloc resection & Resection of a tumor in one piece without visible residual tumor \\
Complete resection & $\begin{array}{l}\text { Resection of a tumor without histological evidence of tumor cell involvement on the lateral and vertical resection margins } \\
\text { Curative resection }\end{array}$ \\
$\begin{array}{l}\text { Resection of an early gastrointestinal cancer, which is considered curative based on complete resection and minimal to no } \\
\text { risk of lymph node metastasis } \\
\text { The criteria for curative resection are different according to the type of cancers (early esophageal, gastric and colorectal } \\
\text { cancers) }\end{array}$ \\
\hline
\end{tabular}

independence and participation of all involved parties in the guideline editing process. The Clinical Practice Guideline Committee in January, 2020 (Joo Young Cho, the president and Chan Guk Park, the congress chairman) reviewed the final version of guideline and approved its publication.

The Clinical Practice Guideline Committee formed the KSGE Task Force on Clinical Practice Guideline, which directed the development of the clinical practice guideline for endoscopic resection of early gastrointestinal cancers. For multidisciplinary development of the clinical practice guideline, Jeong-Sik Byeon, a gastroenterologist and member of KSGE, was appointed as the director of the KSGE Task Force on Clinical Practice Guideline along with the recommended medical experts of KSGE (Jong Wook Kim, Jie-Hyun Kim, Ji Hyun Kim, Yang Won Min, Chan Hyuk Park, Si Hyung Lee, and Jong Yeul Lee), the Korean Society of Gastroenterology (Jung Ho Bae, Dong-Hoon Yang, Hyunsoo Chung, and Kee Don Choi), the Korean College of Helicobacter and Upper Gastrointestinal Research (Jun Chul Park and Hyuk Lee), the Korean Association for the Study of Intestinal Diseases (Min-Seob Kwak), the Korean Society of Gastrointestinal Cancer (Bun Kim and Hyun Jung Lee), and the Korean Society of Pathologists (Hye Seung Lee) as members of the KSGE Task Force. Additionally, two experts (DongAh Park and Miyoung Choi) of clinical practice guideline development from the National Evidence-based Healthcare Collaborating Agency participated in the guideline development. Three sub-committees were formed for each gastrointestinal cancer-SESCC (team leader: Kee Don Choi), early gastric cancer (team leader: Jong Yeul Lee), and early colorectal cancer (Dong-Hoon Yang) - to ensure systematic guideline development. The sub-committees selected key questions for the guideline, conducted a literature search, derived recommendations, and wrote and edited the first draft of the guideline.

To maintain consistency in guideline development among the sub-committees, the KSGE Task Force on Clinical Practice Guideline held four meetings since December 22, 2017. The Task Force also held two workshops to establish a methodolo- gy for guideline development and review the development process (March 12, 2018 and November 10, 2018). These workshops were accompanied by an education session on the methods of guideline development, grading of scientific evidence and recommendations, and achievement of recommendation consensus. The Task Force chose the de novo guideline development approach. The sub-committees for guideline development developed the clinical practice guideline through online and in-person meetings.

\section{Selection of Key Questions}

Selection criteria were established, and a questionnaire was formed through the PICO process wherein key questions to be included in the clinical practice guideline were derived. $\mathrm{P}$ (population) represents patients with SESCC, early gastric cancer, and early colorectal cancer; I (intervention) represents interventions including diagnostic and treatment methods; $\mathrm{C}$ (comparison) includes patient groups for comparison between specific intervention methods; and O (outcome) represents the usefulness of diagnosis or treatment outcome. The PICO processes are presented in Supplementary Material 1. The members of the sub-committees for guideline development gathered questionnaires containing key questions and rated the importance of each question to determine the questions to be included in the clinical practice guideline. Studies were excluded if any of the following was noted: (1) the studies did not involve human subjects or the target patients of the guideline's key questions; (2) the studies did not conduct an intervention related to the key questions and an intervention for comparison; (3) the studies were review articles, case reports or abstracts only; (4) the studies were not published in English or Korean; and (5) the studies' original copies could not be found. In case where $\geq 2$ studies used the same groups of subjects, the smaller studies were excluded.

\section{Literature Search and Selection}

A literature search was conducted using the MEDLINE, EM- 
BASE, Cochrane Library, KoreaMed, and the Guideline International Network in August 2018 by Miyoung Choi, a researcher from the National Evidence-based Healthcare Collaborating Agency. Keywords related to esophageal cancer (("esophageal" OR "esophagus" OR "oesophageal" OR "oesophagus" OR "gullet") AND ("cancer\$" OR “tumo? r" OR "carcinoma\$" OR “adenocarcinoma\$" OR “neoplas\$”)), gastric cancer (("stomach" OR "gastric") AND ("cancer\$" OR "tumo?r" OR "carcinoma\$” OR “adenocarcinoma\$” OR “neoplas\$”)), colorectal cancer ((“colon\$” OR "rectum" OR "colorectal" OR "rectal") AND ("polyp\$" OR "cancer" OR “adenoma\$” OR “adenocarcino\$” OR “carcino\$” OR "tumo? $\mathrm{r}$ ")), and endoscopic resection (("endoscop\$") AND (“dissection" OR "resection" OR “treat\$” OR "ESD")) were used. Different keywords or different combinations of keywords were also used based on the key questions. Duplicate articles were removed. Two committee members were assigned to the key questions, and they independently selected articles according to the inclusion and exclusion criteria. They first removed articles irrelevant to the guideline development based on titles and abstracts and then reviewed the entire content of the remaining articles for further screening. Any disagreements between the two members were resolved through negotiations. In case they did not reach a consensus, the team leader of the corresponding sub-committee made the final decision. The flowchart showing the searching process is shown in Supplementary Material 2.

\section{Bias Assessment and Summary of Evidence and Rec- ommendation Grade}

The validity of the selected articles that would form the basis of the clinical practice guideline was assessed using systematic methods. The revised Cochrane Risk of Bias Tool was used to evaluate randomized comparative studies, ${ }^{18,19}$ and RoBANS 2.0 and Newcastle-Ottawa assessment scale were used to evaluate nonrandomized studies. ${ }^{20}$ The QUADAS-2 (Quality Assessment of Diagnostic Accuracy Studies-2) tool was used for diagnostic studies. ${ }^{21}$ The GRADE (Grading of Recommendations Assessment, Development and Evaluation) method was used to present summaries of evidence. ${ }^{22}$ Although, by default, randomized comparative studies have high levels of evidence, and observational studies low levels of evidence, a study's final level of evidence was determined as high, moderate, low, or very low based on various factors affecting the quality of research.

The grade of recommendation was determined as strong or weak based on the balance between positive and negative effects of the recommendation, quality of evidence, values, and preferences. Strong recommendations are recommended to most patients since the recommendations have more positive than negative effects, are supported by high-quality evidence, are highly valuable, and are more strongly preferred than other interventions. Weak recommendations are also beneficial for many patients although they have relatively small positive effects that are supported by weak evidence. Alternative inter-

Table 2. Summary and Strength of Recommendations for SESCC

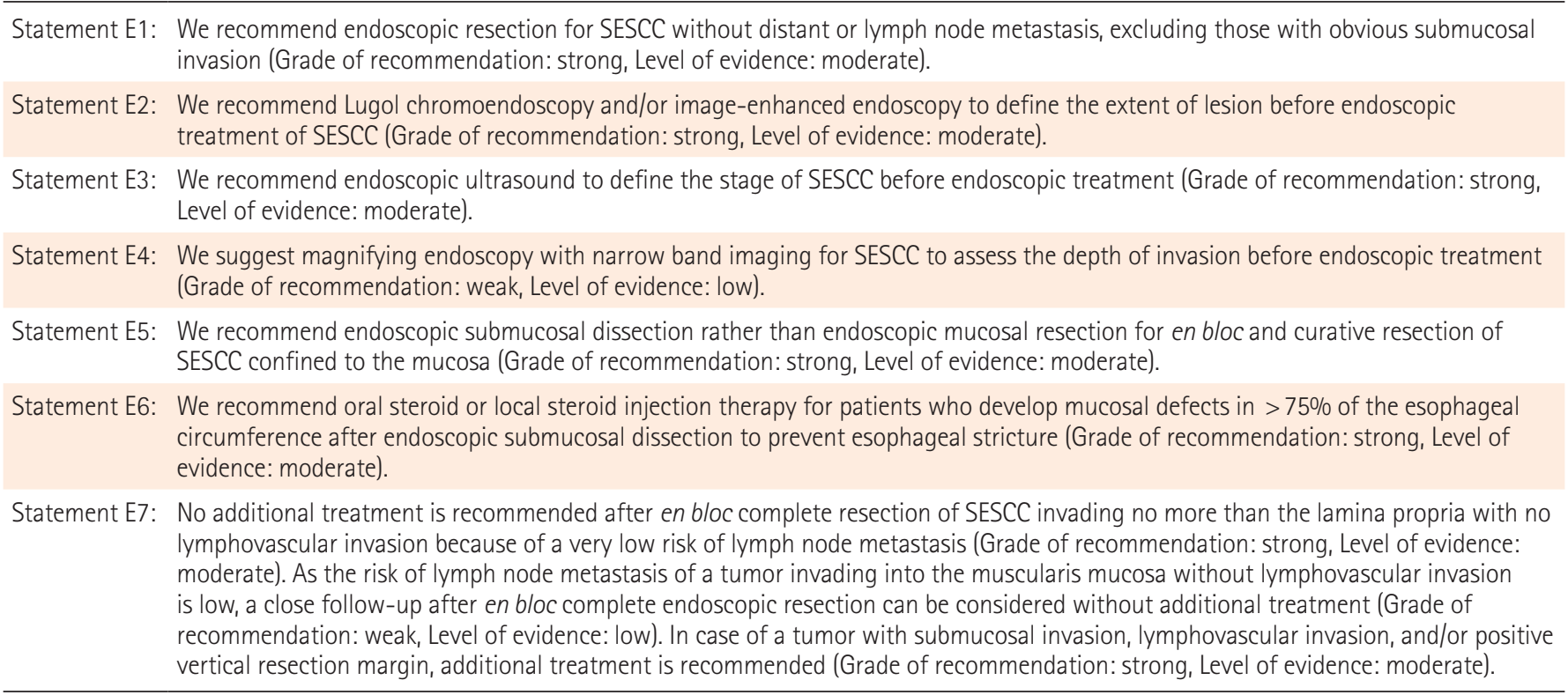

SESCC, superficial esophageal squamous cell carcinoma. 
vention method may be chosen instead of the weakly recommended intervention depending on the health professionals' values and preferences. Tables 2-4 summarize the recommendations with their grades of recommendation and levels of evidence, respectively.

\section{Review and Approval}

An editorial committee consisting of 29 members of KSGE Steering Committee, 14 members from the Insurance Committee, and 15 members from the Research Group for Endoscopic Submucosal Dissection was formed in August, 2019. The members evaluated the first draft of the guideline using open-ended questions. The draft was revised by the KSGE Task Force on Clinical Practice Guideline and re-evaluated by the editorial committee to ensure information balance and guideline completion. For an external review of the guideline, a public meeting in which 38 gastrointestinal endoscopy experts participated was held on August 18, 2019 during the 61st seminar of KSGE in which doctors and nurses from all over the country gathered. Opinions about the guideline were shared during the public meeting and the final draft of guideline was made after its revision based on discussion during the public meeting.

\section{Provision of Clinical Practice Guideline and Plans for Future Updates}

For wide provision and distribution of the clinical practice guideline, we plan to publish the guideline in Intestinal Research, Clinical Endoscopy, the Korean Journal of Gastroenterology, the Korean Journal of Helicobacter and Upper Gastroin-

Table 3. Summary and Strength of Recommendations for Early Gastric Cancer

Statement G1: We recommend chromoendoscopy/image-enhanced endoscopy to determine the extent of lesion before endoscopic treatment of early gastric cancer (Grade of recommendation: strong, Level of evidence: moderate).

Statement G2: Endoscopic ultrasonography before endoscopic resection of early gastric cancer may be helpful in determining the depth of invasion in some patients with early gastric cancer (Grade of recommendation: weak, Level of evidence: moderate).

Statement G3: We recommend endoscopic resection for early gastric cancer of well or moderately differentiated tubular or papillary adenocarcinoma meeting endoscopically estimated tumor size $\leq 2 \mathrm{~cm}$ and endoscopically suspected mucosal cancer without ulcer (Grade of recommendation: strong, Level of evidence: moderate).

Statement G4: We suggest endoscopic resection for early gastric cancer of well or moderately differentiated tubular or papillary adenocarcinoma meeting the following endoscopic findings: 1) mucosal cancer $>2 \mathrm{~cm}$ without ulcer, or 2) mucosal cancer $\leq 3 \mathrm{~cm}$ with ulcer (Grade of recommendation: weak, Level of evidence: moderate).

Statement G5: We suggest endoscopic resection for poorly differentiated tubular adenocarcinoma, poorly cohesive carcinoma, and signet ring cell carcinoma meeting the following endoscopic findings: endoscopically estimated tumor size $\leq 2 \mathrm{~cm}$, endoscopically mucosal cancer and no ulcer in the tumor (Grade of recommendation: weak, Level of evidence: low).

Statement G6: We recommend prophylactic hemostasis of visible vessels on the post-resection ulcer caused by endoscopic resection of early gastric cancer to lower the risk of delayed bleeding (Grade of recommendation: strong, Level of evidence: low).

Statement G7: We recommend proton pump inhibitors to decrease the risk of symptoms and complications associated with iatrogenic ulcers caused by endoscopic resection of early gastric cancer (Grade of recommendation: strong, Level of evidence: high).

Statement G8: We recommend endoscopic closure as the first treatment option for perforation that occurred during endoscopic resection of early gastric cancer (Grade of recommendation: strong, Level of evidence: low).

Statement G9: We recommend surgical gastrectomy if histopathological evaluation after endoscopic resection of early gastric cancer meets the criteria for non-curative resection. An exception applies if cancer invasion is observed at the horizontal resection margin only (Grade of recommendation: strong, Level of evidence: moderate).

Statement G10: We recommend additional endoscopic management rather than surgical gastrectomy if histopathological evaluation of endoscopically resected early gastric cancer specimen shows positive involvement at the horizontal resection margin without any other findings compatible with non-curative resection (Grade of recommendation: strong, Level of evidence: moderate)

Statement G11: We recommend Helicobacter pylori eradication treatment after endoscopic resection of early gastric cancer in $\mathrm{H}$. pylori-infected patients (Grade of recommendation: strong, Level of evidence: high).

Statement G12: We recommend regular surveillance endoscopy every 6-12 months for patients who have had curative endoscopic resection of early gastric cancer based on absolute or expanded criteria for early detection of metachronous gastric cancer (Grade of recommendation: strong, Level of evidence: low).

Statement G13: We suggest regular abdominopelvic computed tomography scan of 6- and 12-month interval for detection of extra-gastric recurrence after curative endoscopic resection of early gastric cancer based on absolute and expanded criteria (Grade of recommendation: weak, Level of evidence: low). 
Table 4. Summary and Strength of Recommendations for Early Colorectal Cancer

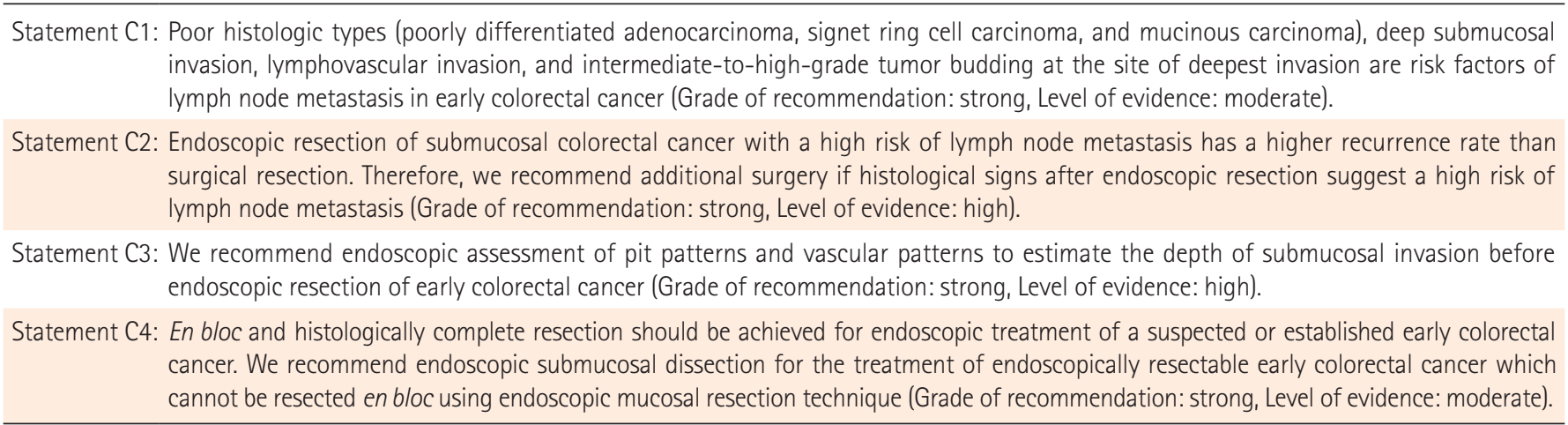

testinal Research, and Journal of Digestive Cancer Reports. We will also upload the guideline on the website of KSGE and submit it to the Korean Medical Guideline Information Center. Because we expect slow distribution of guidelines among endoscopists through databases for clinical practice guidelines, KSGE, the main institution for developing the guideline, will send out the guideline for free via various routes including emails and will actively advertise the guideline in academic conferences, seminars, and workshops. Current recommendations in the clinical practice guideline are based on research conducted up to date and will be subject to revisions based on future findings.

\section{Limitations}

The most critical limitation of this clinical practice guideline is the insufficiency of data pertaining to Koreans. Data from foreign countries cannot be directly used to develop a guideline for the Korean population since the epidemiological and clinical characteristics of early gastrointestinal cancers differ between Korean and foreign populations. In addition, this clinical practice guideline does not aim to provide an absolute treatment standard that physicians should use to manage patients in real clinical settings but aims to help physicians make evidence-based clinical judgments with regard to the treatment of early gastrointestinal cancers. A physician must examine various clinical aspects of a patient before making any treatment decisions. This clinical practice guideline shall not be used to restrict medical practice of physicians, as health insurance criteria, or to make legal judgments regarding treatments performed on a particular patient.

\section{Editorial Independence}

This clinical practice guideline is a project selected and funded by KSGE. KSGE did not influence the process of guideline development in any manner. All parties involved in the guide- line development had no conflict of interests regarding the guideline development.

\section{SUPERFICIAL ESOPHAGEAL SQUAMOUS CELL CARCINOMA}

\section{Statement E1}

We recommend endoscopic resection for SESCC without distant or lymph node metastasis, excluding those with obvious submucosal invasion (Grade of recommendation: strong, Level of evidence: moderate).

SESCC is squamous cell carcinoma of the esophagus that is localized to the mucosa or submucosa. SESCC without distant metastasis and with a low risk of lymph node metastasis is a good target of endoscopic resection. Although endoscopic resection of SESCC can conserve the esophagus, it is important to carefully select patients who will receive the procedure since there is still a possibility of lymph node metastasis. The National Comprehensive Cancer Network guidelines recommend endoscopic resection for SESCC localized to the mucosa and esophagectomy in the presence of submucosal invasion. ${ }^{23}$ The Japan Esophageal Society defines mucosal cancer invading only as deep as the lamina propria as an absolute indication for endoscopic resection as the cancer rarely metastasizes to the lymph nodes. ${ }^{17}$ The European Society of Gastrointestinal Endoscopy (ESGE) defines esophageal cancer invading the lamina propria without lymph node metastasis as an absolute indication for endoscopic resection. ${ }^{1}$ Thus, the depth of invasion of SESCC must be accurately determined using endoscopy, endoscopic ultrasound, and magnifying endoscopy with narrow band imaging (NBI) before performing endoscopic resection of SESCC. ${ }^{24-28}$ However, the evaluation of invasion depth is not perfectly accurate. Therefore, it is ad- 
visable to perform endoscopic resection instead of esophagectomy to avoid unnecessary operations when there is no obvious submucosal invasion because esophagectomy has high morbidities and mortalities. ${ }^{29-31}$ Recent Korean studies report no significant difference in long-term survival between patients with SESCC without obvious submucosal invasion who underwent endoscopic resection as their first treatment and those who underwent esophagectomy, and the rate of postoperative complications was significantly higher in the operated patients. ${ }^{32}$ This may be because additional operations lowered the risk of recurrence following non-curative endoscopic resection. A Chinese study also reported no significant difference in survival rates between patients with SESCC who underwent endoscopic resection and those who underwent surgical resection and reported a lower incidence of treatment-related complications in the former group. ${ }^{33}$ These results show that performing endoscopic resection prior to a surgical resection of SESCC without obvious submucosal invasion may be an effective treatment strategy.

\section{Statement E2}

We recommend Lugol chromoendoscopy and/or imageenhanced endoscopy to define the extent of lesion before endoscopic treatment of SESCC (Grade of recommendation: strong, Level of evidence: moderate).

SESCC manifests as erythematous lesions, subtle discoloration, or nodules. In addition, synchronous SESCC lesions of various sizes are not rare, which are difficult to be distinguished from noncancerous lesions only by white light endoscopy. Therefore, accurate measurement of the size and horizontal border of these lesions is challenging. Lugol chromoendoscopy, which applies the fact that the keratin layer of the mucosa is destroyed by the cancer, is the most effective chromoendoscopy to identify the SESCC lesions. The normal esophageal mucosa turns dark brown when sprayed with Lugol's solution, whereas the mucosa affected by SESCC exhibits a "pink-color sign." That is, the mucosa remains light brown and turns pink 2-3 minutes after being sprayed with the solution. ${ }^{34}$ Studies evaluating the efficacy of Lugol chromoendoscopy in diagnosing lesions suggestive of SESCC in white light endoscopy reported Lugol chromoendoscopy to be $73.8 \%-$ 93.4\% accurate in differentiating high-grade adenoma and SESCC from low-grade adenoma and noncancerous lesions. ${ }^{34,35}$ Thus, Lugol chromoendoscopy effectively assesses the horizontal border of SESCC before endoscopic resection.
Image-enhanced endoscopy is a quick process that causes no inflammation around SESCC lesions unlike Lugol chromoendoscopy. Image-enhanced endoscopy with NBI is the most widely studied image-enhanced endoscopy technique. ${ }^{36}$ In a study of 90 patients with high-grade adenoma and SESCC, the accuracy of image-enhanced endoscopy with NBI was significantly higher than that of white light endoscopy (92\% vs. $67.8 \%$ ), and was similar to that of Lugol chromoendoscopy (92\% vs. $93.4 \%) .{ }^{37}$ In a prospective study that compared the diagnostic accuracy of detecting SESCC between Lugol chromoendoscopy and image-enhanced endoscopy with NBI in 303 patients with high risk of SESCC, the accuracy of the image-enhanced endoscopy with NBI was $91.2 \%$, which was not inferior to that of Lugol chromoendoscopy. ${ }^{38}$ Based on these results, we recommend Lugol chromoendoscopy or imageenhanced endoscopy to determine the border of SESCC prior to endoscopic resection.

\section{Statement E3}

We recommend endoscopic ultrasound to define the stage of SESCC before endoscopic treatment (Grade of recommendation: strong, Level of evidence: moderate).

Endoscopic treatments of SESCC have better prognoses when the depth of invasion is shallow, and unlike gastric cancer, SESCC invading the muscularis mucosa poses a risk of lymph node metastasis. ${ }^{39}$ Accurate staging of SESCC before an endoscopic treatment is thus important. For SESCC, endoscopic ultrasound accurately determines the level of infiltration by the primary tumor (T stage) and the presence or absence of lymph node metastasis (N stage). A study reported endoscopic ultrasound to be $81.6 \%$ sensitive and $99.4 \%$ specific in staging esophageal cancer invading the mucosa and submucosa. ${ }^{40}$ A meta-analysis of 19 studies reported endoscopic ultrasound as an excellent technique to differentiate mucosal invasion from submucosal invasion in SESCC (area under the summary receiver operating characteristic $[\mathrm{ROC}]$ curve $=0.93) .{ }^{26} \mathrm{Ad}-$ ditionally, in another meta-analysis that investigated whether endoscopic ultrasounds can differentiate between esophageal cancer invasions in the lamina propria, muscularis mucosa, and submucosa, endoscopic ultrasounds showed an excellent diagnostic performance (area under the summary ROC curve $=0.98) .{ }^{11}$ 


\section{Statement E4}

We suggest magnifying endoscopy with NBI for SESCC to assess the depth of invasion before endoscopic treatment (Grade of recommendation: weak, Level of evidence: low).

A large-scale, multi-institutional prospective study that investigated whether magnifying endoscopy with NBI can accurately assess the depth of invasion of esophageal cancer reported magnifying endoscopy with NBI to be not superior to conventional endoscopy for squamous cell carcinoma (accuracy of magnifying endoscopy with NBI, 65.3\%; accuracy of conventional endoscopy, $71.4 \% ; P=0.375) .{ }^{10}$ A prospective study conducted in Japan also reported that magnifying endoscopy with NBI is no better than high-resolution endoscopy and highfrequency endoscopic ultrasound. ${ }^{41}$ However, a recent largescale retrospective study that investigated the performance of magnifying endoscopy with NBI in the assessment of the depth of SESCC reported a positive predictive value of $93 \%$ for epithelial/lamina proprial invasion, $65 \%$ for muscularis mucosal/superficial submucosal invasion, and $77 \%$ for deep submucosal invasion, demonstrating that magnifying endoscopy with NBI is useful for determining the depth of invasion of SESCC before an endoscopic treatment. ${ }^{42}$ Therefore, given that the operator is highly experienced, it may be useful to perform magnifying endoscopy with NBI to determine the depth of invasion of SESCC before endoscopic resection.

\section{Statement E5}

We recommend ESD rather than EMR for en bloc and curative resection of SESCC confined to the mucosa (Grade of recommendation: strong, Level of evidence: moderate).

Endoscopic mucosal resection (EMR) is popular as it is relatively easy to perform and is associated with low risks of complications. However, studies have reported high local recurrence rates of 2.8\%-9.8\% after EMR because en bloc resection is difficult by EMR, especially for large lesions. ${ }^{43-47}$ ESD is a technically demanding procedure with high risks of complications but is nonetheless considered appropriate for treating SESCC due to the high en bloc and curative resection rates and low risks of local recurrence. Resection techniques are usually chosen based on lesion size and auxiliary factors such as the patient's conditions and the operator's level of experience.

There is no randomized study comparing EMR and ESD for SESCC. In a meta-analysis of retrospective studies, ESD had higher en bloc and curative resection rates than EMR regard- less of the lesion size. ESD had a significantly lower rate of postoperative local recurrence than EMR $(0.3 \%$ vs. $11.5 \%$ : odds ratio [OR], $0.08 ; 95 \%$ confidence interval [CI], $0.03-0.23 ; P<0.001)$. The rate of postoperative perforation was higher for ESD than for EMR (4.0\% vs. 1.3\%: OR, 2.19; 95\% CI, 1.08-4.47; $P=0.03$ ). However, no significant difference was noted in the rate of stricture formation or bleeding between the two procedures. ${ }^{48}$ Although studies report no difference in the rate of en bloc and curative resection rates between cap-assisted EMR and ESD for lesions measuring < 10 to $15 \mathrm{~mm},{ }^{43,46,47}$ one meta-analysis reported a higher en bloc resection rate for ESD for lesions measuring $<10 \mathrm{~mm}(\mathrm{OR}, 3.58 ; 95 \% \mathrm{CI}, 1.84-7.02 ; P<0.001){ }^{49}$

We recommend to consider ESD first regardless of the lesion size since ESD has higher en bloc and curative resection rates than EMR for SESCC confined to the mucosa and has complication risks within an acceptable range. In case the operator lacks experience with ESD, performing EMR could be considered for only small lesions $<10 \mathrm{~mm}$ in size.

\section{Statement E6}

We recommend oral steroid or local steroid injection therapy for patients who develop mucosal defects in $>75 \%$ of the esophageal circumference after ESD to prevent esophageal stricture (Grade of recommendation: strong, Level of evidence: moderate).

ESD can lead to scar formation around the surgical site followed by esophageal strictures. Ono et al. ${ }^{50}$ reported that the risk of esophageal stricture increased in the presence of mucosal defects in $>75 \%$ of the esophageal circumference. Furthermore, $66 \%-88 \%$ of patients with mucosal defects in $>75 \%$ of the esophageal circumference that were left untreated after esophageal ESD developed an esophageal stricture. ${ }^{51-56} \mathrm{~Pa}-$ tients who developed mucosal defects in $100 \%$ of the esophageal circumference required an average of 33.5 endoscopic balloon dilation (EBD) procedures to treat esophageal stricture. $^{57}$

To prevent stricture after esophageal ESD, oral steroid administration or local steroid injection therapy is used. For oral steroid therapy, prednisolone is administered at $30 \mathrm{mg}$ per day starting 1 or 2 days after the procedure, and the dose is decremented over 2-12 weeks. ${ }^{54,55,57}$ In six studies comparing patients who received oral steroids following ESD to those who did not, oral steroid administration significantly reduced the rate of esophageal stricture formation by $73 \%$ (69\%-80\% without oral steroids and $18 \%-23 \%$ with oral steroids) (OR, 
0.27; 95\% CI, 0.13-0.58). ${ }^{54,55}$ Local steroid injection therapy also effectively prevents esophageal stricture. Studies reported a $78 \%$ reduction in the rate of esophageal stricture formation following local injections of triamcinolone or dexamethasone at the site of ESD (OR, 0.32; 95\% CI, 0.13-0.83). ${ }^{51-53,58}$

In a study that compared oral steroid therapy and preventive EBD, $32 \%$ of patients who underwent EBD twice per week for 8 weeks had an esophageal stricture, whereas only $5 \%$ of patients who were orally administered prednisolone at $30 \mathrm{mg}$ per day starting 2 days after ESD and had the dose gradually decreased over 8 weeks had an esophageal stricture, demonstrating that oral steroid administration is superior to preventive EBD for the prevention of esophageal stricture. ${ }^{56}$

Studies on steroid administration for the prevention of esophageal stricture mostly involve patients who develop mucosal defects in $>75 \%$ of the esophageal circumference and are at high risk of esophageal stricture. In a study that investigated the effect of local steroid injections in patients who underwent esophageal ESD regardless of the size of mucosal defect, local steroid injections had a $70 \%$ preventive effect on esophageal strictures with the rate of stricture formation being $11 \%$ in patients who received local steroid injections and $36 \%$ in those who did not receive them (OR, 0.30; 95\% CI, 0.130.83) ${ }^{58}$ However, considering the risk of esophageal perforation and adverse reactions associated with local steroid injections, it is advisable to consider oral steroid or local steroid injection therapy only for patients who develop mucosal defects in $>75 \%$ of the esophageal circumference who are at high risk of esophageal stricture.

\section{Statement E7}

No additional treatment is recommended after en bloc complete resection of SESCC invading no more than the lamina propria with no lymphovascular invasion because of a very low risk of lymph node metastasis (Grade of recommendation: strong, Level of evidence: moderate). As the risk of lymph node metastasis of a tumor invading into the muscularis mucosa without lymphovascular invasion is low, a close follow-up after en bloc complete endoscopic resection can be considered without additional treatment (Grade of recommendation: weak, Level of evidence: low). In case of a tumor with submucosal invasion, lymphovascular invasion, and/or positive vertical resection margin, additional treatment is recommended (Grade of recommendation: strong, Level of evidence: moderate).

Since the risk of lymph node metastasis associated with SES-
CC is closely related to a tumor's depth of invasion, it is important to accurately evaluate the depth of invasion for deciding whether the endoscopic resection is curative or non-curative ${ }^{59-61}$ Histopathological analyses of patients who underwent esophagectomy with dissection of the regional lymph nodes show that the risk of lymph node metastasis is $26.0 \%-53.8 \%$ in the presence of submucosal invasion of esophageal cancer. ${ }^{59-68}$ Moreover, $8.3 \%-53.1 \%$ of the patients had lymph node metastasis even when esophageal cancer invaded only the upper third of the submucosa. The Japan Esophageal Society and the ESGE guidelines define SESCC with a shallow submucosal invasion of $\leq 200 \mu \mathrm{m}$ as a relative indication for endoscopic resection. However, data regarding the frequency of lymph node metastasis by SESCC with shallow submucosal invasion of $\leq 200 \mu \mathrm{m}$ is limited. ${ }^{67}$ The rate of lymph node metastasis is lower but not negligible at $0.0 \%-15.4 \%$ for esophageal cancer confined to the mucosa ${ }^{59-67}$ Among esophageal cancers confined to the mucosa, invasion of muscularis mucosa is at a higher risk of lymph node metastasis than invasion of lamina propria (8.0\%-27.0\% vs. $0.0 \%-8.7 \%)$. The risk of lymph node metastasis is associated with vascular or lymphatic invasion. ${ }^{59,65,67,69,70}$ A large-scale Japanese study reported a 5-year cumulative incidence of metastasis of primary esophageal cancer invading the muscularis mucosa following endoscopic resection of only $0.7 \%$, suggesting that SESCC invading the muscularis mucosa can still be an indication for endoscopic resection if no lymphovascular invasion is observed. ${ }^{68}$ Two observational studies at Korean institutions supports the claim that en-doscopic resection can be a safe and curative treatment option in SESCC invading to the mucosa. In those studies, no death due to esophageal cancer occurred during a long-term follow-up of patients who underwent endoscopic resection of SESCC with invasion up to the mucosa. ${ }^{71,72}$ There are conflicting research results regarding the association between undifferentiated esophageal cancer and the risk of lymph node metastasis, indicating that undifferentiated esophageal cancer cannot be yet used as an absolute contraindication of endoscopic resection for SESCC. Additional data analyses are needed to derive more confirmative conclusions. ${ }^{59,61,65,68}$

Endoscopic resection is considered curative if histopathological evaluation shows that SESCC does not invade beyond the lamina propria and does not invade the vascular or lymphatic channels. In this case, a close follow-up may be conducted without additional operations. Following en bloc resection of SESCC with muscularis mucosal invasion and no lymphovascular invasion, a follow-up can be considered without 
additional operations after considering the patient's age, accompanying diseases, conditions, and risk of operation since the risk of lymph node metastasis is low. In case of unsuccessful en bloc resection, follow-up strategies considering the possibility that the histopathological assessment may have been inaccurate are necessary.

Additional treatments are needed in case of non-curative resection such as positive vertical resection margin and submucosal invasion and/or lymphovascular invasion suggesting the possibility of lymph node metastases. Esophagectomy with dissection of the regional lymph nodes is the standard treatment for non-curative endoscopic resection. However, since esophagectomy has high postoperative morbidities of $30 \%-40 \%$ and mortalities of $1 \%-2 \%$, physicians must consider the patient's conditions before deciding whether to perform the surgery or not. ${ }^{2931}$ Studies have reported relatively satisfactory outcomes of chemoradiation therapy for non-curative endoscopic resection of SESCC, suggesting that chemoradiation therapy might become a new treatment strategy for noncurative endoscopic resection. ${ }^{73-78}$

\section{EARLY GASTRIC CANCER}

\section{Statement G1}

We recommend chromoendoscopy/image-enhanced endoscopy to determine the extent of lesion before endoscopic treatment of early gastric cancer (Grade of recommendation: strong, Level of evidence: moderate).

Clearly identifying the horizontal border of the lesion before endoscopic resection reduces local recurrence and increases the likelihood of a complete resection. Chromoendoscopy has been used widely to accurately measure lesion borders. Recent advances in endoscopy technology led to the advent of NBI and magnifying endoscopy now commonly used in clinical settings. ${ }^{12,79}$ A study reported that chromoendoscopy using indigo carmine more accurately estimated lesion borders in early gastric cancer than white light endoscopy $(75.9 \%$ vs. $50.0 \%$ ), and chromoendoscopy using indigo carmine and acetic acid estimated lesion borders with $90.7 \%$ accuracy. ${ }^{80}$ A Korean study also reported that chromoendoscopy using indigo carmine and acetic acid estimated lesion borders in early gastric cancer more accurately than white light endoscopy (84.1\% vs. $66.9 \%){ }^{81}$ In a study that compared the accuracy of border prediction between magnifying endoscopy with NBI and chromoendoscopy using indigo carmine, the former tech- nique estimated horizontal borders of lesions more accurately than the latter (81.1\% vs. $72.6 \%){ }^{12}$ Magnifying endoscopy with NBI was also superior to white light endoscopy in terms of sensitivity and specificity for assessment of lesion borders (sensitivity, $92.9 \%$ vs. $42.9 \%$; specificity, $94.7 \%$ vs. $61.0 \%) .{ }^{13}$ Based on these results, we recommend chromoendoscopy and imageenhanced endoscopy to determine the extent of resection before endoscopic resection of early gastric cancer.

\section{Statement G2}

Endoscopic ultrasonography before endoscopic resection of early gastric cancer may be helpful in determining the depth of invasion in some patients with early gastric cancer (Grade of recommendation: weak, Level of evidence: moderate).

Endoscopic ultrasonography is useful for assessing the depth of invasion in gastric cancer and determining the presence or absence of lymph node metastasis. In a meta-analysis on 54 studies evaluating the efficacy of endoscopic ultrasonography in predicting the depth of invasion of a primary tumor in 5,601 patients with gastric cancer, endoscopic ultrasonography accurately differentiated between T3-T4 lesions and T1-T2 lesions with $86 \%$ sensitivity and $91 \%$ specificity. ${ }^{14}$ However endoscopic ultrasonography before endoscopic resection of early gastric cancer has limited accuracy in predicting the depth of invasion. ${ }^{82-88}$ In a large-scale Korean prospective study, the accuracy of distinguishing mucosal and submucosal invasion in early gastric cancer was $67.4 \%$ with endoscopic ultrasonography, which was not superior to $73.7 \%$ of conventional endoscopy. ${ }^{84}$ Another Korean study also reported no significant difference in the accuracy of depth of invasion prediction in early gastric cancer between endoscopic ultrasonography using a miniprobe and white light endoscopy (81.4\% vs. $78.9 \%))^{83}$ However, some studies report that endoscopic ultrasonography may be useful for investigating the depth of invasion of early gastric cancer. According to a Japanese study, the diagnostic accuracy of endoscopic ultrasound was higher than that of white light endoscopy in predicting the depth of invasion of early gastric cancer ( $71 \%$ vs. $63 \%){ }^{85}$ A recent study reported that endoscopic ultrasonography had higher accuracy than chromoendoscopy in predicting the depth of invasion of early gastric cancer ( $79.1 \%$ vs. $76.5 \%)$ and that the depth of invasion could be predicted with $88.3 \%$ accuracy using both chromoendoscopy and endoscopic ultrasonography. ${ }^{82}$ Based on these studies, there is still a role for endoscopic ultrasonog- 
raphy to help differentiating mucosal or submucosal infiltration of early gastric cancer. Therefore, for patients who show signs of submucosal invasion in a white light endoscopic examination, endoscopic ultrasonography could be used to more accurately examine the depth of invasion of a tumor before endoscopic resection. ${ }^{89}$

\section{Statement G3}

We recommend endoscopic resection for early gastric cancer of well or moderately differentiated tubular or papillary adenocarcinoma meeting endoscopically estimated tumor size $\leq 2 \mathrm{~cm}$ and endoscopically suspected mucosal cancer without ulcer (Grade of recommendation: strong, Level of evidence: moderate).

Endoscopic resection is a local treatment for early gastric cancer with a negligible risk of lymph node metastasis. Before Gotoda et al. ${ }^{90}$ proposed expanded indications for endoscopic resection in 2000, well or moderately differentiated tubular or papillary gastric adenocarcinoma measuring $\leq 2 \mathrm{~cm}$ in diameter confined to the mucosa without ulcer and submucosal invasion was an indication for endoscopic resection. Thus, for these lesions, endoscopic resection must be considered as the first line of treatment. The risk of lymph node metastasis must be considered before performing endoscopic resection of early gastric cancer. Several studies have reported the risk of lymph node metastasis to be negligibly low in lesions that satisfy the aforementioned indications $(0.0 \%-0.3 \%))^{90-92}$ In addition, Korean studies reported no significant difference in the 5-year survival rate between endoscopic resection and surgical resection (93.6\%-96.4\% vs. 94.2\%-97.2\%), ${ }^{93-95}$ They also reported no significant difference in the 10-year survival rate between endoscopic resection and surgical resection $(81.9 \%$ vs. $84.9 \%) .{ }^{93}$ However, endoscopic resection had a higher 5 -year cumulative incidence of metachronous gastric cancer than surgical resection $(5.8 \%-10.9 \%$ vs. $0.9 \%-1.1 \%){ }^{93-95}$ Endoscopic resection preserves the entire stomach, which can lead to metachronous tumor formation in the rest parts of the stomach. Therefore, even after curative endoscopic resection, regular follow-up endoscopy is necessary to look for metachronous gastric cancer. Endoscopic resection, which preserves the entire stomach, improves the quality of life, causes lesser complications, requires a shorter hospital stay, and is more cost-effective than surgical resection. ${ }^{93-98}$ In conclusion, we recommend endoscopic resection as the first line of treatment for well or moderately differentiated tubular or papillary gastric adenocarcinoma measuring $\leq 2 \mathrm{~cm}$ in diameter without endoscopic signs of ulcer and submucosal invasion since endoscopic resection is comparable to surgical resection in terms of survival, is associated with a satisfactory quality of life, and is economical. ${ }^{93-96}$

\section{Statement G4}

We suggest endoscopic resection for early gastric cancer of well or moderately differentiated tubular or papillary adenocarcinoma with the following endoscopic findings: (1) mucosal cancer $>2 \mathrm{~cm}$ without ulcer, or (2) mucosal cancer $\leq 3 \mathrm{~cm}$ with ulcer (Grade of recommendation: weak, Level of evidence: moderate).

The World Health Organization histological classification of gastric cancer published in 2000 is widely accepted as the standard classification system for gastric cancer, which defines undifferentiated carcinoma as carcinomas without glandular differentiation and squamous epithelial differentiation. However, most studies on endoscopic resection have classified well or moderately differentiated tubular or papillary adenocarcinoma as differentiated type adenocarcinoma and poorly differentiated tubular adenocarcinoma and poorly cohesive carcinoma as undifferentiated type adenocarcinoma. Expansion of existing indications for endoscopic resection should be considered only if there is no difference in the survival rates between endoscopic resection and standard surgical treatment. In addition, surgery-related mortalities must be compared and reviewed to determine the permissible range of risk of lymph node metastasis. The risk of lymph node metastasis is generally estimated based on the size of tumor, histologic type and grade, depth of invasion, and presence or absence of lymphovascular invasion. The risk of lymph node metastasis and distant metastasis has been reported to be $0.0 \%-0.21 \%$ for well or moderately differentiated tubular or papillary gastric mucosal adenocarcinoma measuring $>2 \mathrm{~cm}$ without ulcers or mucosal cancer measuring $\leq 3 \mathrm{~cm}$ with ulcers if the endoscopically resected tumor shows a negative resection margin and no lymphovascular invasion. Considering that the risk of lymph node or distant metastasis $(0.0 \%-0.21 \%)$ is similar to the mortality of gastrectomy $(0.1 \%-0.3 \%)$, endoscopic resection may be considered for the lesions described above ${ }^{99-101}$ Additionally, studies reported no significant difference between the 5-year survival rate of surgical resection and endoscopic resection (92.0\%-97.2\% vs. $93.3 \%-96.4 \%)$, indicating that endoscopic resection is considered curative for the 
aforementioned lesions with no requirement of further treatment. ${ }^{95,100,102-109}$

Surgical resection is the standard treatment for clinically suspected submucosal invasive gastric cancer in preoperative evaluation. However, studies analyzing pathologic results of patients who underwent gastrectomy due to preoperatively suspected submucosal invasion reported that $28.8 \%-43.0 \%$ of these lesions could have been treated with endoscopic resection. ${ }^{110,111}$ Therefore, further research is needed regarding treatment methods for preoperatively suspected submucosal invasive early gastric cancer.

\section{Statement G5}

We suggest endoscopic resection for poorly differentiated tubular adenocarcinoma, poorly cohesive carcinoma, or signet ring cell carcinoma meeting the following endoscopic findings: endoscopically estimated tumor size $\leq 2 \mathrm{~cm}$, endoscopically mucosal cancer, and no ulcer in the tumor (Grade of recommendation: weak, Level of evidence: low).

Undifferentiated type adenocarcinoma including poorly differentiated tubular adenocarcinoma, poorly cohesive carcinoma and signet ring cell carcinoma of the stomach has not been accepted as an indication for endoscopic resection due to reports that undifferentiated type adenocarcinoma is associated with a high risk of lymph node metastasis. ${ }^{112,113}$ However, retrospective studies reported a low incidence of extra-gastric metastasis during follow-up and high 5-year survival rates of 95.0\%-98.6\% among patients who underwent endoscopic resection for undifferentiated type adenocarcinoma with mucosal invasion, no ulcer and $\leq 2 \mathrm{~cm}$ in size..$^{100,114-118}$ Studies also reported no significant difference in long-term outcomes between endoscopic resection and surgical resection for the aforementioned lesions. ${ }^{95,100,103,118}$ Thus, endoscopic resection may be recommended for undifferentiated type gastric adenocarcinoma with mucosal invasion, no ulcer and $\leq 2 \mathrm{~cm}$ in size. However, since undifferentiated type adenocarcinoma tends to have unclear borders that contribute to low curative resection rates $(45.1 \%-70 \%),{ }^{115,116}$ it is important to clearly identify borders and secure a sufficient resection margin during endoscopic resection. In addition, even in undifferentiated type adenocarcinoma, poorly differentiated tubular adenocarcinoma, poorly cohesive carcinoma and signet ring cell carcinoma can have different biological behaviors, and further studies in this field are needed.

\section{Statement G6}

We recommend prophylactic hemostasis of visible vessels on the post-resection ulcer caused by endoscopic resection of early gastric cancer to lower the risk of delayed bleeding (Grade of recommendation: strong, Level of evidence: low).

\section{Statement G7}

We recommend proton pump inhibitors to decrease the risk of symptoms and complications associated with iatrogenic ulcers caused by endoscopic resection of early gastric cancer (Grade of recommendation: strong, Level of evidence: high).

Reports on the incidence of bleeding associated with endoscopic resection vary depending on the definition of bleeding. Serious immediate bleeding that requires an intraprocedural blood transfusion or surgical treatment has been reported in $<1 \%$ of patients. ${ }^{119}$ Delayed bleeding that occurs after endoscopic resection is defined as bleeding from an iatrogenic ulcer that requires hemostasis, and its incidence has been reported to be $1.3 \%-11.9 \%$. Delayed bleeding usually occurs within 24 hours after endoscopic resection but can occur up to 2 weeks after endoscopic resection. ${ }^{120,121}$ Prophylactic coagulation of visible vessels exposed on the base of an iatrogenic ulcer after endoscopic resection can effectively prevent delayed bleeding. One retrospective study reported a 2.47 -fold increase in the risk of delayed bleeding when prophylactic coagulation was not performed. ${ }^{122}$ However, excessive prophylactic coagulation can increase the risk of post-coagulation syndrome or delayed perforation. ${ }^{123,124}$

Postoperative administration of proton pump inhibitors or histamine $2\left(\mathrm{H}_{2}\right)$ receptor blockers can prevent delayed bleeding. Whether one drug is more effective than the other is unclear with some studies reporting proton pump inhibitors to be more effective in treating iatrogenic ulcers related to endoscopic resection, ${ }^{125,126}$ and others reporting the two drugs to be on a par with one another. ${ }^{127,128}$ One meta-analysis reported no difference between proton pump inhibitors and $\mathrm{H}_{2}$ receptor blockers in their ability to treat iatrogenic ulcers and relieve symptoms but reported a significantly lower incidence of delayed bleeding in patients who were administered proton pump inhibitors (OR, 0.49; 95\% CI, 0.25-0.95) ${ }^{129}$ Various reports regarding the dose and administration period of proton pump inhibitors for iatrogenic ulcers and concomitant use of mucosal protective agents are available. ${ }^{130-142}$ Randomized trials reported that administration of proton pump inhibitors before endoscopic resection is not effective in preventing de- 
layed bleeding and that second look endoscopy also did not effectively prevent delayed bleeding. ${ }^{143-145}$

\section{Statement G8}

We recommend endoscopic closure as the first treatment option for perforation that occurred during endoscopic resection of early gastric cancer (Grade of recommendation: strong, Level of evidence: low).

The incidence of perforation resulting from excessive damage to the muscularis propria during endoscopic resection is $1.2 \%-5.2 \%$ and that of delayed perforation that occurs after endoscopic resection is reported at below $0.5 \%$. The risk of intraoperative perforation varies depending on the location and size of the lesion. ${ }^{146}$ Closure by endoscopic clipping effectively treats intraoperative perforation, and conservative treatments such as fasting and antibiotic administration after successful endoscopic closure usually lead to symptom relief without the need for additional surgical treatments. ${ }^{147-149}$ However, surgical treatment must be considered in case of unsuccessful closure, signs of generalized peritonitis, or delayed perforation. ${ }^{150}$ The endoscopic closure must be performed by an experienced endoscopist. If a patient becomes hemodynamically unstable or has respiratory problems due to tension pneumoperitoneum, rapid decompression of the intra-abdominal pressure using a percutaneous aspiration and/or drainage of intra-abdominal free air is required. ${ }^{151}$ It may also be useful to switch from oxygen to carbon dioxide infusion during endoscopy when perforation occurs. ${ }^{152}$

\section{Statement G9}

We recommend surgical gastrectomy if histopathological evaluation after endoscopic resection of early gastric cancer meets the criteria for non-curative resection. An exception applies if cancer invasion is observed at the horizontal resection margin only (Grade of recommendation: strong, Level of evidence: moderate).

\section{Statement G10}

We recommend additional endoscopic management rather than surgical gastrectomy if histopathological evaluation of endoscopically resected early gastric cancer specimen shows positive involvement at the horizontal resection margin without any other findings compatible with non-curative resection (Grade of recommendation: strong, Level of evidence: moderate).
Curative resection of an absolute indication lesion is assumed when well or moderately differentiated tubular or papillary adenocarcinoma confined to the mucosa measuring $<2 \mathrm{~cm}$ with no histopathological evidence of lymphovascular invasion and ulcers and a negative resection margin is observed following endoscopic en bloc resection of a lesion. Curative resection of an expanded indication lesion is considered when any of the following conditions are observed after en bloc resection: (1) differentiated type mucosal adenocarcinoma such as well or moderately differentiated tubular or papillary adenocarcinoma with a negative resection margin and ulcers of $\geq 2 \mathrm{~cm}$ and without lymphovascular invasion; (2) mucosal adenocarcinoma of $\leq 3 \mathrm{~cm}$ accompanied by ulcers; (3) submucosal invasive cancer of $\leq 3 \mathrm{~cm}$ with submucosal invasion depth $\leq 500 \mu \mathrm{m}$; or (4) undifferentiated type adenocarcinoma such as poorly differentiated tubular adenocarcinoma, poorly cohesive carcinoma, and signet ring cell carcinoma measuring $\leq 2 \mathrm{~cm}$ confined to the mucosa. Lesions that do not meet these criteria for curative resection are considered to have undergone non-curative resection. ${ }^{1,120,153}$ The risk of lymph node metastasis is reported to be $2.6 \%-3.0 \%$ for differentiated type adenocarcinoma that satisfy the criteria for non-curative resection, with the exception of differentiated type adenocarcinoma with a positive horizontal resection margin, and 5\%$20 \%$ for undifferentiated type adenocarcinoma. ${ }^{90,154,155}$ In a large-scale cohort study on patients who received additional surgical treatments due to non-curative resection, lymphatic invasion was associated with the highest risk of lymph node metastasis. Large tumor size, positive vertical resection margin, vascular invasion, and submucosal invasion depth $>500$ $\mu \mathrm{m}$ are reported to increase the risk of lymph node metastasis to a similar extent. ${ }^{156}$ Many studies have demonstrated that lymphovascular invasion is an important risk factor of lymph node metastasis. ${ }^{157-159}$ Considering the risk of lymph node metastasis, patients may require additional surgical gastrectomy including regional lymphadenectomy when they satisfy the criteria for non-curative resection, with the exception of having a positive horizontal resection margin only. Differentiated type mucosal adenocarcinomas less than $2 \mathrm{~cm}$ in size that show lymphovascular invasion are reported to have low risk of lymph node metastasis, in which case the need for additional surgical procedures is not clear. ${ }^{160}$ Although some studies comparing surgical resection following non-curative resection vs. no surgery reported no additional benefits of additional surgery, ${ }^{161-163}$ most retrospective studies have reported an increase in overall survival and disease-specific survival in pa- 
tients who underwent surgical resection. ${ }^{158,159,164-167}$ Furthermore, additional surgical resection following non-curative endoscopic resection has also been reported to increase survival among patients of advanced age. ${ }^{168-170}$

Differentiated type adenocarcinoma with a positive horizontal resection margin that meet all the other criteria for curative resection following en bloc resection is associated with a low risk of lymph node metastasis. A cohort study that followed up patients who had this type of cancer and did not receive additional treatments reported low 5-year recurrence rates among these patients and that recurrent tumors could be curatively treated without any mortality associated with gastric cancer. ${ }^{171}$ Therefore, additional endoscopic resection or argon plasma coagulation treatment may be used instead of surgical resection for tumors with a positive horizontal resection margin. Retrospective cohort studies reported favorable prognoses following these endoscopic treatments and suggested that additional endoscopic treatments within 3 months after the initial endoscopic resection are associated with low recurrence rates. ${ }^{172-174}$ However, it is impossible to determine whether resection is curative following argon plasma coagulation since histological evaluation is impossible; thus, a close follow-up is required after argon plasma coagulation.

\section{Statement G1 1}

We recommend Helicobacter pylori eradication treatment after endoscopic resection of early gastric cancer in $\mathrm{H}$. pylori-infected patients (Grade of recommendation: strong, Level of evidence: high).

H. pylori eradication may be considered for patients who test positive for H. pylori following an endoscopic treatment of early gastric cancer to reduce the risk of metachronous recurrence. Fukase et al. ${ }^{175}$ reported that $H$. pylori eradication significantly reduced the risk of metachronous gastric cancer in patients with early gastric cancer after endoscopic resection in their multicenter randomized controlled study in 2008 (hazard ratio [HR], 0.339; 95\% CI, 0.157-0.729). Based on this study, most clinical practice guidelines recommend $H$. pylori eradication after endoscopic resection of early gastric cancer. ${ }^{176-180}$ Four meta-analyses investigating whether H. pylori eradication after endoscopic resection of early gastric cancer prevents metachronous gastric cancer reported that $H$. pylori eradication significantly reduces the risk of metachronous gastric cancer to $0.42-0.51{ }^{181-184}$ A Korean prospective randomized double-blind, placebo-controlled trial published in
2018 also showed that $50 \%$ and $68 \%$ of metachronous gastric cancer was reduced in patients who received eradication therapy and for those in whom eradication was successful after endoscopic treatment of early gastric cancer, respectively. ${ }^{185}$ Another Korean prospective randomized study published in 2018 reported a 2.02-fold increase in the risk of metachronous gastric cancer in the control group compared with the eradication group. ${ }^{186}$ Therefore, we recommend H. pylori eradication following endoscopic resection of early gastric cancer for prevention of metachronous gastric cancer.

\section{Statement G12}

We recommend regular surveillance endoscopy every 6-12 months for patients who have had curative endoscopic resection of early gastric cancer based on absolute or expanded criteria for early detection of metachronous gastric cancer (Grade of recommendation: strong, Level of evidence: low).

Surveillance strategy for the patients after endoscopic resection has similar follow-up plans compared with those after surgical gastrectomy. However, more careful follow-up should be performed after endoscopic resection of early gastric cancer as it is associated with high incidence of synchronous multiple gastric cancers and metachronous gastric cancers. The Korean clinical practical guideline for gastric cancer recommends patients who undergo endoscopic treatment for early gastric cancer to have a follow-up endoscopic examination on a yearly basis. ${ }^{187}$ The Japanese guideline for endoscopic resection for early gastric cancer recommend an endoscopy examination at a 6- to12-month interval following curative endoscopic resection to detect metachronous gastric cancer and additionally for those with expanded curative criteria recommend ultrasonography or CT-also at 6- to 12-month interval-to detect possible metastasis. ${ }^{7,120}$ The ESGE guidelines for ESD recommend undergoing the first endoscopic surveillance at 3-6 months after curative endoscopic resection, and regular endoscopic examinations on a yearly basis thereafter. ${ }^{1}$ They recommend considering staging abdominal CT scan for expanded indication lesions. ${ }^{1}$

The purpose of follow-up examinations after endoscopic resection is to detect local recurrence at the resection site, synchronous or metachronous gastric cancer, and extra-gastric metastases. One meta-analysis reported the incidence of local recurrence following endoscopic treatment to be $0.3 \%$ for ESD and $5.2 \%$ for EMR. ${ }^{49}$ A Korean multicenter prospective study published in 2018 reported the incidence of local recurrence 
to be $0.7 \%$ in patients who had curative ESD and $2.4 \%$ who had non-curative ESD. ${ }^{188}$ Thus, since the incidence of local recurrence following curative ESD is below $1 \%$, detecting synchronous or metachronous gastric cancer must be prioritized before detecting local recurrences. Since patients with early gastric cancer who receive endoscopic resection have most of their gastric mucosa intact, they are more prone to developing metachronous and synchronous gastric cancers compared with those after surgical gastrectomy. If synchronous cancer is defined as cancer detected within 1 year after an endoscopic resection, and metachronous cancer as cancer detected starting 1 year after an endoscopic resection, the incidence of the respective cancers is reported to be $0.87 \%-11.0 \%$ and $3.6 \%$ $22.7 \%{ }^{101,189-191}$ A Japanese study published in 2015 reported the incidence of metachronous recurrence to increase to $9.5 \%$, $13.1 \%$, and $22.7 \%$ at 5,7 , and 10 years, respectively, after curative ESD. ${ }^{191}$ Another Japanese multicenter study reported the annual average incidence of metachronous gastric cancer to be $3.5 \%{ }^{189}$ A recently conducted Korean study reported that the annual average incidence of synchronous and metachronous gastric cancer is $2.47 \%$, and that patients who had followup examinations for over 1 year were significantly more likely to require surgery for metachronous cancer than patients who underwent follow-up examinations for $\leq 1$ year. ${ }^{192}$ Based on these results, early detection of metachronous and synchronous gastric cancer that develops after endoscopic resection is crucial for a successful follow-up. Patients must undergo follow-up endoscopy every 6-12 months within 5 years after an endoscopic resection for the detection of local recurrence and metachronous or synchronous cancer. It is advisable to continue undergoing follow-up endoscopy after the 5 -year mark as the risk of metachronous gastric cancer consistently increases even after 5 years. ${ }^{191,193}$ Further research is needed to establish more detailed and precise standards regarding the interval and duration of follow-up surveillance endoscopy.

\section{Statement G13}

We suggest regular abdominopelvic CT scan of 6- to 12-month interval for detection of extra-gastric recurrence after curative endoscopic resection of early gastric cancer based on absolute and expanded criteria (Grade of recommendation: weak, Level of evidence: low).

Very few clinical practice guidelines on follow-up abdominopelvic CT scan for endoscopic resection of early gastric cancer are available. Japanese guidelines recommend routine ultra- sounds or CT at a 6- to 12-month interval for lesions meeting expanded criteria, ${ }^{7,120}$ and ESGE guideline recommends to consider staging abdominopelvic CT for lesions meeting expanded criteria. ${ }^{1}$ A Korean study published in 2015 reported lymph node metastases 5 and 4 years after curative resection in two patients with absolute and expanded criteria lesions, respectively. ${ }^{101}$ In another Korean study on 15 cases of extragastric recurrence published in 2017, 66.7\% (4/6) of expanded criteria lesions and $83.3 \%$ (5/6) of out-of-indication lesions showed extra-gastric recurrences on CT without any intragastric recurrences, demonstrating the need for follow-up CT in patients with expanded criteria lesions. ${ }^{194}$

However, another Korean study reported detecting extragastric lymph node recurrence on CT in only two (one case of absolute criteria and one of expanded criteria) among total of 2,182 patients who underwent curative endoscopic resection, suggesting that CT after curative endoscopic resection is unnecessary for patients who meet expanded criteria considering the cost and radiation dose of $\mathrm{CT} .^{195}$ In addition, a study that followed up 894 mucosal cancers using endoscopy and abdominopelvic CT following their curative endoscopic resection reported CT signs of recurrence in only two cases, suggesting that CT plays a minimal role in follow-up after endoscopic resection. ${ }^{196}$ Precise standards for the target subjects and interval of follow-up abdominopelvic CT are yet to be established, and further research is needed in this regard.

\section{EARLY COLORECTAL CANCER}

\section{Statement C1}

Poor histologic types (poorly differentiated adenocarcinoma, signet ring cell carcinoma, and mucinous carcinoma), deep submucosal invasion, lymphovascular invasion, and intermediate-to-high-grade tumor budding at the site of deepest invasion are risk factors of lymph node metastasis in early colorectal cancer (Grade of recommendation: strong, Level of evidence: moderate).

Predicting the risk of potential lymph node metastasis of early colorectal cancer affects the decision of whether to additionally perform a radical surgery following endoscopic or surgical local excision of early colorectal cancer. Histologic grades are a traditional predictor of lymph node metastasis of early colorectal cancer. Poor histologic types (poorly differentiated adenocarcinoma, signet ring cell carcinoma, and mucinous carcinoma) are associated with a higher risk of lymph node 
metastasis than moderately-to-well differentiated adenocarcinoma, and the risk of metastasis increases in proportion to the histologic grade. ${ }^{197-202}$ Multivariate analyses have shown that poor histologic types (poorly differentiated adenocarcinoma, signet ring cell carcinoma, mucinous carcinoma) have increased ORs (2.93-45.9) for lymph node metastasis compared with well differentiated adenocarcinomas. ${ }^{203-205}$ Four meta-analyses also showed early colorectal cancers with poor histologic types to have an increased risk of lymph node metastasis with ORs ranging between 4.78 and 8.27.2,206-208

Well differentiated intramucosal colorectal cancer does not metastasize to the lymph nodes, whereas $6 \%-20 \%$ of early colorectal cancers that invade the submucosa metastasize to the lymph nodes. ${ }^{8,206-209}$ In studies using the relative depth of submucosal invasion, pedunculated polyps are classified according to the Haggitt classification, and nonpedunculated polyps are classified using the Kudo or Kikuchi classification based on the depth of invasion. ${ }^{210-212}$ The risk of lymph node metastasis increases in proportion to the depth of submucosal invasion determined by these classification methods (Haggitt level 4 and Kudo sm2-3). ${ }^{197-199,205,209,213,214}$ In studies that measured the absolute depth of submucosal invasion from the muscularis mucosa and evaluated the risk of lymph node metastasis, depth of vertical invasion of $\geq 1,000 \mu \mathrm{m}$ of nonpedunculated cancer were associated with the risk of lymph node metastasis, and the risk increased in proportion to the depth of invasion. ${ }^{201,203,215-219}$ In meta-analyses evaluating the risk of lymph node metastases in colorectal cancer, depth of submucosal invasion of $\geq 1,000 \mu \mathrm{m}$ increased the OR of lymph node metastasis to $3.0-5.93{ }^{8,206-208}$ However, the risk of metastasis based on the absolute depth of submucosal invasion has a relatively low predictive power. ${ }^{8,201}$ For this reason, the width of invasion has been also used as a quantitative measure of the risk of lymph node metastasis to complement the absolute depth of invasion.

In many studies including multivariate analyses, lymphovascular invasion was an independent risk factor for predicting local lymph node metastasis..$^{198-205,220}$ There have been five meta-analyses that evaluated the risks for lymph node metastasis according to lymphatic and vascular invasion; lymphatic invasion (OR, 4.15-6.91), vascular invasion (OR, 2.20-4.03), and lymphovascular (either lymphatic or vascular) invasion (OR, 3.9-5.47) all had increased lymph node metastases. $^{8,206-208,221}$

Tumor budding is defined as the presence of a single tumor cell or a cluster of $<5$ tumor cells at the tumor-invasive front of resected specimens. ${ }^{22,223}$ The definition of tumor budding varies between studies, but tumor budding is generally classified as intermediate-to-high if $\geq 5$ tumor buds are observed. Intermediate-to-high grade tumor budding is associated with an increased risk of lymph node metastasis. ${ }^{19,201,219,224,225}$ According to some meta-analyses, the presence of tumor budding increases the OR of lymph node metastasis by 3.26- to 7.74fold. ${ }^{8,206-208,221,223}$ A recent large-scale, multi-institutional Japanese study suggests that poorly differentiated clusters at the invasive front are also a useful histologic predictor of lymph node metastasis. ${ }^{201,225}$ Poorly differentiated clusters are composed of $\geq 5$ cancer cells present at invasive front of the tumor that lack full glandular formation. Therefore, compared with tumor budding, poorly differentiated clusters are more easily recognized in hematoxylin and eosin staining and do not require auxiliary immunohistochemical staining.

\section{Statement C2}

Endoscopic resection of submucosal colorectal cancer with a high risk of lymph node metastasis has a higher recurrence rate than surgical resection. Therefore, we recommend additional surgery if histological signs after endoscopic resection suggest a high risk of lymph node metastasis (Grade of recommendation: strong, Level of evidence: high).

Early colorectal cancer confined to the mucosa of the large intestine does not metastasize to the lymph nodes. Thus, complete endoscopic resection of a primary tumor eliminates the possibility of recurrence, and no further treatment is required in case of mucosal colorectal cancer. A population-based study conducted in the Uinted States reported no difference in the 5-year survival rate between endoscopic resection and surgical treatment for mucosal or submucosal colorectal cancers ( $\leq$ stage 1) with a longest diameter of $\leq 4 \mathrm{~cm} .{ }^{226}$ Mounzer et al. ${ }^{227}$ also reported no difference in 5-year colorectal cancerspecific recurrence-free survival rates (97.6\% vs. $97.5 \% ; P=$ 0.75 ) and colorectal cancer-specific mortalities (HR, 1.10; 95\% CI, $0.72-1.69 ; P=0.65$ ) between endoscopic resection and surgical treatment for colorectal cancer confined to the mucosa.

However, one study has reported significantly lower recurrence-free survival rates and higher colorectal cancer-specific mortalities for endoscopic resection of submucosal colorectal cancer than for surgical treatment (HR, 2.40; 95\% CI, 1.75$3.29 ; P<0.001){ }^{227}$ In addition, studies comparing endoscopic resection and surgical resection for submucosal colorectal cancer reported local recurrence rates of $2.3 \%-6.4 \%$ for endo- 
scopic resection ${ }^{228-230}$ and relatively low local recurrence rates of $0.9 \%-1.87 \%$ for surgical resection. ${ }^{228-230}$ Prognoses after endoscopic and surgical resection depend on whether the submucosal colorectal cancer is associated with a high risk of lymph node metastasis. A Korean study conducted in 2014 reported no difference between endoscopic resection and surgical resection in the mean 37 months (range, 6-98 months) cumulative incidence of recurrence in case of mucosal and superficial submucosal colorectal cancer with low risks of lymph node metastasis $(P=0.641){ }^{231}$ Yoda et al. ${ }^{232}$ reported a high 5 -year recurrence-free survival rate of $98 \%$ for low-risk submucosal colorectal cancer. Conversely, early colorectal cancer accompanied by risk factors of lymph node metastasis was associated with a significantly higher incidence of lymph node metastasis (15.5\%) as opposed to when early colorectal cancer was not accompanied by the risk factors $(7.1 \%)(P=0.001){ }^{229}$ In another Japanese study, ${ }^{232}$ higher 5 -year recurrence-free survival rates were observed in patients with high-risk, early submucosal colorectal cancer who underwent additional surgery after endoscopic treatment than in those who did not undergo additional surgery ( $97 \%$ vs. $89 \% ; P=0.130$ ). Succeeding studies have reported high recurrence rates and significantly lower survival rates for early colorectal cancer accompanied by risk factors of lymph node metastasis that was treated endoscopically only. ${ }^{233-235}$ Thus, although endoscopic resection effectively treats mucosal colorectal cancer and submucosal colorectal cancer without the risk factors of lymph node metastasis, additional surgery should be considered for submucosal colorectal cancer with the risk factors of lymph node metastasis.

\section{Statement C3}

We recommend endoscopic assessment of pit patterns and vascular patterns to estimate the depth of submucosal invasion before endoscopic resection of early colorectal cancer (Grade of recommendation: strong, Level of evidence: high).
Submucosal colorectal cancer accompanied by risk factors of lymph node metastasis requires surgery. Many studies have investigated the association between the depth of submucosal invasion, which is a risk factor for lymph node metastasis, and endoscopic features. Estimating the depth of invasion prior to treatment of early colorectal cancer is essential for choosing the appropriate method of surgical or endoscopic treatment, and this can be done using magnifying chromoendoscopy and NBI

Kudo's pit pattern classification is useful for estimating the depth of submucosal invasion in early colorectal cancer (Table 5). Type $V$, especially $V_{N}$ pit pattern observed by magnifying chromoendoscopy indicates a high possibility of deep submucosal invasion. ${ }^{236-238}$ Studies analyzing the pit patterns of lesions suspected as early colorectal cancer reported the incidence of submucosal invasion to be mere $1 \%, 5 \%$, and $8 \%$ for type $\mathrm{III}_{\mathrm{L}}, \mathrm{III}_{\mathrm{S}}$, and IV pit patterns, respectively, but $14 \%$ for type $\mathrm{V}_{\mathrm{I}}$ and $80 \%$ for type $\mathrm{V}_{\mathrm{N}}{ }^{239}$ The sensitivity of pit patterns in estimating the depth of submucosal invasion varies depending on the macroscopic appearance of the lesions. The diagnostic accuracy of pit pattern for deep submucosal invasion in polypoid, flat, and depressed lesions was $75.8 \%, 85.7 \%$, and $98.6 \%$, respectively, and are thus useful for diagnosing deep submucosal colorectal cancer and selecting an appropriate treatment method. ${ }^{240}$ A meta-analysis on 17 studies that analyzed the diagnostic performance of magnifying chromoendoscopy reported magnifying chromoendoscopy to have $81 \%$ sensitivity and $95 \%$ specificity in diagnosing deep submucosal invasion. ${ }^{15}$ A meta-analysis on nine studies including three abstracts in which magnifying chromoendoscopy had $84 \%$ sensitivity and $97 \%$ specificity confirmed the diagnostic usefulness of magnifying chromoendoscopy. ${ }^{241}$ Indigo carmine and crystal violet are commonly used in magnifying chromoendoscopy with no significant difference in diagnostic accuracy between the two. ${ }^{15}$

$\mathrm{NBI}$ is used to examine the microvascular architecture and

Table 5. Kudo's Pit Pattern for the Endoscopic Diagnosis of Colorectal Neoplasia ${ }^{238}$

\begin{tabular}{|c|c|c|c|c|c|c|c|}
\hline $\begin{array}{l}\text { Pit pattern } \\
\text { classification }\end{array}$ & Type I & Type II & Type III & Type III & Type IV & Type $\mathrm{V}_{\mathrm{i}}$ & Type $V_{N}$ \\
\hline Description & $\begin{array}{l}\text { Round } \\
\text { (normal) } \\
\text { pits }\end{array}$ & Asteroid pits & $\begin{array}{l}\text { Tubular or round } \\
\text { pits, smaller than } \\
\text { the normal pits }\end{array}$ & $\begin{array}{c}\text { Tubular or round } \\
\text { pits, larger than } \\
\text { normal pits }\end{array}$ & $\begin{array}{l}\text { Branched or } \\
\text { gyrus-like pits }\end{array}$ & $\begin{array}{l}\text { Irregular } \\
\text { arrangement and } \\
\text { sizes of type IIIS, } \\
\text { IIIL, IV pit patterns }\end{array}$ & $\begin{array}{l}\text { Amorphous or } \\
\text { non-structural } \\
\text { pit patterns }\end{array}$ \\
\hline $\begin{array}{r}\text { Most likely } \\
\text { histology }\end{array}$ & Normal & $\begin{array}{l}\text { Hyperplastic polyp } \\
\text { Sessile serrated } \\
\text { lesion }\end{array}$ & $\begin{array}{l}\text { Adenoma } \\
\text { Intramucosal } \\
\text { carcinoma }\end{array}$ & Adenoma & $\begin{array}{l}\text { Adenoma } \\
\text { Intramucosal } \\
\text { carcinoma }\end{array}$ & $\begin{array}{l}\text { Intramucosal cancer } \\
\text { Superficial } \\
\text { submucosal cancer }\end{array}$ & $\begin{array}{l}\text { Deep submucosal } \\
\text { cancer }\end{array}$ \\
\hline
\end{tabular}


surface structure. NBI findings suggesting deep submucosal invasion are as follows: completely unclear or amorphous surface pattern, severely irregular thickness and arrangement of capillary vessels, and avascular or loose microvessel areas. ${ }^{242-244}$ Several NBI classification systems have been proposed to aid optical diagnosis of colorectal tumors, such as Sano's classification, Hiroshima's classification, and later, NBI International Colorectal Endoscopic (NICE) classification, and the Japan NBI Expert Team (JNET) classification (Table 6). The sensitivity, specificity, and accuracy of Sano IIIA/IIIB for differentiating intramucosal/superficial submucosal cancer from deep submucosal cancer are $85 \%, 89 \%$, and $88 \%$, respectively. ${ }^{245}$ The diagnostic sensitivity, specificity, and accuracy of Hiroshima class C3 patterns for deep submucosal cancer are $67 \%, 99 \%$, and $93 \%$ with excellent interobserver and intraobserver agreement $\left(\kappa=0.749\right.$ and $\kappa=0.745$, respectively). ${ }^{246}$ JNET type III had diagnostic sensitivity, specificity, and accuracy of $55.4 \%, 99.8 \%, 96.6 \%$, respectively. ${ }^{247,248}$ In a meta-analysis on 13 studies on the accuracy of NBI in diagnosing deep submucosal cancer, NBI had $77 \%$ sensitivity and $98 \%$ specificity. ${ }^{15}$ A recent meta-analysis on 17 studies including three abstracts reported NBI to have $74 \%$ sensitivity and $98 \%$ specificity, ${ }^{241}$ demonstrating that NBI accurately estimates the deep submucosal invasion in early colorectal cancer.

In addition to pit patterns and surface microvascular changes, the hardness of a lesion, deep and irregular depression on the tumor surface, absence of changes in the tumor shape upon air inflation, fold convergence toward the tumor, and non-lifting signs (the submucosa below the lesion does not lift when a solution is injected into the submucosa) are macroscopic signs of deep submucosal cancer. ${ }^{249,250}$ The non-lifting sign is reported to indicate submucosal fibrosis or deep submucosal invasion, ${ }^{251}$ but it has lower sensitivity and accuracy in predicting deep submucosal cancer than other macroscopic endoscopic findings associated with deep submucosal invasion. ${ }^{252}$ Thus, to date, there is insufficient evidence to prove that non-lifting sign is a highly useful predictor of deep submucosal invasion. In a meta-analysis on six studies assessing the accuracy of macroscopic appearance in predicting deep submucosal cancer, macroscopic appearance had $80 \%-98 \%$ specificity but only $18 \%-66 \%$ sensitivity. ${ }^{15}$ Therefore, magnifying chromoendoscopy and NBI may be more useful for predicting deep submucosal cancer than macroscopic appearance. ${ }^{15}$

A meta-analysis comparing the accuracy of magnifying chromoendoscopy and NBI in predicting deep submucosal cancer reported no difference in sensitivity (magnifying chromoendoscopy $81 \%$ vs. NBI $77 \%, P=0.41)$ and specificity $(95 \%$ vs. $98 \%, P=0.09$ ) between the two techniques. In a recent meta-analysis on 17 studies including three abstracts, there was no difference in specificity between magnifying chromoendoscopy and NBI, but magnifying chromoendoscopy had a higher sensitivity ( $84 \%$ vs. $74 \%, P<0.01$ ). ${ }^{253}$ A questionnaire survey conducted among 30 experts on magnifying and image-enhanced endoscopy showed that magnifying chromoendoscopy is superior to NBI in predicting deep submucosal cancer ( $88 \%$ vs. $83 \%, P=0.0013) .{ }^{253}$ However, since most of the studies included in these meta-analyses were conducted in Korea and Japan, further research is needed.

In conclusion, for macroscopic signs of deep submucosal invasion, Kudo VN pit patterns, Sano IIIB, Hiroshima C3, and JNET type 3, the risk of deep submucosal invasion is high and primary surgery should be performed. Whereas the pit patterns and the NBI findings have excellent specificity, the sensitivity is relatively low in diagnosing deep submucosal invasion. They may have excellent diagnostic accuracy, but are not substitutes for histopathological features. Thus, if a lesion with

Table 6. JNET Classification for the Endoscopic Diagnosis of Colorectal Neoplasia ${ }^{246}$

\begin{tabular}{|c|c|c|c|c|}
\hline JNET classification & JNET 1 & JNET 2A & JNET 2B & JNET 3 \\
\hline Vessel pattern & Invisible & $\begin{array}{l}\text { Regular caliber } \\
\text { Regular distribution (meshed } \\
\text { or spiral pattern) }\end{array}$ & $\begin{array}{l}\text { Variable caliber } \\
\text { Irregular distribution }\end{array}$ & $\begin{array}{l}\text { Loose vessel areas } \\
\text { Interruption of thick vessels }\end{array}$ \\
\hline Surface pattern & $\begin{array}{l}\text { Regular dark or white spots } \\
\text { Similar to surrounding normal } \\
\text { mucosa }\end{array}$ & $\begin{array}{l}\text { Regular (tubular/branched/ } \\
\text { papillary) }\end{array}$ & Irregular or obscure & Amorphous area \\
\hline Most likely histology & $\begin{array}{l}\text { Hyperplastic polyp } \\
\text { Sessile serrated lesion }\end{array}$ & $\begin{array}{l}\text { Low-grade intramucosal } \\
\text { neoplasia }\end{array}$ & $\begin{array}{l}\text { High-grade intramucosal } \\
\text { neoplasia } \\
\text { Superficial submucosal } \\
\text { invasive cancer }\end{array}$ & $\begin{array}{l}\text { Deep submucosal invasive } \\
\text { cancer }\end{array}$ \\
\hline
\end{tabular}

JNET, Japan narrow band imaging (NBI) Expert Team. 
high risk features for deep submucosal invasion can be safely and easily resected by endoscopy, endoscopic resection can be tried first and the need for further surgery may be determined based on histopathologic findings of endoscopic resection specimen.

\section{Statement C4}

En bloc and histologically complete resection should be achieved for endoscopic treatment of a suspected or established early colorectal cancer. We recommend ESD for the treatment of endoscopically resectable early colorectal cancer which cannot be resected en bloc using EMR technique (Grade of recommendation: strong, Level of evidence: moderate).

Deep submucosal invasion, poor histologic types (poorly differentiated adenocarcinoma, signet ring cell carcinoma, and mucinous carcinoma), lymphovascular invasion, tumor budding/poorly differentiated clusters are risk factors of lymph node metastasis from early colorectal cancer. Additional surgery is required when any of these histopathological signs or histologically incompletely resected submucosal cancer such as positive vertical resection margin is observed following endoscopic resection. En bloc resection is important for assessing the need for additional surgery as it increases the rate of curative resection of early colorectal cancer and allows accurate histopathologic evaluation. ${ }^{49,254-260}$ In a meta-analysis on studies comparing between ESD and EMR of colorectal lesions conducted by Fujiya et al. in 2015, the rate of en bloc resection was 91.7\% for ESD and 46.7\% for EMR with an OR of 6.84 (95\% CI, 3.30-14.18); ESD had a higher en bloc resection rate than EMR. In the same study, the rate of curative resection was also significantly higher for ESD (80.3\%) than for EMR (42.3\%) with an OR of 4.26 (95\% CI, 3.77-6.57). ${ }^{257}$ In a meta-analysis on studies comparing ESD and EMR for sessile colorectal lesions measuring $\geq 20 \mathrm{~mm}$ conducted by Arezzo et al. in 2016, the rate of en bloc resection was $89.9 \%$ for ESD and 34.9\% for EMR with a relative risk of 1.93 (95\% CI, 1.46$2.54) .{ }^{258}$ Additionally, the rate of R0 resection was $79.6 \%$ for ESD and 36.2\% for EMR with a relative risk of 2.01 (95\% CI, 1.76-2.29). Based on these results, Arezzo et al. ${ }^{258}$ concluded that ESD is superior to EMR for en bloc resection and R0 resection of sessile colorectal lesions measuring $\geq 20 \mathrm{~mm}$.

Reports on the complications of colon polypectomy including bleeding and perforation have varied between studies. ${ }^{257-259}$ One meta-analysis reported the incidence of perfora- tion to be higher for ESD $(4.0 \%-5.7 \%)$ than for EMR $(0.8 \%-$ $1.4 \%) .{ }^{259}$ Most complications occurring after ESD can be treated endoscopically, and $<1 \%$ of all colorectal lesions require surgery due to complications of ESD; therefore, ESD is acceptably safe considering the high efficacy of the procedure. ${ }^{261}$ However, the risk of complications and the rate of en bloc or curative resection significantly depend on the operator's level of experience since ESD of colorectal lesions is more difficult to perform than other polypectomy methods of colorectal lesions. ${ }^{262,263}$ Therefore, physicians experienced in therapeutic endoscopy after sufficient training of ESD must perform colorectal ESD in clinical settings where they can cope with emergency situations due to ESD-related complications. ${ }^{262-266}$

\section{CONCLUSION}

Endoscopic resection of early gastrointestinal cancer causes fewer adverse events, requires a shorter hospital stay, does not require bowel resection, and is more economical than surgical resection. However, endoscopic resection is not indicated for all patients with early gastrointestinal cancer. It is important to select patients with early gastrointestinal cancer that can be treated by endoscopic resection. Furthermore, excellent long-term outcomes can be ensured only via appropriate post-resection care such as additional surgery if necessary and regular follow-up after endoscopic resection. This clinical practice guideline proposes a standard treatment process for gastroenterologists performing endoscopic resection, thereby contributing to the prevention of unnecessary health care or inappropriate treatments and to the provision of relevant clinical recommendations for endoscopic resection of early gastrointestinal cancer.

\section{ADDITIONAL INFORMATION}

\section{Funding Source}

This guideline project was financially supported by Korean Society of Gastrointestinal Endoscopy (KSGE).

\section{Conflict of Interest}

No potential conflict of interest relevant to this article was reported.

\section{Author Contribution}

Conceptualization: Cho JY, Lee ST, Chun HJ. Data curation: Kim Jie-Hyun, Kim Ji Hyun, Min YW, Lee SH, Bae JH, Chung 
H, Choi KD, Park JC, Lee H, Kwak MS, Kim B, Lee HJ, Lee HS. Investigation: Kim Jie-Hyun, Kim Ji Hyun, Min YW, Lee SH, Bae JH, Chung H, Park JC, Lee H, Kwak MS, Kim B, Lee HJ, Lee HS. Project administration: Choi M, Park DA. Supervision: Choi KD, Lee HS, Choi M, Park DA, Park CG. Writing - original draft: Park CH, Yang DH. Writing - review \& editing: Kim JW, Lee JY, Byeon JS. Approval of final manuscript: all authors

\section{ORCID}

$\begin{array}{ll}\text { Park CH } & \text { https://orcid.org/0000-0003-3824-3481 } \\ \text { Yang DH } & \text { https://orcid.org/0000-0001-7756-2704 } \\ \text { Kim JW } & \text { https://orcid.org/0000-0003-0505-2697 } \\ \text { Kim JH } & \text { https://orcid.org/0000-0002-9198-3326 } \\ \text { Kim JH } & \text { https://orcid.org/0000-0003-0861-2792 } \\ \text { Min YW } & \text { https://orcid.org/0000-0001-7471-1305 } \\ \text { Lee SH } & \text { https://orcid.org/0000-0001-7221-7506 } \\ \text { Bae JH } & \text { https://orcid.org/0000-0001-7669-1213 } \\ \text { Chung H } & \text { https://orcid.org/0000-0001-5159-357X } \\ \text { Choi KD } & \text { https://orcid.org/0000-0002-2517-4109 } \\ \text { Park JC } & \text { https://orcid.org/0000-0001-8018-0010 } \\ \text { Lee H } & \text { https://orcid.org/0000-0003-4271-7205 } \\ \text { Kwak MS } & \text { https://orcid.org/0000-0002-8988-7423 } \\ \text { Kim B } & \text { https://orcid.org/0000-0002-0039-7728 } \\ \text { Lee HJ } & \text { https://orcid.org/0000-0003-2764-9339 } \\ \text { Lee HS } & \text { https://orcid.org/0000-0002-1667-7986 } \\ \text { Choi M } & \text { https://orcid.org/0000-0002-2424-9965 } \\ \text { Park DA } & \text { https://orcid.org/0000-0001-7225-3152 } \\ \text { Byeon JS } & \text { https://orcid.org/0000-0002-9793-6379 } \\ \text { Park CG } & \text { https://orcid.org/0000-0002-9581-2655 } \\ \text { Cho JY } & \text { https://orcid.org/0000-0002-7182-5806 } \\ \text { Lee ST } & \text { https://orcid.org/0000-0002-0758-1923 } \\ \text { Chun HJ } & \text { https://orcid.org/0000-0002-5539-361X }\end{array}$

\section{Supplementary Material}

Supplementary materials are available at the Intestinal Research website (https://www.irjournal.org).

\section{REFERENCES}

1. Pimentel-Nunes P, Dinis-Ribeiro M, Ponchon T, et al. Endoscopic submucosal dissection: European Society of Gastrointestinal Endoscopy (ESGE) Guideline. Endoscopy 2015;47: 829-854.

2. Eom BW, Jung KW, Won YJ, Yang H, Kim YW. Trends in gastric cancer incidence according to the clinicopathological characteristics in Korea, 1999-2014. Cancer Res Treat 2018;
50:1343-1350.

3. Kim SG, Lyu DH, Park CM, et al. Current status of endoscopic submucosal dissection for early gastric cancer in Korea: role and benefits. Korean J Intern Med 2019;34:785-793.

4. Miyamoto S, Muto M, Hamamoto Y, et al. A new technique for endoscopic mucosal resection with an insulated-tip electrosurgical knife improves the completeness of resection of intramucosal gastric neoplasms. Gastrointest Endosc 2002; 55:576-581.

5. Bok GH, Cho JY. ESD Hands-on course using ex vivo and in vivo models in South Korea. Clin Endosc 2012;45:358-361.

6. Park CH, Lee H, Kim DW, et al. Clinical safety of endoscopic submucosal dissection compared with surgery in elderly patients with early gastric cancer: a propensity-matched analysis. Gastrointest Endosc 2014;80:599-609.

7. Japanese Gastric Cancer A. Japanese gastric cancer treatment guidelines 2014 (ver. 4). Gastric Cancer 2017;20:1-19.

8. Bosch SL, Teerenstra S, de Wilt JH, Cunningham C, Nagtegaal ID. Predicting lymph node metastasis in pT1 colorectal cancer: a systematic review of risk factors providing rationale for therapy decisions. Endoscopy 2013;45:827-834.

9. Kim TJ, Kim ER, Hong SN, Kim YH, Chang DK. Current practices in endoscopic submucosal dissection for colorectal neoplasms: a survey of indications among Korean endoscopists. Intest Res 2017;15:228-235.

10. Ebi M, Shimura T, Yamada T, et al. Multicenter, prospective trial of white-light imaging alone versus white-light imaging followed by magnifying endoscopy with narrow-band imaging for the real-time imaging and diagnosis of invasion depth in superficial esophageal squamous cell carcinoma. Gastrointest Endosc 2015;81:1355-1361.

11. Ishihara R, Matsuura N, Hanaoka N, et al. Endoscopic imaging modalities for diagnosing invasion depth of superficial esophageal squamous cell carcinoma: a systematic review and meta-analysis. BMC Gastroenterol 2017;17:24.

12. Nagahama T, Yao K, Maki S, et al. Usefulness of magnifying endoscopy with narrow-band imaging for determining the horizontal extent of early gastric cancer when there is an unclear margin by chromoendoscopy (with video). Gastrointest Endosc 2011;74:1259-1267.

13. Kato M, Kaise M, Yonezawa J, et al. Magnifying endoscopy with narrow-band imaging achieves superior accuracy in the differential diagnosis of superficial gastric lesions identified with white-light endoscopy: a prospective study. Gastrointest Endosc 2010;72:523-529.

14. Mocellin S, Marchet A, Nitti D. EUS for the staging of gastric 
cancer: a meta-analysis. Gastrointest Endosc 2011;73:11221134.

15. Backes Y, Moss A, Reitsma JB, Siersema PD, Moons LM. Narrow band imaging, magnifying chromoendoscopy, and gross morphological features for the optical diagnosis of tl colorectal cancer and deep submucosal invasion: a systematic review and meta-analysis. Am J Gastroenterol 2017;112:54-64.

16. Ajani JA, D’Amico TA, Bentrem DJ, et al. Esophageal and esophagogastric junction cancers, Version 2.2019, NCCN clinical practice guidelines in oncology. J Natl Compr Canc Netw 2019;17:855-883.

17. Japan Esophageal Society. Japanese classification of esophageal cancer, 11th edition: part I. Esophagus 2017;14:1-36.

18. Sterne JAC, Savović J, Page MJ, et al. RoB 2: a revised tool for assessing risk of bias in randomised trials. Bmj 2019;366: 14898.

19. Higgins JPT, Green S. Cochrane handbook for systematic reviews of interventions, version 5.1.0 [Internet]. c2011 [cited 2019 Jul 26]. https://handbook-5-1.cochrane.org/.

20. Stang A. Critical evaluation of the Newcastle-Ottawa scale for the assessment of the quality of nonrandomized studies in meta-analyses. Eur J Epidemiol 2010;25:603-605.

21. Whiting PF, Rutjes AW, Westwood ME, et al. QUADAS-2: a revised tool for the quality assessment of diagnostic accuracy studies. Ann Intern Med 2011;155:529-536.

22. Guyatt GH, Oxman AD, Kunz R, et al. Incorporating considerations of resources use into grading recommendations. BM] 2008;336:1170-1173.

23. Ajani JA, D’Amico TA, Almhanna K, et al. Esophageal and esophagogastric junction cancers, version 1.2015. J Natl Compr Canc Netw 2015;13:194-227.

24. Endoscopic Classification Review Group. Update on the Paris classification of superficial neoplastic lesions in the digestive tract. Endoscopy 2005;37:570-578.

25. Lee WC, Lee TH, Jang JY, et al. Staging accuracy of endoscopic ultrasound performed by nonexpert endosonographers in patients with resectable esophageal squamous cell carcinoma: is it possible? Dis Esophagus 2015;28:574-578.

26. Thosani N, Singh H, Kapadia A, et al. Diagnostic accuracy of EUS in differentiating mucosal versus submucosal invasion of superficial esophageal cancers: a systematic review and meta-analysis. Gastrointest Endosc 2012;75:242-253.

27. Dhupar R, Rice RD, Correa AM, et al. Endoscopic ultrasound estimates for tumor depth at the gastroesophageal junction are inaccurate: implications for the liberal use of endoscopic resection. Ann Thorac Surg 2015;100:1812-1816.
28. Oyama T, Inoue H, Arima M, et al. Prediction of the invasion depth of superficial squamous cell carcinoma based on microvessel morphology: magnifying endoscopic classification of the Japan Esophageal Society. Esophagus 2017;14:105-112.

29. Ra J, Paulson EC, Kucharczuk J, et al. Postoperative mortality after esophagectomy for cancer: development of a preoperative risk prediction model. Ann Surg Oncol 2008;15:15771584.

30. Chang AC, Ji H, Birkmeyer NJ, Orringer MB, Birkmeyer JD. Outcomes after transhiatal and transthoracic esophagectomy for cancer. Ann Thorac Surg 2008;85:424-429.

31. Connors RC, Reuben BC, Neumayer LA, Bull DA. Comparing outcomes after transthoracic and transhiatal esophagectomy: a 5-year prospective cohort of 17,395 patients. J Am Coll Surg 2007;205:735-740.

32. Min YW, Lee H, Song BG, et al. Comparison of endoscopic submucosal dissection and surgery for superficial esophageal squamous cell carcinoma: a propensity score-matched analysis. Gastrointest Endosc 2018;88:624-633.

33. Zhang Y, Ding H, Chen T, et al. Outcomes of endoscopic submucosal dissection vs esophagectomy for T1 esophageal squamous cell carcinoma in a real-world cohort. Clin Gastroenterol Hepatol 2019;17:73-81.

34. Shimizu Y, Omori T, Yokoyama A, et al. Endoscopic diagnosis of early squamous neoplasia of the esophagus with iodine staining: high-grade intra-epithelial neoplasia turns pink within a few minutes. J Gastroenterol Hepatol 2008;23:546550.

35. Ishihara R, Kanzaki H, Iishi H, et al. Pink-color sign in esophageal squamous neoplasia, and speculation regarding the underlying mechanism. World J Gastroenterol 2013;19:43004308.

36. Uedo N, Fujishiro M, Goda K, et al. Role of narrow band imaging for diagnosis of early-stage esophagogastric cancer: current consensus of experienced endoscopists in Asia-Pacific region. Dig Endosc 2011;23 Suppl 1:58-71.

37. Gai W, Jin XF, Du R, Li L, Chai TH. Efficacy of narrow-band imaging in detecting early esophageal cancer and risk factors for its occurrence. Indian J Gastroenterol 2018;37:79-85.

38. Goda K, Dobashi A, Yoshimura N, et al. Narrow-band imaging magnifying endoscopy versus lugol chromoendoscopy with pink-color sign assessment in the diagnosis of superficial esophageal squamous neoplasms: a randomised noninferiority trial. Gastroenterol Res Pract 2015;2015:639462.

39. Rice TW, Patil DT, Blackstone EH. 8th edition AJCC/UICC staging of cancers of the esophagus and esophagogastric 
junction: application to clinical practice. Ann Cardiothorac Surg 2017;6:119-130.

40. Puli SR, Reddy JB, Bechtold ML, Antillon D, Ibdah JA, Antillon MR. Staging accuracy of esophageal cancer by endoscopic ultrasound: a meta-analysis and systematic review. World J Gastroenterol 2008;14:1479-1490.

41. Goda K, Tajiri H, Ikegami M, et al. Magnifying endoscopy with narrow band imaging for predicting the invasion depth of superficial esophageal squamous cell carcinoma. Dis Esophagus 2009;22:453-460.

42. Katada C, Tanabe S, Wada T, et al. Retrospective assessment of the diagnostic accuracy of the depth of invasion by narrow band imaging magnifying endoscopy in patients with superficial esophageal squamous cell carcinoma. J Gastrointest Cancer 2019;50:292-297.

43. Ishihara R, Iishi H, Uedo N, et al. Comparison of EMR and endoscopic submucosal dissection for en bloc resection of early esophageal cancers in Japan. Gastrointest Endosc 2008;68: 1066-1072.

44. Takahashi H, Arimura Y, Masao H, et al. Endoscopic submucosal dissection is superior to conventional endoscopic resection as a curative treatment for early squamous cell carcinoma of the esophagus (with video). Gastrointest Endosc 2010;72:255-264.

45. Teoh AY, Chiu PW, Yu Ngo DK, Wong SK, Lau JY, Ng EK. Outcomes of endoscopic submucosal dissection versus endoscopic mucosal resection in management of superficial squamous esophageal neoplasms outside Japan. J Clin Gastroenterol 2010;44:e190-e194.

46. Urabe Y, Hiyama T, Tanaka S, Yoshihara M, Arihiro K, Chayama K. Advantages of endoscopic submucosal dissection versus endoscopic oblique aspiration mucosectomy for superficial esophageal tumors. J Gastroenterol Hepatol 2011;26:275280.

47. Yamashita T, Zeniya A, Ishii H, et al. Endoscopic mucosal resection using a cap-fitted panendoscope and endoscopic submucosal dissection as optimal endoscopic procedures for superficial esophageal carcinoma. Surg Endosc 2011;25: 2541-2546.

48. Guo HM, Zhang XQ, Chen M, Huang SL, Zou XP. Endoscopic submucosal dissection vs endoscopic mucosal resection for superficial esophageal cancer. World J Gastroenterol 2014;20: 5540-5547.

49. Cao Y, Liao C, Tan A, Gao Y, Mo Z, Gao F. Meta-analysis of endoscopic submucosal dissection versus endoscopic mucosal resection for tumors of the gastrointestinal tract. Endoscopy
2009;41:751-757.

50. Ono S, Fujishiro M, Niimi K, et al. Predictors of postoperative stricture after esophageal endoscopic submucosal dissection for superficial squamous cell neoplasms. Endoscopy 2009;41: 661-665.

51. Hashimoto S, Kobayashi M, Takeuchi M, Sato Y, Narisawa R, Aoyagi Y. The efficacy of endoscopic triamcinolone injection for the prevention of esophageal stricture after endoscopic submucosal dissection. Gastrointest Endosc 2011;74:13891393.

52. Hanaoka N, Ishihara R, Takeuchi Y, et al. Intralesional steroid injection to prevent stricture after endoscopic submucosal dissection for esophageal cancer: a controlled prospective study. Endoscopy 2012;44:1007-1011.

53. Takahashi H, Arimura Y, Okahara S, et al. A randomized controlled trial of endoscopic steroid injection for prophylaxis of esophageal stenoses after extensive endoscopic submucosal dissection. BMC Gastroenterol 2015;15:1.

54. Kataoka M, Anzai S, Shirasaki T, et al. Efficacy of short period, low dose oral prednisolone for the prevention of stricture after circumferential endoscopic submucosal dissection (ESD) for esophageal cancer. Endosc Int Open 2015;3:E113-E117.

55. Zhou G, Yuan F, Cai J, et al. Efficacy of prednisone for prevention of esophageal stricture after endoscopic submucosal dissection for superficial esophageal squamous cell carcinoma. Thorac Cancer 2017;8:489-494.

56. Yamaguchi N, Isomoto $H$, Nakayama T, et al. Usefulness of oral prednisolone in the treatment of esophageal stricture after endoscopic submucosal dissection for superficial esophageal squamous cell carcinoma. Gastrointest Endosc 2011;73: 1115-1121.

57. Sato H, Inoue H, Kobayashi Y, et al. Control of severe strictures after circumferential endoscopic submucosal dissection for esophageal carcinoma: oral steroid therapy with balloon dilation or balloon dilation alone. Gastrointest Endosc 2013;78:250-257.

58. Nagami Y, Shiba M, Tominaga K, et al. Locoregional steroid injection prevents stricture formation after endoscopic submucosal dissection for esophageal cancer: a propensity score matching analysis. Surg Endosc 2016;30:1441-1449.

59. Eguchi T, Nakanishi Y, Shimoda T, et al. Histopathological criteria for additional treatment after endoscopic mucosal resection for esophageal cancer: analysis of 464 surgically resected cases. Mod Pathol 2006;19:475-480.

60. Akutsu Y, Uesato M, Shuto K, et al. The overall prevalence of metastasis in $\mathrm{T} 1$ esophageal squamous cell carcinoma: a ret- 
rospective analysis of 295 patients. Ann Surg 2013;257:10321038.

61. Choi JY, Park YS, Jung HY, et al. Feasibility of endoscopic resection in superficial esophageal squamous carcinoma. Gastrointest Endosc 2011;73:881-889.

62. Tachibana M, Yoshimura H, Kinugasa S, et al. Clinicopathological features of superficial squamous cell carcinoma of the esophagus. Am J Surg 1997;174:49-53.

63. Endo M, Yoshino K, Kawano T, Nagai K, Inoue H. Clinicopathologic analysis of lymph node metastasis in surgically resected superficial cancer of the thoracic esophagus. Dis Esophagus 2000;13:125-129.

64. Araki K, Ohno S, Egashira A, Saeki H, Kawaguchi H, Sugimachi K. Pathologic features of superficial esophageal squamous cell carcinoma with lymph node and distal metastasis. Cancer 2002;94:570-575.

65. Bollschweiler E, Baldus SE, Schroder W, et al. High rate of lymph-node metastasis in submucosal esophageal squamous-cell carcinomas and adenocarcinomas. Endoscopy 2006;38:149-156.

66. Kim DU, Lee JH, Min BH, et al. Risk factors of lymph node metastasis in T1 esophageal squamous cell carcinoma. J Gastroenterol Hepatol 2008;23:619-625.

67. Moriya H, Ohbu M, Kobayashi N, et al. Lymphatic tumor emboli detected by D2-40 immunostaining can more accurately predict lymph-node metastasis. World J Surg 2011;35:20312037.

68. Yamashina T, Ishihara R, Nagai K, et al. Long-term outcome and metastatic risk after endoscopic resection of superficial esophageal squamous cell carcinoma. Am J Gastroenterol 2013;108:544-551.

69. Oyama T, Tomori A, Hotta K, et al. Endoscopic submucosal dissection of early esophageal cancer. Clin Gastroenterol Hepatol 2005;3:S67-S70.

70. Katada C, Muto M, Momma K, et al. Clinical outcome after endoscopic mucosal resection for esophageal squamous cell carcinoma invading the muscularis mucosae: a multicenter retrospective cohort study. Endoscopy 2007;39:779-783.

71. Park HC, Kim DH, Gong EJ, et al. Ten-year experience of esophageal endoscopic submucosal dissection of superficial esophageal neoplasms in a single center. Korean J Intern Med 2016;31:1064-1072.

72. Song BG, Min YW, Cha RR, et al. Endoscopic submucosal dissection under general anesthesia for superficial esophageal squamous cell carcinoma is associated with better clinical outcomes. BMC Gastroenterol 2018;18:80.
73. Motoori M, Yano M, Ishihara R, et al. Comparison between radical esophagectomy and definitive chemoradiotherapy in patients with clinical T1bN0M0 esophageal cancer. Ann Surg Oncol 2012;19:2135-2141.

74. Kawaguchi G, Sasamoto R, Abe E, et al. The effectiveness of endoscopic submucosal dissection followed by chemoradiotherapy for superficial esophageal cancer. Radiat Oncol 2015; 10:31.

75. Ikeda A, Hoshi N, Yoshizaki T, et al. Endoscopic submucosal dissection (ESD) with additional therapy for superficial esophageal cancer with submucosal invasion. Intern Med 2015;54:2803-2813.

76. Hamada K, Ishihara R, Yamasaki Y, et al. Efficacy and safety of endoscopic resection followed by chemoradiotherapy for superficial esophageal squamous cell carcinoma: a retrospective study. Clin Transl Gastroenterol 2017;8:e110.

77. Kurokawa Y, Muto M, Minashi K, Boku N, Fukuda H; Gastrointestinal Oncology Study Group of Japan Clinical Oncology G. A phase II trial of combined treatment of endoscopic mucosal resection and chemoradiotherapy for clinical stage I esophageal carcinoma: Japan Clinical Oncology Group Study JCOG0508. Jpn J Clin Oncol 2009;39:686-689.

78. Minashi K, Nihei K, Mizusawa J, et al. Efficacy of endoscopic resection and selective chemoradiotherapy for stage I esophageal squamous cell carcinoma. Gastroenterology 2019;157: 382-390.

79. Ezoe Y, Muto M, Uedo N, et al. Magnifying narrowband imaging is more accurate than conventional white-light imaging in diagnosis of gastric mucosal cancer. Gastroenterology 2011; 141:2017-2025.

80. Kawahara Y, Takenaka R, Okada H, et al. Novel chromoendoscopic method using an acetic acid-indigocarmine mixture for diagnostic accuracy in delineating the margin of early gastric cancers. Dig Endosc 2009;21:14-19.

81. Lee BE, Kim GH, Park DY, et al. Acetic acid-indigo carmine chromoendoscopy for delineating early gastric cancers: its usefulness according to histological type. BMC Gastroenterol 2010;10:97.

82. Tsujii Y, Kato M, Inoue T, et al. Integrated diagnostic strategy for the invasion depth of early gastric cancer by conventional endoscopy and EUS. Gastrointest Endosc 2015;82:452-459.

83. Choi J, Kim SG, Im JP, Kim JS, Jung HC, Song IS. Is endoscopic ultrasonography indispensable in patients with early gastric cancer prior to endoscopic resection? Surg Endosc 2010;24:3 177-3185.

84. Choi J, Kim SG, Im JP, Kim JS, Jung HC, Song IS. Comparison 
of endoscopic ultrasonography and conventional endoscopy for prediction of depth of tumor invasion in early gastric cancer. Endoscopy 2010;42:705-713.

85. Yanai H, Noguchi T, Mizumachi S, et al. A blind comparison of the effectiveness of endoscopic ultrasonography and endoscopy in staging early gastric cancer. Gut 1999;44:361-365.

86. Yanai H, Matsumoto Y, Harada T, et al. Endoscopic ultrasonography and endoscopy for staging depth of invasion in early gastric cancer: a pilot study. Gastrointest Endosc 1997;46: 212-216.

87. Okada K, Fujisaki J, Kasuga A, et al. Endoscopic ultrasonography is valuable for identifying early gastric cancers meeting expanded-indication criteria for endoscopic submucosal dissection. Surg Endosc 2011;25:841-848.

88. Akashi K, Yanai H, Nishikawa J, et al. Ulcerous change decreases the accuracy of endoscopic ultrasonography diagnosis for the invasive depth of early gastric cancer. Int J Gastrointest Cancer 2006;37:133-138.

89. Yoshida S, Tanaka S, Kunihiro K, et al. Diagnostic ability of high-frequency ultrasound probe sonography in staging early gastric cancer, especially for submucosal invasion. Abdom Imaging 2005;30:518-523.

90. Gotoda T, Yanagisawa A, Sasako M, et al. Incidence of lymph node metastasis from early gastric cancer: estimation with a large number of cases at two large centers. Gastric Cancer 2000;3:219-225.

91. Nishizawa T, Yahagi N. Long-term outcomes of using endoscopic submucosal dissection to treat early gastric cancer. Gut Liver 2018;12:119-124.

92. Abdelfatah MM, Barakat M, Lee H, et al. The incidence of lymph node metastasis in early gastric cancer according to the expanded criteria in comparison with the absolute criteria of the Japanese Gastric Cancer Association: a systematic review of the literature and meta-analysis. Gastrointest Endosc 2018;87:338-347.

93. Choi KS, Jung HY, Choi KD, et al. EMR versus gastrectomy for intramucosal gastric cancer: comparison of long-term outcomes. Gastrointest Endosc 2011;73:942-948.

94. Choi IJ, Lee JH, Kim YI, et al. Long-term outcome comparison of endoscopic resection and surgery in early gastric cancer meeting the absolute indication for endoscopic resection. Gastrointest Endosc 2015;81:333-341.

95. Hahn KY, Park CH, Lee YK, et al. Comparative study between endoscopic submucosal dissection and surgery in patients with early gastric cancer. Surg Endosc 2018;32:73-86.

96. Choi JH, Kim ES, Lee YJ, et al. Comparison of quality of life and worry of cancer recurrence between endoscopic and surgical treatment for early gastric cancer. Gastrointest Endosc 2015;82:299-307.

97. Kim JH, Kim SS, Lee JH, et al. Early detection is important to reduce the economic burden of gastric cancer. J Gastric Cancer 2018;18:82-89.

98. Kim YI, Kim YA, Kim CG, et al. Serial intermediate-term quality of life comparison after endoscopic submucosal dissection versus surgery in early gastric cancer patients. Surg Endosc 2018;32:2114-2122.

99. Kim TS, Min BH, Kim KM, Lee JH, Rhee PL, Kim JJ. Endoscopic submucosal dissection for papillary adenocarcinoma of the stomach: low curative resection rate but favorable longterm outcomes after curative resection. Gastric Cancer 2019; 22:363-368.

100. Lee S, Choi KD, Han M, et al. Long-term outcomes of endoscopic submucosal dissection versus surgery in early gastric cancer meeting expanded indication including undifferentiated-type tumors: a criteria-based analysis. Gastric Cancer 2018;21:490-499.

101. Min BH, Kim ER, Kim KM, et al. Surveillance strategy based on the incidence and patterns of recurrence after curative endoscopic submucosal dissection for early gastric cancer. Endoscopy 2015;47:784-793.

102. Chang JY, Shim KN, Tae CH, et al. Comparison of clinical outcomes after endoscopic submucosal dissection and surgery in the treatment of early gastric cancer: a single-institute study. Medicine (Baltimore) 2017;96:e7210.

103. Chiu PW, Teoh AY, To KF, et al. Endoscopic submucosal dissection (ESD) compared with gastrectomy for treatment of early gastric neoplasia: a retrospective cohort study. Surg Endosc 2012;26:3584-3591.

104. Cho JH, Cha SW, Kim HG, et al. Long-term outcomes of endoscopic submucosal dissection for early gastric cancer: a comparison study to surgery using propensity score-matched analysis. Surg Endosc 2016;30:3762-3773.

105. Feng F, Sun L, Xu G, et al. Is it reasonable to treat early gastric cancer with mucosal infiltration and well differentiation by endoscopic submucosal resection? J Gastrointest Surg 2015; 19:2111-2119.

106. Fukunaga S, Nagami Y, Shiba M, et al. Long-term prognosis of expanded-indication differentiated-type early gastric cancer treated with endoscopic submucosal dissection or surgery using propensity score analysis. Gastrointest Endosc 2017;85: 143-152.

107. Gong EJ, Kim DH, Ahn JY, et al. Comparison of long-term out- 
comes of endoscopic submucosal dissection and surgery for esophagogastric junction adenocarcinoma. Gastric Cancer 2017;20:84-91.

108. Kim YI, Kim YW, Choi IJ, et al. Long-term survival after endoscopic resection versus surgery in early gastric cancers. Endoscopy 2015;45:293-301.

109. Pyo JH, Lee H, Min BH, et al. Long-term outcome of endoscopic resection vs. surgery for early gastric cancer: a non-inferiority-matched cohort study. Am J Gastroenterol 2016;111: 240-249.

110. Fujiya K, Takizawa K, Tokunaga M, et al. The value of diagnostic endoscopic submucosal dissection for patients with clinical submucosal invasive early gastric cancer. Gastric Cancer 2018;21:124-132.

111. Lee HD, Chung H, Kim SG, et al. Exploring the possibility of endoscopic submucosal dissection for clinical submucosal invasive early gastric cancers. Surg Endosc 2019;33:40084015.

112. Kim DY, Joo JK, Ryu SY, Kim YJ, Kim SK. Factors related to lymph node metastasis and surgical strategy used to treat early gastric carcinoma. World J Gastroenterol 2004;10:737740 .

113. Kim JH, Lee YC, Kim H, et al. Endoscopic resection for undifferentiated early gastric cancer. Gastrointest Endosc 2009;69: e1-e9.

114. Abe S, Oda I, Suzuki H, et al. Short- and long-term outcomes of endoscopic submucosal dissection for undifferentiated early gastric cancer. Endoscopy 2013;45:703-707.

115. Ahn JY, Park HJ, Park YS, et al. Endoscopic resection for undifferentiated-type early gastric cancer: immediate endoscopic outcomes and long-term survivals. Dig Dis Sci 2016;61:11581164.

116. Kim JH, Kim YH, Jung DH, et al. Follow-up outcomes of endoscopic resection for early gastric cancer with undifferentiated histology. Surg Endosc 2014;28:2627-2633.

117. Oda I, Oyama T, Abe S, et al. Preliminary results of multicenter questionnaire study on long-term outcomes of curative endoscopic submucosal dissection for early gastric cancer. Dig Endosc 2014;26:214-219.

118. Park JC, Lee YK, Kim SY, et al. Long-term outcomes of endoscopic submucosal dissection in comparison to surgery in undifferentiated-type intramucosal gastric cancer using propensity score analysis. Surg Endosc 2018;32:2046-2057.

119. Fujishiro M, Chiu PW, Wang HP. Role of antisecretory agents for gastric endoscopic submucosal dissection. Dig Endosc 2013;25 Suppl 1:86-93.
120. Ono H, Yao K, Fujishiro M, et al. Guidelines for endoscopic submucosal dissection and endoscopic mucosal resection for early gastric cancer. Dig Endosc 2016;28:3-15.

121. Park CH, Lee SK. Preventing and controlling bleeding in gastric endoscopic submucosal dissection. Clin Endosc 2013;46: 456-462.

122. Takizawa K, Oda I, Gotoda T, et al. Routine coagulation of visible vessels may prevent delayed bleeding after endoscopic submucosal dissection: an analysis of risk factors. Endoscopy 2008;40:179-183.

123. Kang SH, Lee K, Lee HW, Park GE, Hong YS, Min BH. Delayed perforation occurring after endoscopic submucosal dissection for early gastric cancer. Clin Endosc 2015;48:251255.

124. Lee H, Cheoi KS, Chung H, et al. Clinical features and predictive factors of coagulation syndrome after endoscopic submucosal dissection for early gastric neoplasm. Gastric Cancer 2012;15:83-90.

125. Uedo N, Takeuchi Y, Yamada T, et al. Effect of a proton pump inhibitor or an H2-receptor antagonist on prevention of bleeding from ulcer after endoscopic submucosal dissection of early gastric cancer: a prospective randomized controlled trial. Am J Gastroenterol 2007;102:1610-1616.

126. Ye BD, Cheon JH, Choi KD, et al. Omeprazole may be superior to famotidine in the management of iatrogenic ulcer after endoscopic mucosal resection: a prospective randomized controlled trial. Aliment Pharmacol Ther 2006;24:837-843.

127. Imaeda H, Hosoe N, Suzuki H, et al. Effect of lansoprazole versus roxatidine on prevention of bleeding and promotion of ulcer healing after endoscopic submucosal dissection for superficial gastric neoplasia. J Gastroenterol 2011;46:12671272.

128. Tomita T, Kim Y, Yamasaki T, et al. Prospective randomized controlled trial to compare the effects of omeprazole and famotidine in preventing delayed bleeding and promoting ulcer healing after endoscopic submucosal dissection. J Gastroenterol Hepatol 2012;27:1441-1446.

129. Yang Z, Wu Q, Liu Z, Wu K, Fan D. Proton pump inhibitors versus histamine-2-receptor antagonists for the management of iatrogenic gastric ulcer after endoscopic mucosal resection or endoscopic submucosal dissection: a meta-analysis of randomized trials. Digestion 2011;84:315-320.

130. Arai M, Matsumura T, Okimoto K, et al. Two-week treatment with proton pump inhibitor is sufficient for healing post endoscopic submucosal dissection ulcers. World J Gastroenterol 2014;20:16318-16322. 
131. Niimi K, Fujishiro M, Goto O, et al. Prospective single-arm trial of two-week rabeprazole treatment for ulcer healing after gastric endoscopic submucosal dissection. Dig Endosc 2012; 24:110-116.

132. Lee SH, Lee CK, Chung IK, et al. Optimal duration of proton pump inhibitor in the treatment of endoscopic submucosal dissection-induced ulcers: a retrospective analysis and prospective validation study. Dig Dis Sci 2012;57:429-434.

133. Shin WG, Kim SJ, Choi MH, et al. Can rebamipide and proton pump inhibitor combination therapy promote the healing of endoscopic submucosal dissection-induced ulcers? A randomized, prospective, multicenter study. Gastrointest Endosc 2012;75:739-747.

134. Higuchi K, Takeuchi T, Uedo N, et al. Efficacy and safety of 1-week Helicobacter pylori eradication therapy and 7-week rebamipide treatment after endoscopic submucosal dissection of early gastric cancer in comparison with 8-week PPI standard treatment: a randomized, controlled, prospective, multicenter study. Gastric Cancer 2015;18:612-617.

135. Fujiwara S, Morita Y, Toyonaga T, et al. A randomized controlled trial of rebamipide plus rabeprazole for the healing of artificial ulcers after endoscopic submucosal dissection. J Gastroenterol 2011;46:595-602.

136. Jung SW, Kim SY, Choe JW, et al. Standard and double-dose intravenous proton pump inhibitor injections for prevention of bleeding after endoscopic resection. J Gastroenterol Hepatol 2017;32:778-781.

137. Park JH, Baek EK, Choi CH, et al. Comparison of the efficacy of 4- and 8-week lansoprazole treatment for ESD-induced gastric ulcers: a randomized, prospective, controlled study. Surg Endosc 2014;28:235-241.

138. Nakamura K, Ihara E, Akiho H, et al. Limited effect of rebamipide in addition to proton pump inhibitor (PPI) in the treatment of post-endoscopic submucosal dissection gastric ulcers: a randomized controlled trial comparing PPI plus rebamipide combination therapy with PPI monotherapy. Gut Liver 2016;10:917-924.

139. Kawano S, Okada H, Kawahara Y, et al. Proton pump inhibitor dose-related healing rate of artificial ulcers after endoscopic submucosal dissection: a prospective randomized controlled trial. Digestion 2011;84:46-53.

140. Kim EH, Park SW, Nam E, Lee JG, Park CH. Comparative efficacy of various anti-ulcer medications after gastric endoscopic submucosal dissection: a systematic review and network meta-analysis. Surg Endosc 2019;33:1271-1283.

141. Oh TH, Jung HY, Choi KD, et al. Degree of healing and heal- ing-associated factors of endoscopic submucosal dissectioninduced ulcers after pantoprazole therapy for 4 weeks. Dig Dis Sci 2009;54:1494-1499.

142. Park HJ, Kim HS, Kim BR, et al. Half-dose rabeprazole has an equal efficacy to standard-dose rabeprazole on endoscopic submucosal dissection-induced ulcer. Dig Dis Sci 2013;58: 1054-1061.

143. Mochizuki S, Uedo N, Oda I, et al. Scheduled second-look endoscopy is not recommended after endoscopic submucosal dissection for gastric neoplasms (the SAFE trial): a multicentre prospective randomised controlled non-inferiority trial. Gut 2015;64:397-405.

144. Ryu HY, Kim JW, Kim HS, et al. Second-look endoscopy is not associated with better clinical outcomes after gastric endoscopic submucosal dissection: a prospective, randomized, clinical trial analyzed on an as-treated basis. Gastrointest Endosc 2013;78:285-294.

145. Nishizawa T, Suzuki H, Akimoto T, et al. Effects of preoperative proton pump inhibitor administration on bleeding after gastric endoscopic submucosal dissection: a systematic review and meta-analysis. United European Gastroenterol J 2016;4:5-10.

146. Oda I, Suzuki H, Nonaka S, Yoshinaga S. Complications of gastric endoscopic submucosal dissection. Dig Endosc 2013;25 Suppl 1:71-78.

147. Jeon SW, Jung MK, Kim SK, et al. Clinical outcomes for perforations during endoscopic submucosal dissection in patients with gastric lesions. Surg Endosc 2010;24:911-916.

148. Jeong G, Lee JH, Yu MK, et al. Non-surgical management of microperforation induced by EMR of the stomach. Dig Liver Dis 2006;38:605-608.

149. Minami S, Gotoda T, Ono H, Oda I, Hamanaka H. Complete endoscopic closure of gastric perforation induced by endoscopic resection of early gastric cancer using endoclips can prevent surgery (with video). Gastrointest Endosc 2006;63: 596-601

150. Paspatis GA, Dumonceau JM, Barthet M, et al. Diagnosis and management of iatrogenic endoscopic perforations: European Society of Gastrointestinal Endoscopy (ESGE) position statement. Endoscopy 2014;46:693-711.

151. Fu K, Ishikawa T, Yamamoto T, Kaji Y. Paracentesis for successful treatment of tension pneumoperitoneum related to endoscopic submucosal dissection. Endoscopy 2009;41 Suppl 2:E245.

152. ASGE Technology Committee, Lo SK, Fujii-Lau LL, et al. The use of carbon dioxide in gastrointestinal endoscopy. Gastro- 
intest Endosc 2016;83:857-865.

153. Japanese Gastric Cancer Association. Japanese gastric cancer treatment guidelines 2010 (ver. 3). Gastric Cancer 2011;14: 113-123.

154. Hirasawa T, Gotoda T, Miyata S, et al. Incidence of lymph node metastasis and the feasibility of endoscopic resection for undifferentiated-type early gastric cancer. Gastric Cancer 2009;12:148-152.

155. Pyo JH, Shin CM, Lee H, et al. A risk-prediction model based on lymph-node metastasis for incorporation into a treatment algorithm for signet ring cell-type intramucosal gastric cancer. Ann Surg 2016;264:1038-1043.

156. Hatta W, Gotoda T, Oyama T, et al. A scoring system to stratify curability after endoscopic submucosal dissection for early gastric cancer: "eCura system”. Am J Gastroenterol 2017;112: 874-881.

157. Kawata N, Kakushima N, Takizawa K, et al. Risk factors for lymph node metastasis and long-term outcomes of patients with early gastric cancer after non-curative endoscopic submucosal dissection. Surg Endosc 2017;31:1607-1616.

158. Hatta W, Gotoda T, Oyama T, et al. Is radical surgery necessary in all patients who do not meet the curative criteria for endoscopic submucosal dissection in early gastric cancer? A multi-center retrospective study in Japan. J Gastroenterol 2017;52:175-184.

159. Suzuki H, Oda I, Abe S, et al. Clinical outcomes of early gastric cancer patients after noncurative endoscopic submucosal dissection in a large consecutive patient series. Gastric Cancer 2017;20:679-689.

160. Pyo JH, Lee H, Min YW, et al. Feasibility of endoscopic resection in early gastric cancer with lymphovascular invasion. Ann Surg Oncol 2019;26:449-455.

161. Choi JY, Jeon SW, Cho KB, et al. Non-curative endoscopic resection does not always lead to grave outcomes in submucosal invasive early gastric cancer. Surg Endosc 2015;29:18421849.

162. Toyokawa T, Ohira M, Tanaka H, et al. Optimal management for patients not meeting the inclusion criteria after endoscopic submucosal dissection for gastric cancer. Surg Endosc 2016;30:2404-2414.

163. Toya Y, Endo M, Nakamura S, et al. Clinical outcomes of noncurative endoscopic submucosal dissection with negative resected margins for gastric cancer. Gastrointest Endosc 2017; 85:1218-1224.

164. Hatta W, Gotoda T, Oyama T, et al. Is the eCura system useful for selecting patients who require radical surgery after noncu- rative endoscopic submucosal dissection for early gastric cancer? A comparative study. Gastric Cancer 2018;21:481-489.

165. Eom BW, Kim YI, Kim KH, et al. Survival benefit of additional surgery after noncurative endoscopic resection in patients with early gastric cancer. Gastrointest Endosc 2017;85:155163.

166. Kim ER, Lee H, Min BH, et al. Effect of rescue surgery after non-curative endoscopic resection of early gastric cancer. $\mathrm{Br}$ Surg 2015;102:1394-1401.

167. Suzuki S, Gotoda T, Hatta W, et al. Survival benefit of additional surgery after non-curative endoscopic submucosal dissection for early gastric cancer: a propensity score matching analysis. Ann Surg Oncol 2017;24:3353-3360.

168. Jung DH, Lee YC, Kim JH, et al. Additive treatment improves survival in elderly patients after non-curative endoscopic resection for early gastric cancer. Surg Endosc 2017;31:13761382.

169. Kusano C, Iwasaki M, Kaltenbach T, Conlin A, Oda I, Gotoda T. Should elderly patients undergo additional surgery after non-curative endoscopic resection for early gastric cancer? Long-term comparative outcomes. Am J Gastroenterol 2011; 106:1064-1069

170. Pyo JH, Lee H, Min BH, et al. Comparison of long-term outcomes after non-curative endoscopic resection in older patients with early gastric cancer. Ann Surg Oncol 2017;24: 2624-2631.

171. Sekiguchi M, Suzuki H, Oda I, et al. Risk of recurrent gastric cancer after endoscopic resection with a positive lateral margin. Endoscopy 2014;46:273-278.

172. Han JP, Hong SJ, Kim HK, et al. Risk stratification and management of non-curative resection after endoscopic submucosal dissection for early gastric cancer. Surg Endosc 2016;30: 184-189.

173. Jeon MY, Park JC, Hahn KY, Shin SK, Lee SK, Lee YC. Longterm outcomes after noncurative endoscopic resection of early gastric cancer: the optimal time for additional endoscopic treatment. Gastrointest Endosc 2018;87:1003-1013.

174. Oh S, Kim SG, Choi JM, et al. Ablation of residual gastric tumor by argon plasma coagulation after endoscopic resection. Surg Endosc 2017;31:1093-1100.

175. Fukase K, Kato M, Kikuchi S, et al. Effect of eradication of Helicobacter pylori on incidence of metachronous gastric carcinoma after endoscopic resection of early gastric cancer: an open-label, randomised controlled trial. Lancet 2008;372: 392-397.

176. Kim SG, Jung HK, Lee HL, et al. Guidelines for the diagnosis 
and treatment of Helicobacter pylori infection in Korea, 2013 revised edition. J Gastroenterol Hepatol 2014;29:1371-1386.

177. Malfertheiner P, Megraud F, O'Morain CA, et al. Management of Helicobacter pylori infection-the Maastricht V/Florence Consensus Report. Gut 2017;66:6-30.

178. Chey WD, Leontiadis GI, Howden CW, Moss SF. ACG clinical guideline: treatment of Helicobacter pylori infection. Am J Gastroenterol 2017;112:212-239.

179. Mahachai V, Vilaichone RK, Pittayanon R, et al. Helicobacter pylori management in ASEAN: The Bangkok consensus report. J Gastroenterol Hepatol 2018;33:37-56.

180. Liu WZ, Xie Y, Lu H, et al. Fifth Chinese national consensus report on the management of Helicobacter pylori infection. Helicobacter 2018;23:e12475.

181. Yoon SB, Park JM, Lim CH, Cho YK, Choi MG. Effect of Helicobacter pylori eradication on metachronous gastric cancer after endoscopic resection of gastric tumors: a meta-analysis. Helicobacter 2014;19:243-248.

182. Bang CS, Baik GH, Shin IS, et al. Helicobacter pylori eradication for prevention of metachronous recurrence after endoscopic resection of early gastric cancer. J Korean Med Sci 2015;30:749-756.

183. Lee YC, Chiang TH, Chou CK, et al. Association between Helicobacter pylori eradication and gastric cancer incidence: a systematic review and meta-analysis. Gastroenterology 2016; 150:1113-1124.

184. Sugano K. Effect of Helicobacter pylori eradication on the incidence of gastric cancer: a systematic review and meta-analysis. Gastric Cancer 2019;22:435-445.

185. Choi IJ, Kook MC, Kim YI, et al. Helicobacter pylori therapy for the prevention of metachronous gastric cancer. N Engl J Med 2018;378:1085-1095.

186. Choi JM, Kim SG, Choi J, et al. Effects of Helicobacter pylori eradication for metachronous gastric cancer prevention: a randomized controlled trial. Gastrointest Endosc 2018;88: 475-485.

187. Lee JH, Kim JG, Jung HK, et al. Synopsis on clinical practice guideline of gastric cancer in Korea: an evidence-based approach. Korean J Gastroenterol 2014;63:66-81.

188. Kim SG, Park CM, Lee NR, et al. Long-term clinical outcomes of endoscopic submucosal dissection in patients with early gastric cancer: a prospective multicenter cohort study. Gut Liver 2018;12:402-410.

189. Kato M, Nishida T, Yamamoto K, et al. Scheduled endoscopic surveillance controls secondary cancer after curative endoscopic resection for early gastric cancer: a multicentre retro- spective cohort study by Osaka University ESD study group. Gut 2013;62:1425-1432.

190. Nasu J, Doi T, Endo H, Nishina T, Hirasaki S, Hyodo I. Characteristics of metachronous multiple early gastric cancers after endoscopic mucosal resection. Endoscopy 2005;37:990-993.

191. Abe S, Oda I, Suzuki H, et al. Long-term surveillance and treatment outcomes of metachronous gastric cancer occurring after curative endoscopic submucosal dissection. Endoscopy 2015;47:1113-1118.

192. Hahn KY, Park JC, Kim EH, et al. Incidence and impact of scheduled endoscopic surveillance on recurrence after curative endoscopic resection for early gastric cancer. Gastrointest Endosc 2016;84:628-638.

193. Yang HJ, Kim SG, Lim JH, et al. Novel risk stratification for metachronous recurrence after curative endoscopic submucosal dissection for early gastric cancer. Gastrointest Endosc 2018;87:419-428.

194. Lee S, Choi KD, Hong SM, et al. Pattern of extragastric recurrence and the role of abdominal computed tomography in surveillance after endoscopic resection of early gastric cancer: Korean experiences. Gastric Cancer 2017;20:843-852.

195. Choi KS, Kim SH, Kim SG, Han JK. Early gastric cancers: is ct surveillance necessary after curative endoscopic submucosal resection for cancers that meet the expanded criteria? Radiology 2016;281:444-453.

196. Park CH, Kim EH, Chung H, et al. Role of computed tomography scan for the primary surveillance of mucosal gastric cancer after complete resection by endoscopic submucosal dissection. Surg Endosc 2014;28:1307-1313.

197. Jung SA, Yang SK, Kang GH, et al. Risk factors of lymph node metastasis in submucosally invasive colorectal carcinoma: with special reference to the depth of invasion. Korean J Gastrointest Endosc 2001;22:411-418.

198. Choi PW, Yu CS, Jang SJ, Jung SH, Kim HC, Kim JC. Risk factors for lymph node metastasis in submucosal invasive colorectal cancer. World J Surg 2008;32:2089-2094.

199. Sung HY, Kang WK, Kim SW, et al. Risk factors for lymph node metastasis in patients with submucosal invasive colorectal carcinoma. Journal of the Korean Surgical Society 2010;78:207-212.

200. Lee SH, Kang HJ, Ahn BK, et al. Clinicopathologic factors for prediction of lymph node metastasis in submucosally invasive colorectal carcinoma. J Korean Surg Soc 2011;80:111118.

201. Ueno H, Hase K, Hashiguchi Y, et al. Novel risk factors for lymph node metastasis in early invasive colorectal cancer: a 
multi-institution pathology review. J Gastroenterol 2014;49: 1314-1323.

202. Han J, Hur H, Min BS, Lee KY, Kim NK. Predictive factors for lymph node metastasis in submucosal invasive colorectal carcinoma: a new proposal of depth of invasion for radical surgery. World J Surg 2018;42:2635-2641.

203. Kim B, Kim EH, Park SJ, et al. The risk of lymph node metastasis makes it unsafe to expand the conventional indications for endoscopic treatment of T1 colorectal cancer: a retrospective study of 428 patients. Medicine (Baltimore) 2016;95: e4373.

204. Al-Sukhni E, Attwood K, Gabriel EM, LeVea CM, Kanehira K, Nurkin SJ. Lymphovascular and perineural invasion are associated with poor prognostic features and outcomes in colorectal cancer: a retrospective cohort study. Int J Surg 2017;37:42-49.

205. Ha RK, Han KS, Sohn DK, et al. Histopathologic risk factors for lymph node metastasis in patients with T1 colorectal cancer. Ann Surg Treat Res 2017;93:266-271.

206. Beaton C, Twine CP, Williams GL, Radcliffe AG. Systematic review and meta-analysis of histopathological factors influencing the risk of lymph node metastasis in early colorectal cancer. Colorectal Dis 2013;15:788-797.

207. Mou S, Soetikno R, Shimoda T, Rouse R, Kaltenbach T. Pathologic predictive factors for lymph node metastasis in submucosal invasive (T1) colorectal cancer: a systematic review and meta-analysis. Surg Endosc 2013;27:2692-2703.

208. Choi JY, Jung SA, Shim KN, et al. Meta-analysis of predictive clinicopathologic factors for lymph node metastasis in patients with early colorectal carcinoma. J Korean Med Sci 2015;30:398-406

209. Tanaka S, Haruma K, Teixeira CR, et al. Endoscopic treatment of submucosal invasive colorectal carcinoma with special reference to risk factors for lymph node metastasis. J Gastroenterol 1995;30:710-717.

210. Kikuchi R, Takano M, Takagi K, et al. Management of early invasive colorectal cancer. Risk of recurrence and clinical guidelines. Dis Colon Rectum 1995;38:1286-1295.

211. Kudo S. Endoscopic mucosal resection of flat and depressed types of early colorectal cancer. Endoscopy 1993;25:455-461.

212. Haggitt RC, Glotzbach RE, Soffer EE, Wruble LD. Prognostic factors in colorectal carcinomas arising in adenomas: implications for lesions removed by endoscopic polypectomy. Gastroenterology 1985;89:328-336.

213. Park YJ, Kim WH, Paeng SS, Park JG. Histoclinical analysis of early colorectal cancer. World J Surg 2000;24:1029-1035.
214. Choi DH, Sohn DK, Chang HJ, Lim SB, Choi HS, Jeong SY. Indications for subsequent surgery after endoscopic resection of submucosally invasive colorectal carcinomas: a prospective cohort study. Dis Colon Rectum 2009;52:438-445.

215. Lim KH, Jung SW, Jeong ID, et al. Risk factors for lymph node metastasis after endoscopic resection for early colorectal cancer. Intest Res 2008;6:103-109.

216. Lee SH, Cho HD, Park DI, et al. Pathological predictors for defining a therapeutic strategy for early colon cancer after endoscopic resection: multicenter retrospective analysis from surgically resected specimens. Hepatogastroenterology 2014; 61:642-646.

217. Nakadoi K, Oka S, Tanaka S, et al. Condition of muscularis mucosae is a risk factor for lymph node metastasis in $\mathrm{T} 1$ colorectal carcinoma. Surg Endosc 2014;28:1269-1276.

218. Nishida T, Egashira Y, Akutagawa H, et al. Predictors of lymph node metastasis in T1 colorectal carcinoma: an immunophenotypic analysis of 265 patients. Dis Colon Rectum 2014;57: 905-915.

219. Kawachi H, Eishi Y, Ueno H, et al. A three-tier classification system based on the depth of submucosal invasion and budding/sprouting can improve the treatment strategy for T1 colorectal cancer: a retrospective multicenter study. Modern Pathology 2015;28:872-879.

220. Barresi V, Reggiani Bonetti L, Vitarelli E, Di Gregorio C, Ponz de Leon M, Barresi G. Immunohistochemical assessment of lymphovascular invasion in stage I colorectal carcinoma: prognostic relevance and correlation with nodal micrometastases. Am J Surg Pathol 2012;36:66-72.

221. Wada H, Shiozawa M, Katayama K, et al. Systematic review and meta-analysis of histopathological predictive factors for lymph node metastasis in T1 colorectal cancer. J Gastroenterol 2015;50:727-734.

222. Ueno H, Murphy J, Jass JR, Mochizuki H, Talbot IC. Tumour 'budding' as an index to estimate the potential of aggressiveness in rectal cancer. Histopathology 2002;40:127-132.

223. Cappellesso R, Luchini C, Veronese N, et al. Tumor budding as a risk factor for nodal metastasis in pT1 colorectal cancers: a meta-analysis. Human Pathology 2017;65:62-70.

224. Masaki T, Matsuoka H, Sugiyama M, Abe N, Sakamoto A, Atomi Y. Actual number of tumor budding as a new tool for the individualization of treatment of $\mathrm{T} 1$ colorectal carcinomas. J Gastroenterol Hepatol 2006;21:1115-1121.

225. Yim K, Won DD, Lee IK, Oh ST, Jung ES, Lee SH. Novel predictors for lymph node metastasis in submucosal invasive colorectal carcinoma. World J Gastroenterol 2017;23:5936- 
5944.

226. Gangireddy VGR, Coleman T, Kanneganti P, et al. Polypectomy versus surgery in early colon cancer: size and location of colon cancer affect long-term survival. Int J Colorectal Dis 2018;33:1349-1357.

227. Mounzer R, Das A, Yen RD, et al. Endoscopic and surgical treatment of malignant colorectal polyps: a population-based comparative study. Gastrointest Endosc 2015;81:733-740.

228. Kogler P, Kafka-Ritsch R, Öfner D, et al. Is limited surgery justified in the treatment of T1 colorectal cancer? Surg Endosc 2013;27:817-825.

229. Belderbos TD, van Erning FN, de Hingh IH, van Oijen MG, Lemmens VE, Siersema PD. Long-term recurrence-free survival after standard endoscopic resection versus surgical resection of submucosal invasive colorectal cancer: a population-based study. Clin Gastroenterol Hepatol 2017;15:403411.

230. Kim JB, Lee HS, Lee HJ, et al. Long-term outcomes of endoscopic versus surgical resection of superficial submucosal colorectal cancer. Dig Dis Sci 2015;60:2785-2792.

231. Heo J, Jeon SW, Jung MK, Kim SK, Kim J, Kim S. Endoscopic resection as the first-line treatment for early colorectal cancer: comparison with surgery. Surg Endosc 2014;28:34353442.

232. Yoda Y, Ikematsu H, Matsuda T, et al. A large-scale multicenter study of long-term outcomes after endoscopic resection for submucosal invasive colorectal cancer. Endoscopy 2013;45:718-724.

233. Yoshii S, Nojima M, Nosho K, et al. Factors associated with risk for colorectal cancer recurrence after endoscopic resection of T1 tumors. Clin Gastroenterol Hepatol 2014;12:292302.

234. Asayama N, Oka S, Tanaka S, et al. Long-term outcomes after treatment for $\mathrm{T} 1$ colorectal carcinoma. Int J Colorectal Dis 2016;31:571-578.

235. Tamaru Y, Oka S, Tanaka S, et al. Long-term outcomes after treatment for $\mathrm{T} 1$ colorectal carcinoma: a multicenter retrospective cohort study of Hiroshima GI Endoscopy Research Group. J Gastroenterol 2017;52:1169-1179.

236. Kudo S, Tamura S, Nakajima T, Yamano H, Kusaka H, Watanabe H. Diagnosis of colorectal tumorous lesions by magnifying endoscopy. Gastrointest Endosc 1996;44:8-14.

237. Hurlstone DP, Cross SS, Adam I, et al. Endoscopic morphological anticipation of submucosal invasion in flat and depressed colorectal lesions: clinical implications and subtype analysis of the kudo type $\mathrm{V}$ pit pattern using high-magnifica- tion-chromoscopic colonoscopy. Colorectal Dis 2004;6:369375 .

238. Ohta A, Tominaga K, Sakai Y. Efficacy of magnifying colonoscopy for the diagnosis of colorectal neoplasia: comparison with histopathological findings. Dig Endosc 2004;16:308-314.

239. Tanaka S, Haruma K, Nagata S, Oka S, Chayama K. Diagnosis of invasion depth in early colorectal carcinoma by pit pattern analysis with magnifying endoscopy. Dig Endosc 2001;13:S2S5.

240. Matsuda T, Fujii T, Saito Y, et al. Efficacy of the invasive/noninvasive pattern by magnifying chromoendoscopy to estimate the depth of invasion of early colorectal neoplasms. Am J Gastroenterol 2008;103:2700-2706.

241. Zhang QW, Teng LM, Zhang XT, et al. Narrow-band imaging in the diagnosis of deep submucosal colorectal cancers: a systematic review and meta-analysis. Endoscopy 2017;49: 564-580.

242. Hirata M, Tanaka S, Oka S, et al. Evaluation of microvessels in colorectal tumors by narrow band imaging magnification. Gastrointest Endosc 2007;66:945-952.

243. Wada Y, Kudo SE, Kashida H, et al. Diagnosis of colorectal lesions with the magnifying narrow-band imaging system. Gastrointest Endosc 2009;70:522-531.

244. Yoo HY, Lee MS, Ko BM, et al. Correlation of narrow band imaging with magnifying colonoscopy and histology in colorectal tumors. Clin Endosc 2011;44:44-50.

245. Ikematsu H, Matsuda T, Emura F, et al. Efficacy of capillary pattern type IIIA/IIIB by magnifying narrow band imaging for estimating depth of invasion of early colorectal neoplasms. BMC Gastroenterol 2010;10:33.

246. Oba S, Tanaka S, Oka S, et al. Characterization of colorectal tumors using narrow-band imaging magnification: combined diagnosis with both pit pattern and microvessel features. Scand J Gastroenterol 2010;45:1084-1092.

247. Sumimoto K, Tanaka S, Shigita K, et al. Clinical impact and characteristics of the narrow-band imaging magnifying endoscopic classification of colorectal tumors proposed by the Japan NBI Expert Team. Gastrointest Endosc 2017;85:816-821.

248. Iwatate M, Sano Y, Tanaka S, et al. Validation study for development of the Japan NBI Expert Team classification of colorectal lesions. Dig Endosc 2018;30:642-651.

249. Li X, Chen H, Gao Y, Chen X, Ge Z. Prediction of histology and invasive depth of colorectal neoplasia based on morphology of surface depression using magnifying chromocolonoscopy. Int J Colorectal Dis 2010;25:79-85.

250. Hisabe T, Tsuda S, Hoashi T, et al. Validity of conventional en- 
doscopy using "non-extension sign" for optical diagnosis of colorectal deep submucosal invasive cancer. Endosc Int Open 2018;6:E156-E164.

251. Uno Y, Munakata A. The non-lifting sign of invasive colon cancer. Gastrointest Endosc 1994;40:485-489.

252. Kobayashi N, Saito Y, Sano Y, et al. Determining the treatment strategy for colorectal neoplastic lesions: endoscopic assessment or the non-lifting sign for diagnosing invasion depth? Endoscopy 2007;39:701-705.

253. Sakamoto T, Nakajima T, Matsuda T, et al. Comparison of the diagnostic performance between magnifying chromoendoscopy and magnifying narrow-band imaging for superficial colorectal neoplasms: an online survey. Gastrointest Endosc 2018;87:1318-1323.

254. De Ceglie A, Hassan C, Mangiavillano B, et al. Endoscopic mucosal resection and endoscopic submucosal dissection for colorectal lesions: a systematic review. Crit Rev Oncol Hematol 2016;104:138-155.

255. Belderbos TD, Leenders M, Moons LM, Siersema PD. Local recurrence after endoscopic mucosal resection of nonpedunculated colorectal lesions: systematic review and metaanalysis. Endoscopy 2014;46:388-402.

256. Fuccio L, Repici A, Hassan C, et al. Why attempt en bloc resection of non-pedunculated colorectal adenomas? A systematic review of the prevalence of superficial submucosal invasive cancer after endoscopic submucosal dissection. Gut 2018;67:1464-1474.

257. Fujiya M, Tanaka K, Dokoshi T, et al. Efficacy and adverse events of EMR and endoscopic submucosal dissection for the treatment of colon neoplasms: a meta-analysis of studies comparing EMR and endoscopic submucosal dissection. Gastrointest Endosc 2015;81:583-595.

258. Arezzo A, Passera R, Marchese N, Galloro G, Manta R, Ciroc- chi R. Systematic review and meta-analysis of endoscopic submucosal dissection vs endoscopic mucosal resection for colorectal lesions. United European Gastroenterol J 2016;4: $18-29$.

259. Liggi M, Cadoni S, Gallittu P. Endoscopic submucosal dissection, endoscopic mucosal resection and hybrid techniques for large nonpedunculated colorectal tumors: a meta analysis and systematic review. J Interv Gastroenterol 2014;4:117-125.

260. Sato T, Fukuzawa M, Gotoda T, Moriyasu F. Comparison of clinical outcomes between colorectal EMR and ESD. J Tokyo Med Univ 2016;74:154-162.

261. Repici A, Hassan C, De Paula Pessoa D, et al. Efficacy and safety of endoscopic submucosal dissection for colorectal neoplasia: a systematic review. Endoscopy 2012;44:137-150.

262. Shiga H, Endo K, Kuroha M, et al. Endoscopic submucosal dissection for colorectal neoplasia during the clinical learning curve. Surg Endosc 2014;28:2120-2128.

263. Sakamoto T, Saito Y, Fukunaga S, Nakajima T, Matsuda T. Learning curve associated with colorectal endoscopic submucosal dissection for endoscopists experienced in gastric endoscopic submucosal dissection. Dis Colon Rectum 2011; 54:1307-1312.

264. Bhurwal A, Bartel MJ, Heckman MG, et al. Endoscopic mucosal resection: learning curve for large nonpolypoid colorectal neoplasia. Gastrointest Endosc 2016;84:959-968.

265. Probst A, Golger D, Anthuber M, Märkl B, Messmann H. Endoscopic submucosal dissection in large sessile lesions of the rectosigmoid: learning curve in a European center. Endoscopy 2012;44:660-667.

266. Jeon HH, Lee HS, Youn YH, Park JJ, Park H. Learning curve analysis of colorectal endoscopic submucosal dissection (ESD) for laterally spreading tumors by endoscopists experienced in gastric ESD. Surg Endosc 2016;30:2422-2430. 
See "Clinical practice guideline for endoscopic resection of early gastrointestinal cancer" on pages $127-157$.

\section{Supplementary Material 1. PICOs for Each Statement}

\section{Description of PICOs for Superficial Esophageal Squamous Cell Carcinoma}

Statement E1: We recommend endoscopic resection for SESCC without distant or lymph node metastasis, excluding those with obvious submucosal invasion. (Grade of recommendation: strong, Level of evidence: moderate)

Q1. What are the indications for endoscopic resection of superficial esophageal squamous cell carcinoma?

Patient: Patients who undergo either endoscopic resection or esophagectomy for superficial esophageal squamous cell carcinoma without lymph node metastasis

Intervention: Endoscopic resection

Comparator: Esophagectomy

Outcome: Survival rate

Study design: Randomized controlled trial (RCT) or non-RCT

Statement E2: We recommend Lugol chromoendoscopy and/or image-enhanced endoscopy to define the extent of lesion before endoscopic treatment of SESCC. (Grade of recommendation: strong, Level of evidence: moderate)

Q1. Does chromoendoscopy or image-enhanced endoscopy before endoscopic resection of superficial esophageal squamous cell carcinoma help the evaluation of the lateral margin of the lesion?

Patient: Patients who were diagnosed with superficial esophageal squamous cell carcinoma

Intervention: Chromoendoscopy, image-enhanced endoscopy

Comparator: No chromoendoscopy or image-enhanced endoscopy after diagnosis of superficial esophageal squamous cell carcinoma

Outcome: Lateral margin

Study design: RCT or non-RCT

Statement E3: We recommend endoscopic ultrasound to define the stage of SESCC before endoscopic treatment. (Grade of recommendation: strong, Level of evidence: moderate)

Q1. Does endoscopic ultrasound (EUS) before endoscopic resection of superficial esophageal squamous cell carcinoma help to stage the disease?

Patient: Patients who were diagnosed with superficial esophageal squamous cell carcinoma

Intervention: EUS

Comparator: No EUS after diagnosis of superficial esophageal squamous cell carcinoma

Outcome: Depth of invasion, lymph node metastasis

Study design: RCT or non-RCT

Statement E4: We suggest magnifying endoscopy with narrow band imaging for SESCC to assess the depth of invasion before endoscopic treatment. (Grade of recommendation: weak, Level of evidence: low)

Q1. Does magnifying endoscopy with narrow band imaging (MENBI) before endoscopic resection of superficial esophageal squamous cell carcinoma help the evaluation of the depth of invasion? 
Patient: Patients who were diagnosed with superficial esophageal squamous cell carcinoma

Intervention: MENBI

Comparator: No MENBI after diagnosis of superficial esophageal squamous cell carcinoma

Outcome: Depth of invasion

Study design: RCT or non-RCT

Statement E5: We recommend endoscopic submucosal dissection rather than endoscopic mucosal resection for en bloc and curative resection of SESCC confined to the mucosa. (Grade of recommendation: strong, Level of evidence: moderate)

Q1. Is ESD more effective than EMR in patients with superficial esophageal squamous cell carcinoma in terms of en bloc resection, $\mathrm{R} 0$ resection and curative resection?

Patient: Patients who undergo endoscopic resection for superficial esophageal squamous cell carcinoma

Intervention: Endoscopic submucosal dissection

Comparator: Endoscopic mucosal resection

Outcome: en bloc resection, $\mathrm{R} 0$ resection, curative resection

Study design: RCT or non-RCT

Statement E6: We recommend oral steroid or local steroid injection therapy for patients who develop mucosal defects in $>75 \%$ of the esophageal circumference after endoscopic submucosal dissection to prevent esophageal stricture. (Grade of recommendation: strong, Level of evidence: moderate)

Q1. Is steroid administration needed after endoscopic resection in patients with superficial esophageal squamous cell carcinoma to decrease the risk of stenosis?

Patient: Patients who undergo endoscopic resection for superficial esophageal squamous cell carcinoma

Intervention: Steroid administration after endoscopic resection (oral administration or local injection)

Comparator: No steroid administration after endoscopic resection

Outcome: Stenosis rate, number of endoscopic dilatation, adverse event

Study design: RCT or non-RCT

Statement E7: No additional treatment is recommended after en bloc complete resection of SESCC invading no more than the lamina propria with no lymphovascular invasion because of a very low risk of lymph node metastasis. (Grade of recommendation: strong, Level of evidence: moderate) As the risk of lymph node metastasis of a tumor invading into the muscularis mucosa without lymphovascular invasion is low, a close follow-up after en bloc complete endoscopic resection can be considered without additional treatment. (Grade of recommendation: weak, Level of evidence: low) In case of a tumor with submucosal invasion, lymphovascular invasion, and/or positive vertical resection margin, additional treatment is recommended. (Grade of recommendation: strong, Level of evidence: moderate)

Q1. Is there a difference between observation without surgery and rescue surgery in terms of recurrence and survival in patients who achieve R0 resection by endoscopic resection for mucosal esophageal squamous cell carcinoma without lymphovascular invasion?

Patient: Patients who achieve R0 resection by endoscopic resection for mucosal esophageal squamous cell carcinoma without lymphovascular invasion

Intervention: Observation

Comparator: Rescue (additional) surgery

Outcome: Recurrence and survival rates

Study design: RCT or non-RCT 


\section{Description of PICOs for Early Gastric Cancer}

Statement G1: We recommend chromoendoscopy/image-enhanced endoscopy to determine the extent of lesion before endoscopic treatment of early gastric cancer (Grade of recommendation: strong, Level of evidence: moderate)

Q1. Does chromoendoscopy or image-enhanced endoscopy before endoscopic resection of early gastric cancer help the evaluation of the lateral margin of the lesion?

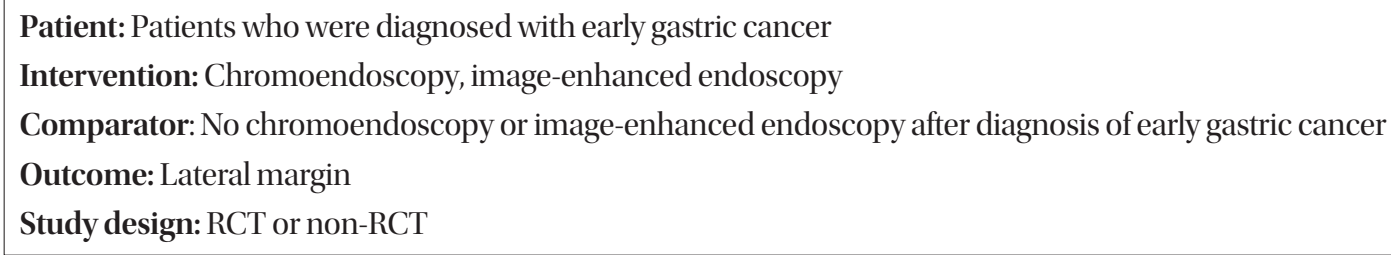

Statement G2: Endoscopic ultrasonography before endoscopic resection of early gastric cancer may be helpful in determining the depth of invasion in some patients with early gastric cancer. (Grade of recommendation: weak, Level of evidence: moderate) Q1.Does EUS before endoscopic resection of early gastric cancer help the evaluation of the depth of invasion?

Patient: Patients who were diagnosed with early gastric cancer

Intervention: EUS

Comparator: No EUS after diagnosis of early gastric cancer

Outcome: Depth of invasion

Study design: RCT or non-RCT

Statement G3: We recommend endoscopic resection for early gastric cancer of well or moderately differentiated tubular or papillary adenocarcinoma meeting endoscopically estimated tumor size $\leq \mathbf{2 m}$ and endoscopically suspected mucosal cancer without ulcer. (Grade of recommendation: strong, Level of evidence: moderate)

Q1. Can we recommend endoscopic resection for early gastric cancer of well or moderately differentiated tubular or papillary adenocarcinoma meeting endoscopically estimated tumor size $\leq 2 \mathrm{~cm}$ and endoscopically suspected mucosal cancer without ulcer?

Patient: Patients with early gastric cancer of well or moderately differentiated tubular or papillary adenocarcinoma meeting endoscopically estimated tumor size $\leq 2 \mathrm{~cm}$ and endoscopically suspected mucosal cancer without ulcer

Intervention: Endoscopic resection

Comparator: Gastrectomy with lymph node dissection

Outcome: Survival rate

Study design: RCT or non-RCT

Statement G4: We suggest endoscopic resection for early gastric cancer of well or moderately differentiated tubular or papillary adenocarcinoma with the following endoscopic findings: 1) mucosal cancer $>2 \mathrm{~cm}$ without ulcer, or 2) mucosal cancer $\leq 3 \mathrm{~cm}$ with ulcer. (Grade of recommendation: weak, Level of evidence: moderate)

Q1. Can we suggest endoscopic resection for early gastric cancer of well or moderately differentiated tubular or papillary adenocarcinoma with the following endoscopic findings: 1) mucosal cancer $>2 \mathrm{~cm}$ without ulcer, or 2) mucosal cancer $\leq 3 \mathrm{~cm}$ with ulcer?

Patient: Patients with early gastric cancer of well or moderately differentiated tubular or papillary adenocarcinoma with the following endoscopic findings: 1) mucosal cancer $>2 \mathrm{~cm}$ without ulcer, or 2) mucosal cancer $\leq 3 \mathrm{~cm}$ with ulcer

Intervention: Endoscopic resection

Comparator: Gastrectomy with lymph node dissection

Outcome: Survival rate

Study design: RCT or non-RCT 
Statement G5: We suggest endoscopic resection for poorly differentiated tubular adenocarcinoma, poorly cohesive carcinoma, or signet ring cell carcinoma meeting the following endoscopic findings: endoscopically estimated tumor size $\leq 2 \mathrm{~cm}$, endoscopically mucosal cancer, and no ulcer in the tumor (Grade of recommendation: weak, Level of evidence: low)

Q1. Can we suggest endoscopic resection for poorly differentiated tubular adenocarcinoma, poorly cohesive carcinoma, or signet ring cell carcinoma meeting the following endoscopic findings: endoscopically estimated tumor size $\leq 2 \mathrm{~cm}$, endoscopically mucosal cancer, and no ulcer in the tumor?

Patient: Patients with early gastric cancer of poorly differentiated tubular adenocarcinoma, poorly cohesive carcinoma, or signet ring cell carcinoma meeting the following endoscopic findings: endoscopically estimated tumor size $\leq 2 \mathrm{~cm}$, endoscopically mucosal cancer, and no ulcer in the tumor

Intervention: Endoscopic resection

Comparator: Gastrectomy with lymph node dissection

Outcome: Survival rate

Study design: RCT or non-RCT

Statement G6: We recommend prophylactic hemostasis of visible vessels on the post-resection ulcer caused by endoscopic resection of early gastric cancer to lower the risk of delayed bleeding (Grade of recommendation: strong, Level of evidence: low) Q1. Can prophylactic hemostasis of visible vessels on the post-resection ulcer caused by endoscopic resection of early gastric cancer reduce the risk of delayed bleeding?

Patient: Patients who underwent endoscopic resection for early gastric cancer

Intervention: Prophylactic hemostasis of visible vessels on the post-resection ulcer

Comparator: No prophylactic hemostasis

Outcome: Delayed bleeding

Study design: RCT or non-RCT

Statement G7: We recommend proton pump inhibitors to decrease the risk of symptoms and complications associated with iatrogenic ulcers caused by endoscopic resection of early gastric cancer. (Grade of recommendation: strong, Level of evidence: high)

Q1. Can proton pump inhibitors decrease the risk of symptoms and complications associated with iatrogenic ulcers caused by endoscopic resection of early gastric cancer?

Patient: Patients who underwent endoscopic resection for early gastric cancer

Intervention: Use of proton pump inhibitors

Comparator: No use of proton pump inhibitors

Outcome: Symptoms and complications associated with iatrogenic ulcers

Study design: RCT or non-RCT

Statement G8: We recommend endoscopic closure as the first treatment option for perforation that occurred during endoscopic resection of early gastric cancer. (Grade of recommendation: strong, Level of evidence: low)

Q1. What is the first treatment option for perforation that occurred during endoscopic resection of early gastric cancer?

Patient: Patients with perforation that occurred during endoscopic resection

Intervention: Endoscopic closure

Comparator: Surgery or conservative management

Outcome: Closure rate

Study design: RCT or non-RCT 
Statement G9: We recommend surgical gastrectomy if histopathological evaluation after endoscopic resection of early gastric cancer meets the criteria for non-curative resection. An exception applies if cancer invasion is observed at the horizontal resection margin only. (Grade of recommendation: strong, Level of evidence: moderate)

Q1. Is there a difference between observation without surgery and rescue surgery in terms of recurrence and survival in patients with early gastric cancer meeting the criteria for non-curative resection (an exception applies if cancer invasion is observed at the horizontal resection margin only)?

Patient: Patients with early gastric cancer meeting the criteria for non-curative resection (an exception applies if cancer invasion is observed at the horizontal resection margin only)

Intervention: Rescue surgery

Comparator: Observation without surgery

Outcome: Recurrence and survival

Study design: RCT or non-RCT

Statement G10: We recommend additional endoscopic management rather than surgical gastrectomy if histopathological evaluation of endoscopically resected early gastric cancer specimen shows positive involvement at the horizontal resection margin without any other findings compatible with non-curative resection. (Grade of recommendation: strong, Level of evidence: moderate)

Q1. Is there a difference between additional endoscopic therapy without surgery and rescue surgery in terms of recurrence and survival in patients with early gastric cancer with positive involvement at the horizontal resection margin without any other findings compatible with non-curative resection?

Patient: Patients with early gastric cancer with positive involvement at the horizontal resection margin without any other findings compatible with non-curative resection

Intervention: Additional endoscopic therapy

Comparator: Rescue surgery

Outcome: Recurrence and survival

Study design: RCT or non-RCT

Statement G11: We recommend Helicobacter pylori (H. pylori) eradication treatment after endoscopic resection of early gastric cancer in $\mathrm{H}$. pylori-infected patients. (Grade of recommendation: strong, Level of evidence: high)

Q1. Can Helicobacter pylori eradication treatment after endoscopic resection of early gastric cancer reduce the metachronous gastric cancer in $H$. pylori-infected patients?

Patient: $H$. pylori-infected patients after endoscopic resection of early gastric cancer

Intervention: Helicobacter pylori eradication treatment

Comparator: No eradication

Outcome: Incidence of the metachronous gastric cancer

Study design: RCT or non-RCT

Statement G12: We recommend regular surveillance endoscopy every 6-12 months for patients who have had curative endoscopic resection of early gastric cancer based on absolute or expanded criteria for early detection of metachronous gastric cancer. (Grade of recommendation: strong, Level of evidence: low)

Q1. Does regular surveillance endoscopy every 6-12 months help the early detection of metachronous gastric cancer in patients who have had curative endoscopic resection of early gastric cancer based on absolute or expanded criteria? 
Patient: Patients who have had curative endoscopic resection of early gastric cancer based on absolute or expanded criteria

Intervention: Surveillance endoscopy every 6-12 months

Comparator: No surveillance endoscopy

Outcome: Early detection of metachronous gastric cancer

Study design: RCT or non-RCT

Statement G13: We suggest regular abdominopelvic computed tomography scan of 6- to 12-month interval for detection of extra-gastric recurrence after curative endoscopic resection of early gastric cancer based on absolute and expanded criteria. (Grade of recommendation: weak, Level of evidence: low)

Q1. Does regular abdominopelvic computed tomography scan every 6-12 months help the detection of extra-gastric recurrence in patients who have had curative endoscopic resection of early gastric cancer based on absolute or expanded criteria?

Patient: Patients who have had curative endoscopic resection of early gastric cancer based on absolute or expanded criteria Intervention: Abdominopelvic computed tomography scan every 6-12 months

Comparator: No surveillance computed tomography scan

Outcome: Detection of extra-gastric recurrence

Study design: RCT or non-RCT

\section{Description of PICOs for Early Colorectal Cancer}

Statement C1: Poor histologic types (poorly differentiated adenocarcinoma, signet ring cell carcinoma, and mucinous carcinoma), deep submucosal invasion, lymphovascular invasion, and intermediate-to-high-grade tumor budding at the site of deepest invasion are risk factors of lymph node metastasis in early colorectal cancer. (Grade of recommendation: strong, Level of evidence: moderate

Q1. Does intramucosal colorectal cancer have the risk of lymph node metastasis?

Patient: Patients who were diagnosed with intramucosal colorectal cancer

Intervention: Not applicable

Comparator: Not applicable

Outcome: Incidence of lymph node metastasis

Study design: RCT or non-RCT

Q2. Is the risk of lymph node metastasis higher in the deep submucosal invasive colorectal cancer than in the superficial submucosal invasive colorectal cancer?

Patient: Patients who were diagnosed with submucosal colorectal cancer

Intervention: Patients who were diagnosed with deep submucosal colorectal cancer

Comparator: Patients who were diagnosed with superficial submucosal colorectal cancer

Outcome: Incidence of lymph node metastasis

Study design: RCT or non-RCT

Q3. Is the risk of lymph node metastasis higher in the submucosal invasive colorectal cancer with lymphovascular invasion than in the submucosal invasive colorectal cancer without lymphovascular invasion? 
Patient: Patients who were diagnosed with submucosal colorectal cancer

Patient: Patients who were diagnosed with submucosal colorectal cancer with lymphovascular invasion

Comparator: Patients who were diagnosed with submucosal colorectal cancer without lymphovascular invasion

Outcome: Incidence of lymph node metastasis

Study design: RCT or non-RCT

Q4. Is the risk of lymph node metastasis higher in the submucosal invasive colorectal cancer with tumor budding than in the submucosal invasive colorectal cancer without tumor budding?

Patient: Patients who were diagnosed with submucosal colorectal cancer

Patient: Patients who were diagnosed with submucosal colorectal cancer with tumor budding

Comparator: Patients who were diagnosed with submucosal colorectal cancer without tumor budding

Outcome: Incidence of lymph node metastasis

Study design: RCT or non-RCT

Q5. Is the risk of lymph node metastasis higher in the poorly differentiated early colorectal cancer than in the well or moderately differentiated early colorectal cancer?

Patient: Patients who were diagnosed with early colorectal cancer

Intervention: Patients who were diagnosed with poorly differentiated early colorectal cancer

Comparator: Patients who were diagnosed with well or moderately differentiated early colorectal cancer

Outcome: Incidence of lymph node metastasis

Study design: RCT or non-RCT

Statement C2: Endoscopic resection of submucosal colorectal cancer with a high risk of lymph node metastasis has a higher recurrence rate than surgical resection. Therefore, we recommend additional surgery if histological signs after endoscopic resection suggest a high risk of lymph node metastasis. (Grade of recommendation: strong, Level of evidence: high)

Q1. Are the recurrence and survival rates different between the endoscopic resection and the surgical resection for the submucosal invasive colorectal cancer with low risk of lymph node metastasis?

Patient: Patients who were diagnosed with submucosal colorectal cancer with low risk of lymph node metastasis

Intervention: Endoscopic resection

Comparator: Surgery

Outcome: Recurrence and/or survival rates

Study design: RCT or non-RCT

Q2. Are the recurrence and survival rates different between the endoscopic resection and the surgical resection for the submucosal invasive colorectal cancer with high risk of lymph node metastasis?

Patient: Patients who were diagnosed with submucosal colorectal cancer with high risk of lymph node metastasis

Intervention: Endoscopic resection

Comparator: Surgery

Outcome: Recurrence and/or survival rates

Study design: RCT or non-RCT 
Statement C3: We recommend endoscopic assessment of pit patterns and vascular patterns to estimate the depth of submucosal invasion before endoscopic resection of early colorectal cancer. (Grade of recommendation: strong, Level of evidence: high)

Q1. For the diagnosis of suspected/established early colorectal cancer, is narrow band imaging useful to differentiate mucosal/superficial submucosal cancer from deep submucosal cancer compared with white light endoscopy?

Patient: Patients who have suspected or established early colorectal cancer

Intervention: Narrow band imaging

Comparator: White light endoscopy

Outcome: Differentiation of mucosal/superficial submucosal cancer from deep submucosal cancer (diagnostic accuracy)

Study design: RCT or non-RCT

Q2. For the diagnosis of suspected/established early colorectal cancer, is chromoendoscopy useful to differentiate mucosal/superficial submucosal cancer from deep submucosal cancer compared with white light endoscopy?

Patient: Patients who have suspected or established early colorectal cancer

Intervention: Chromoendoscopy

Comparator: White light endoscopy

Outcome: Differentiation of mucosal/superficial submucosal cancer from deep submucosal cancer (diagnostic accuracy)

Study design: RCT or non-RCT

Q3. For the diagnosis of suspected/established early colorectal cancer, is magnifying endoscopy useful to differentiate mucosal/ superficial submucosal cancer from deep submucosal cancer compared with conventional endoscopy?

Patient: Patients who have suspected or established early colorectal cancer

Intervention: Magnifying endoscopy

Comparator: Conventional (non-magnifying) endoscopy

Outcome: Differentiation of mucosal/superficial submucosal cancer from deep submucosal cancer (diagnostic accuracy)

Study design: RCT or non-RCT

Statement C4. En bloc and histologically complete resection should be achieved for endoscopic treatment of a suspected or established early colorectal cancer. We recommend endoscopic submucosal dissection for the treatment of endoscopically resectable early colorectal cancer which cannot be resected en bloc using endoscopic mucosal resection technique. (Grade of recommendation: strong, Level of evidence: moderate)

Q1. Does endoscopic submucosal dissection provide higher en bloc resection rate for suspected or established early colorectal cancer than endoscopic mucosal resection or other endoscopic resection techniques?

Patient: Patients who have suspected or established early colorectal cancer

Intervention: Endoscopic submucosal dissection

Comparator: Endoscopic mucosal resection, endoscopic resection techniques other than endoscopic submucosal dissection

Outcome: En bloc resection rate

Study design: RCT or non-RCT 


\section{Supplementary Material 2. Search Flowcharts}

\section{Superficial Esophageal Squamous Cell Carcinoma}

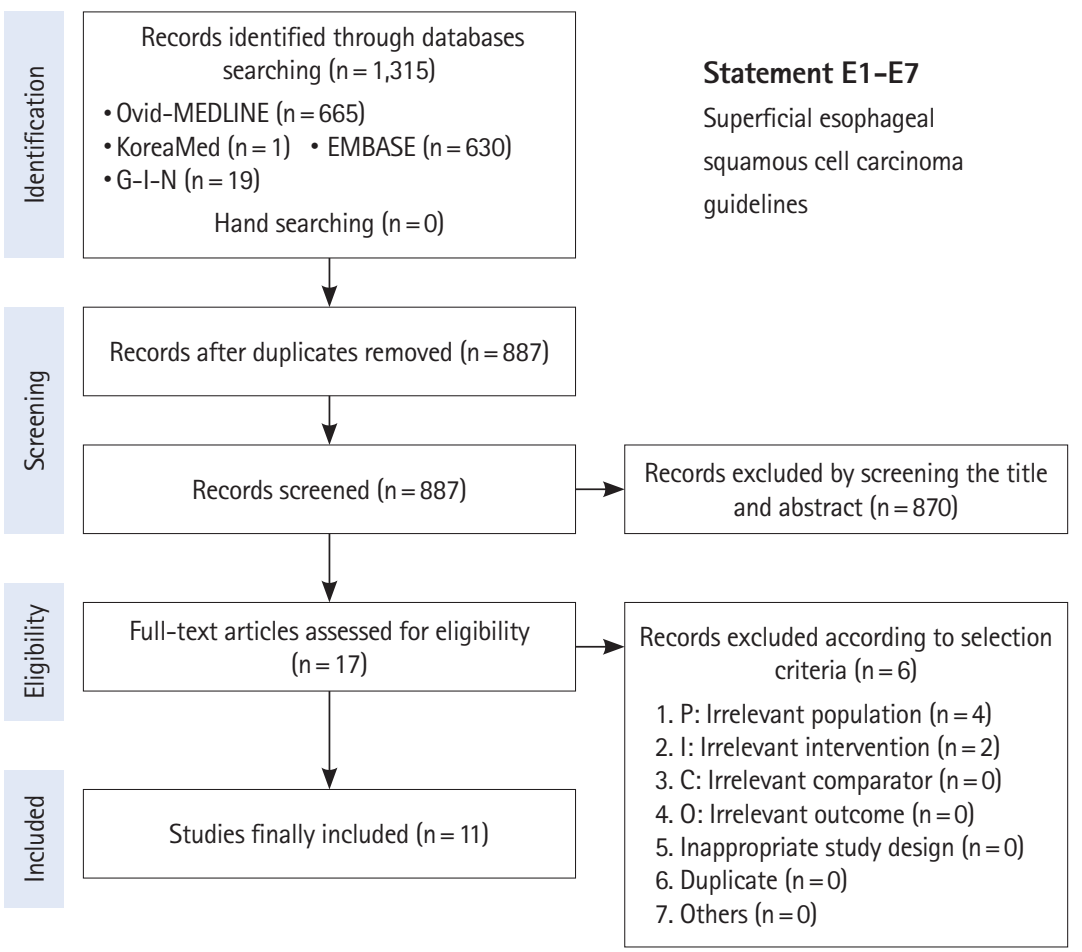




\section{Early Gastric Cancer}

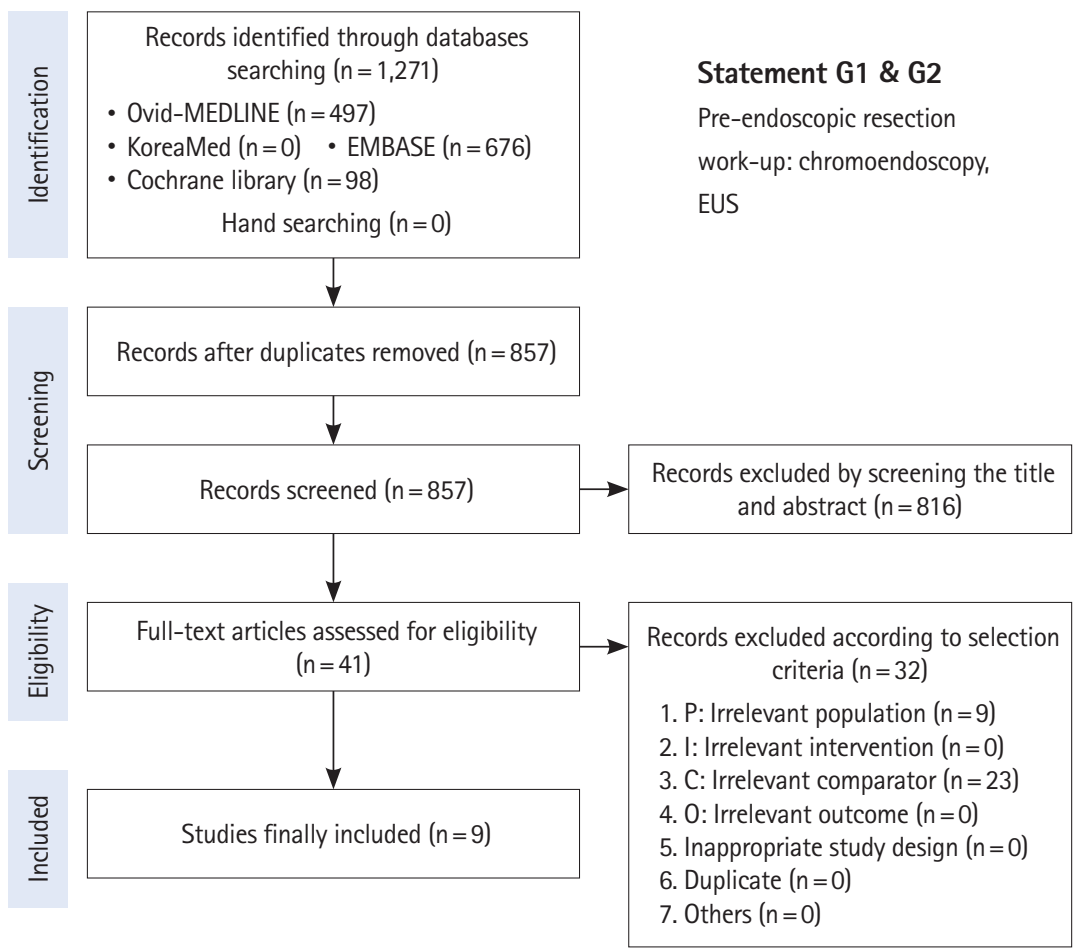




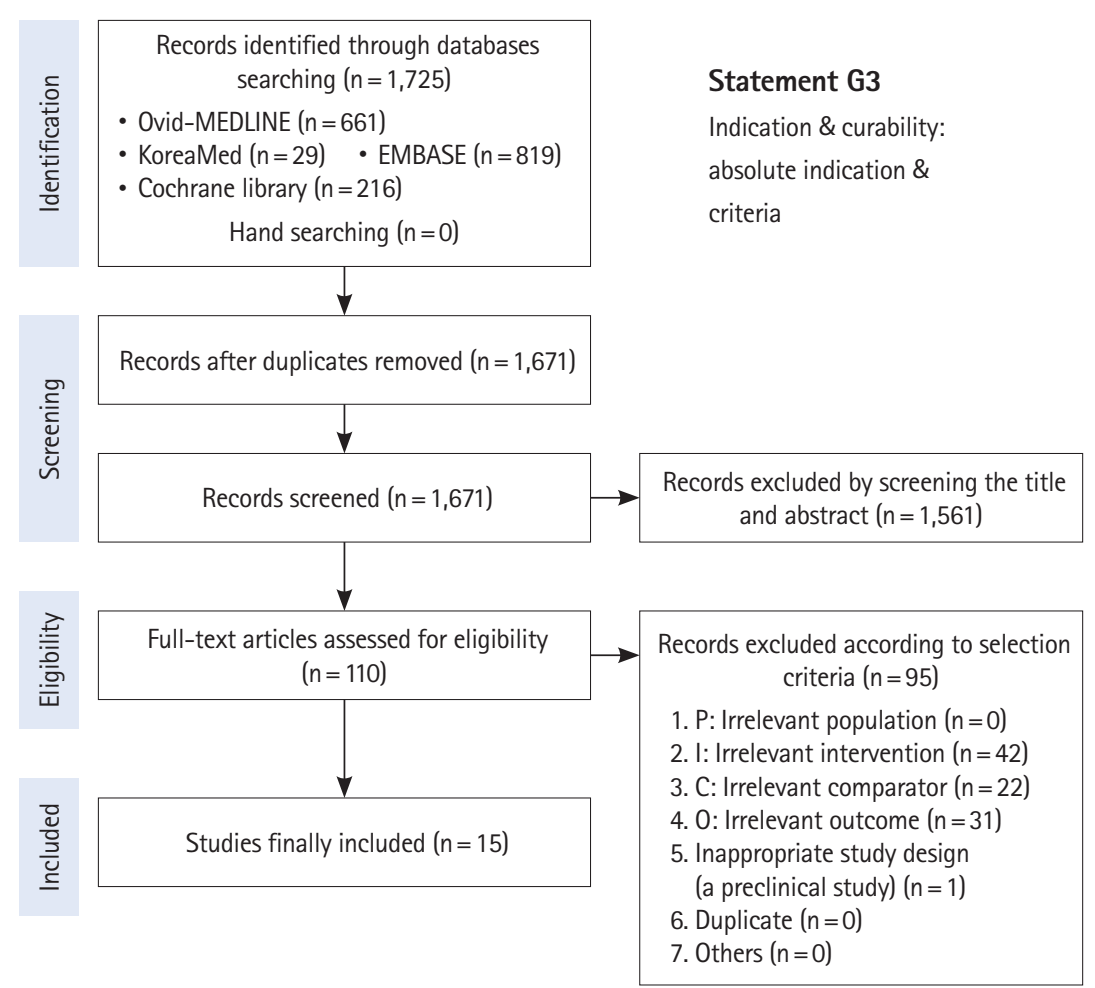




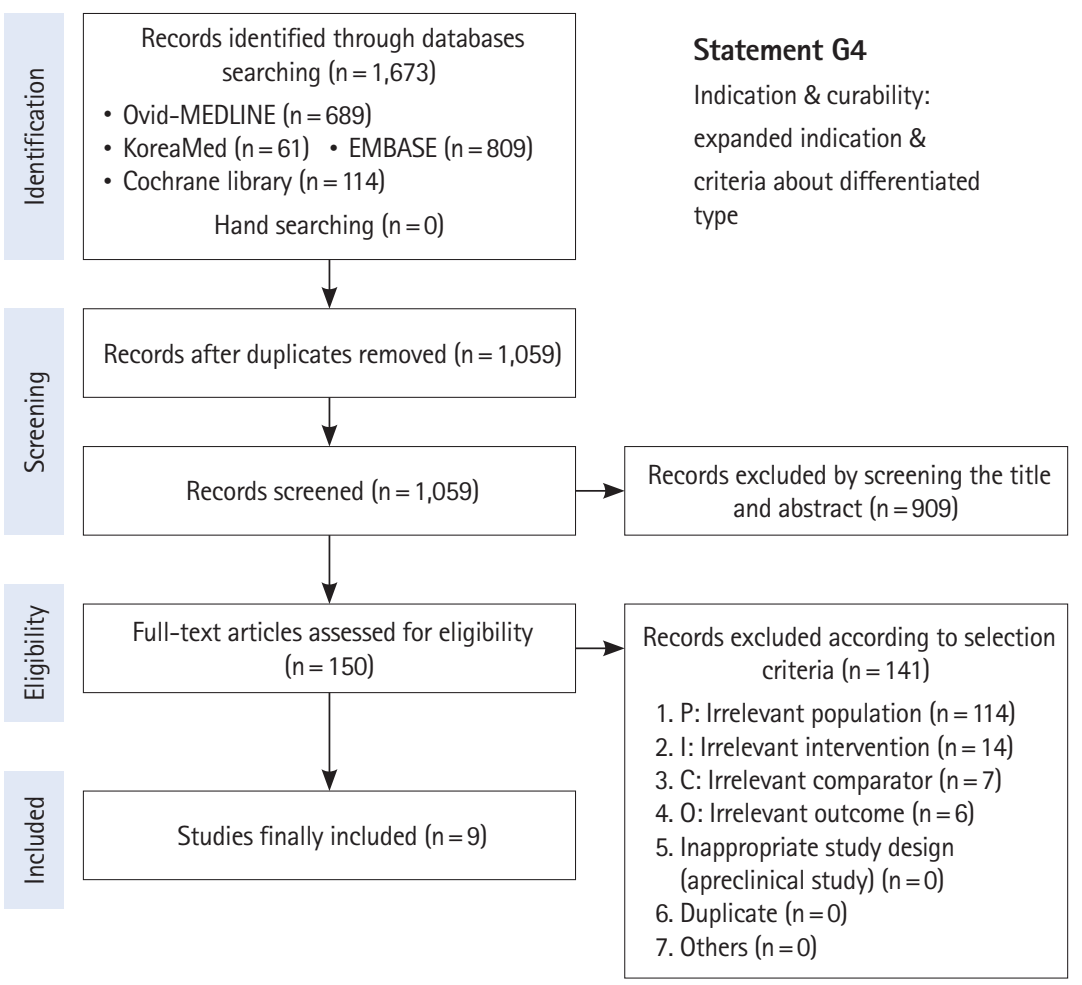




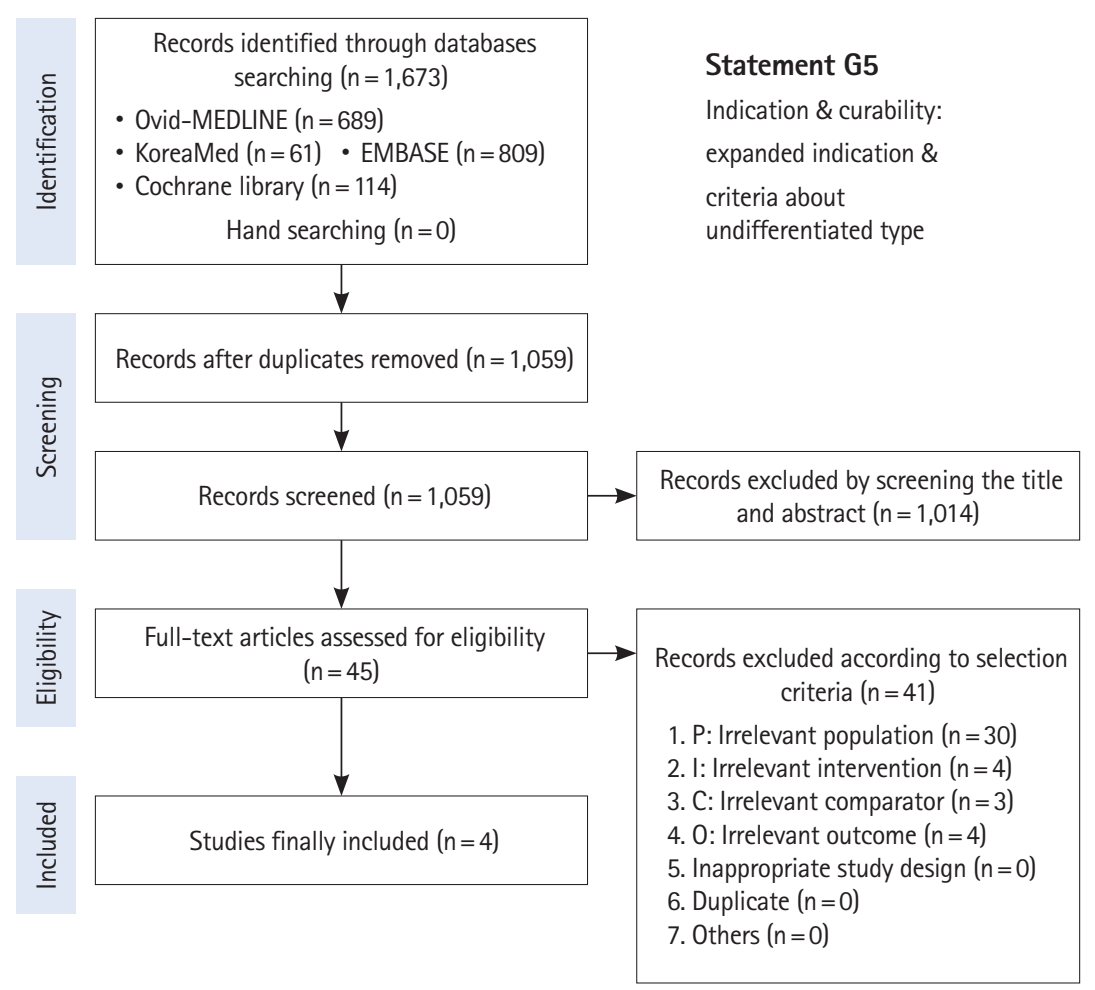




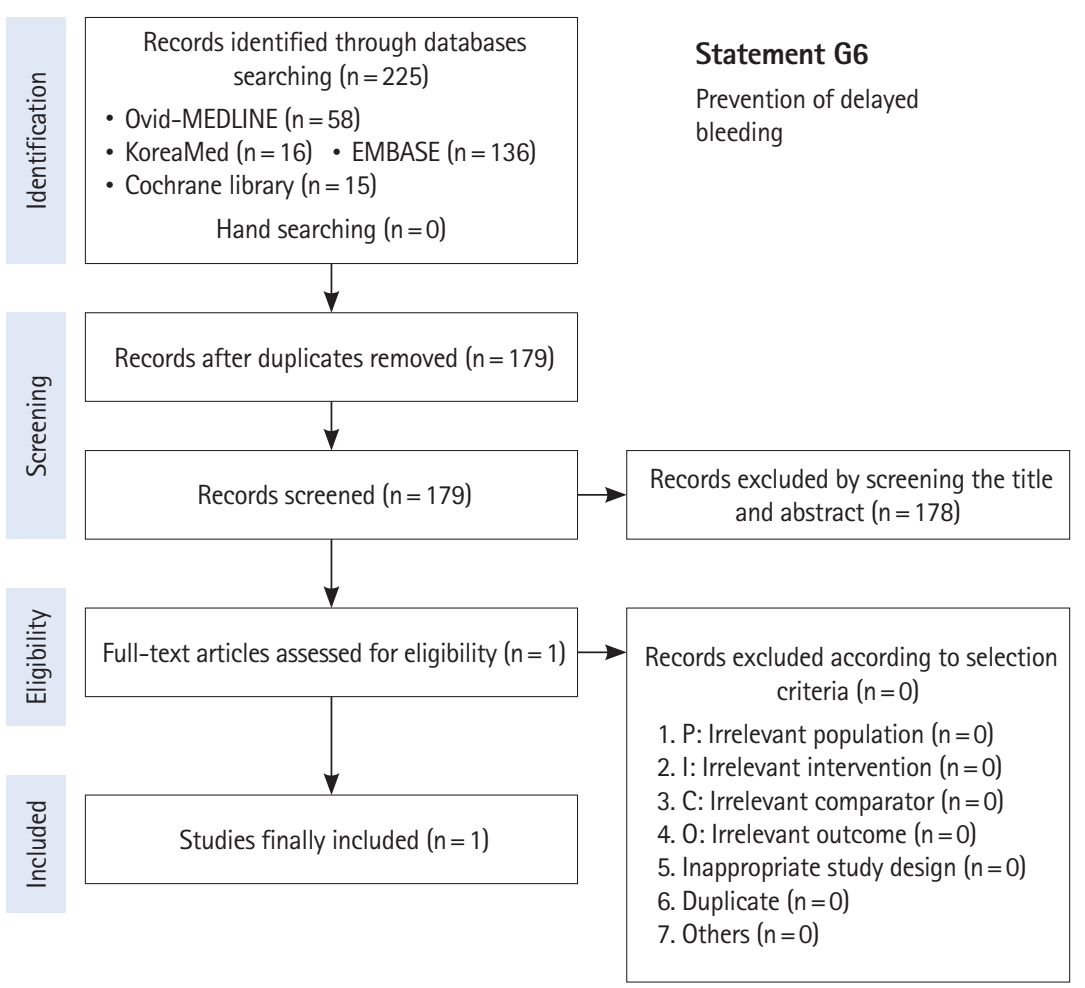




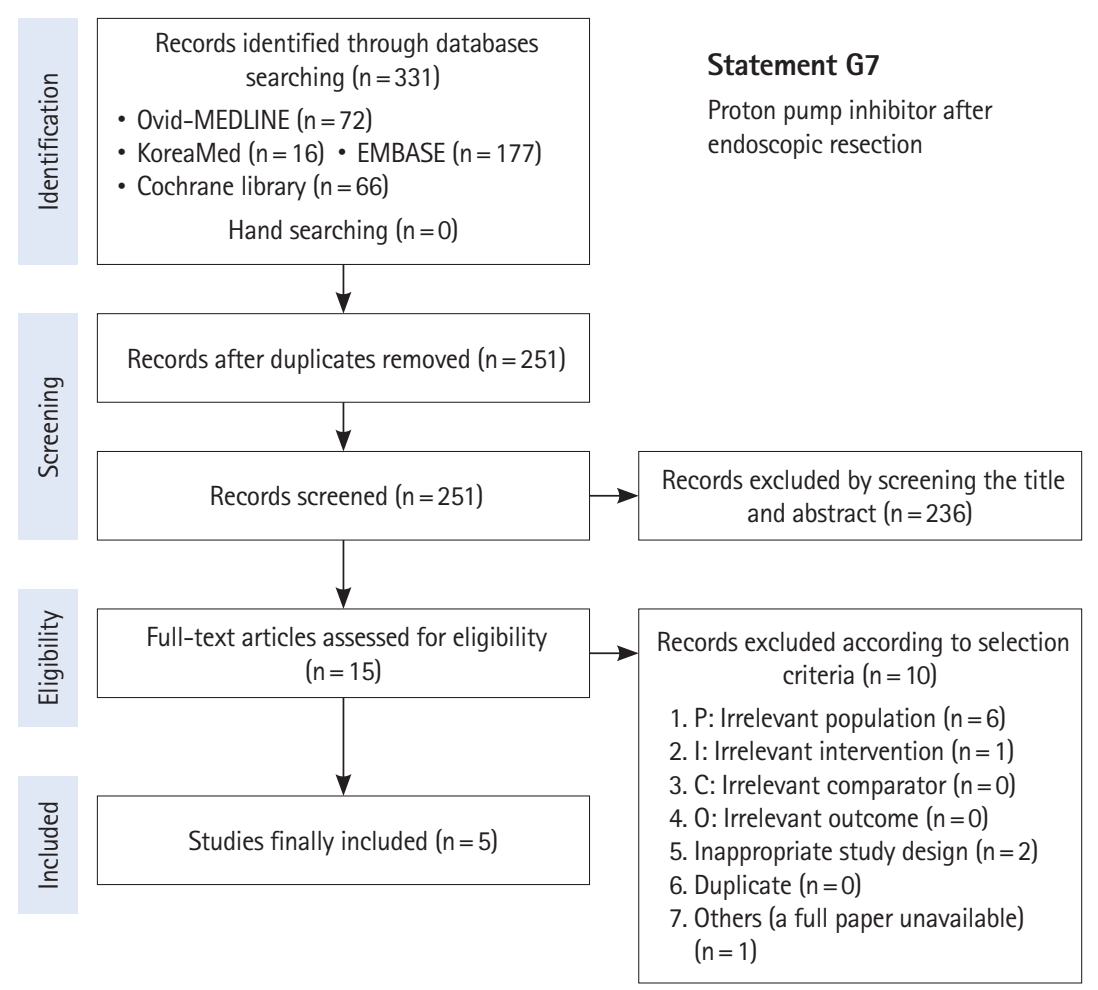




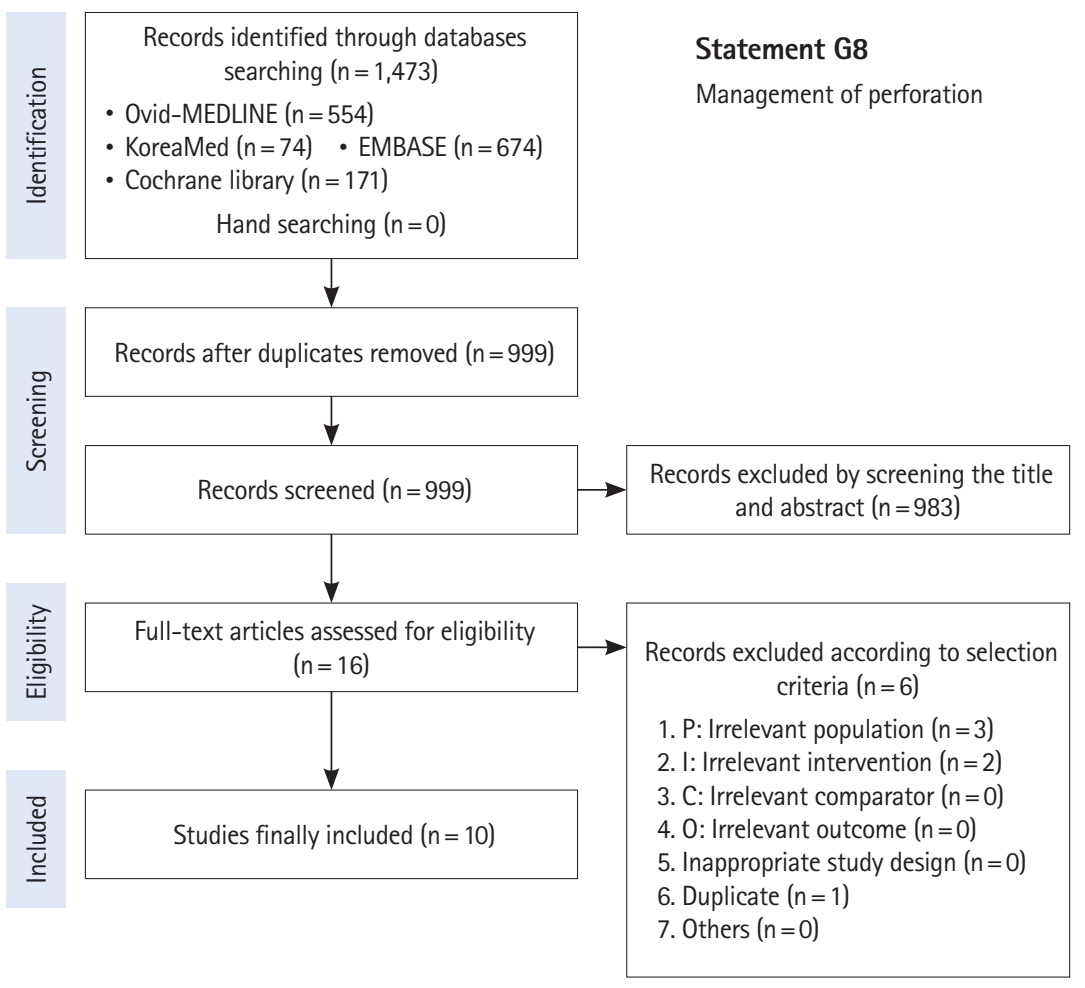




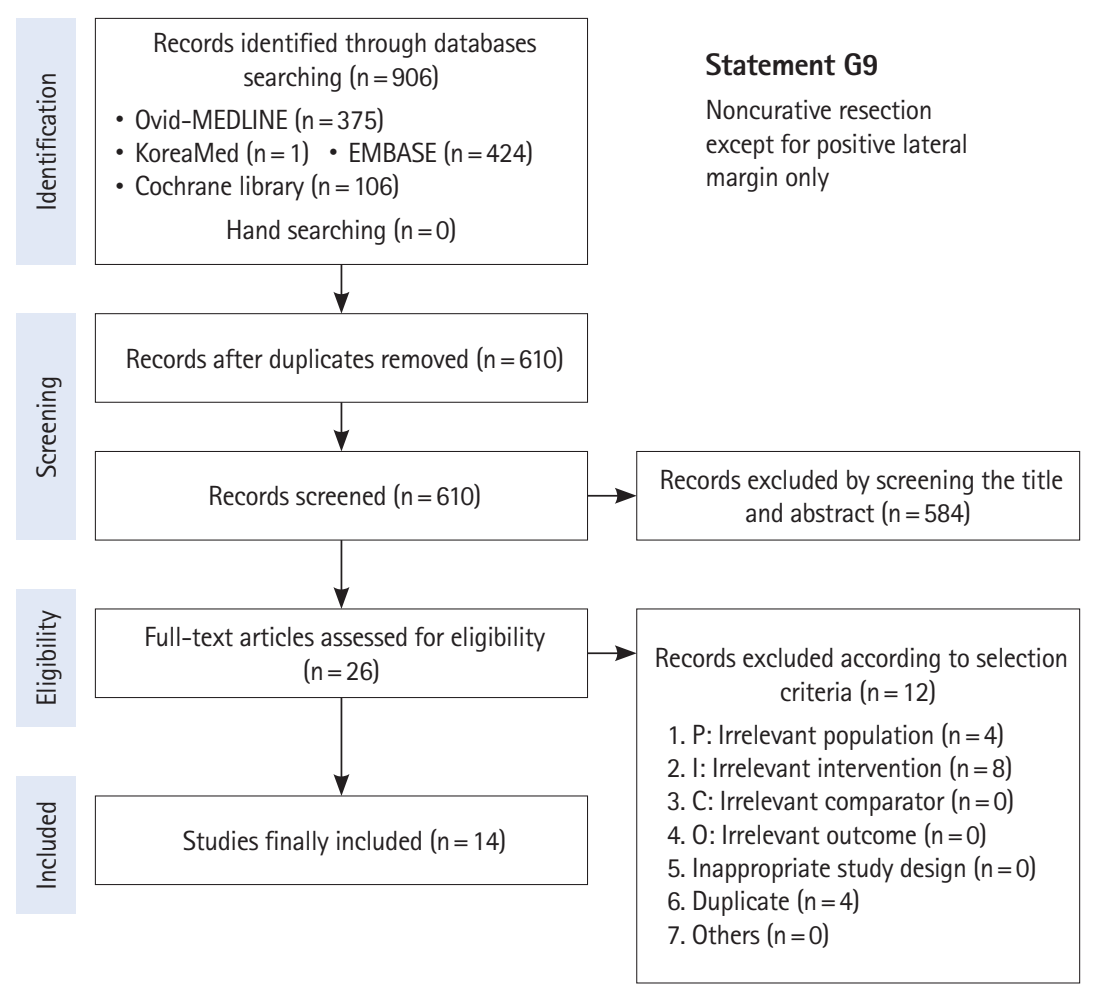




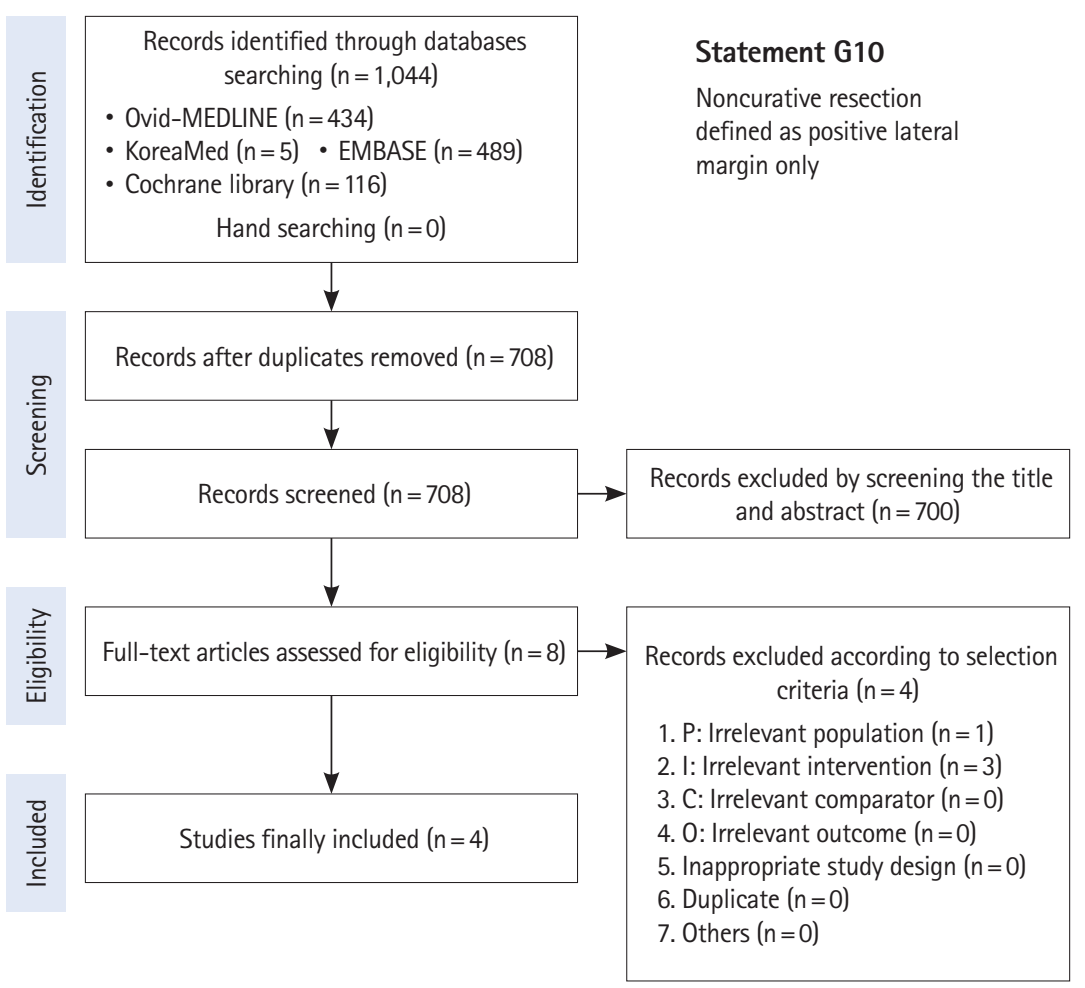




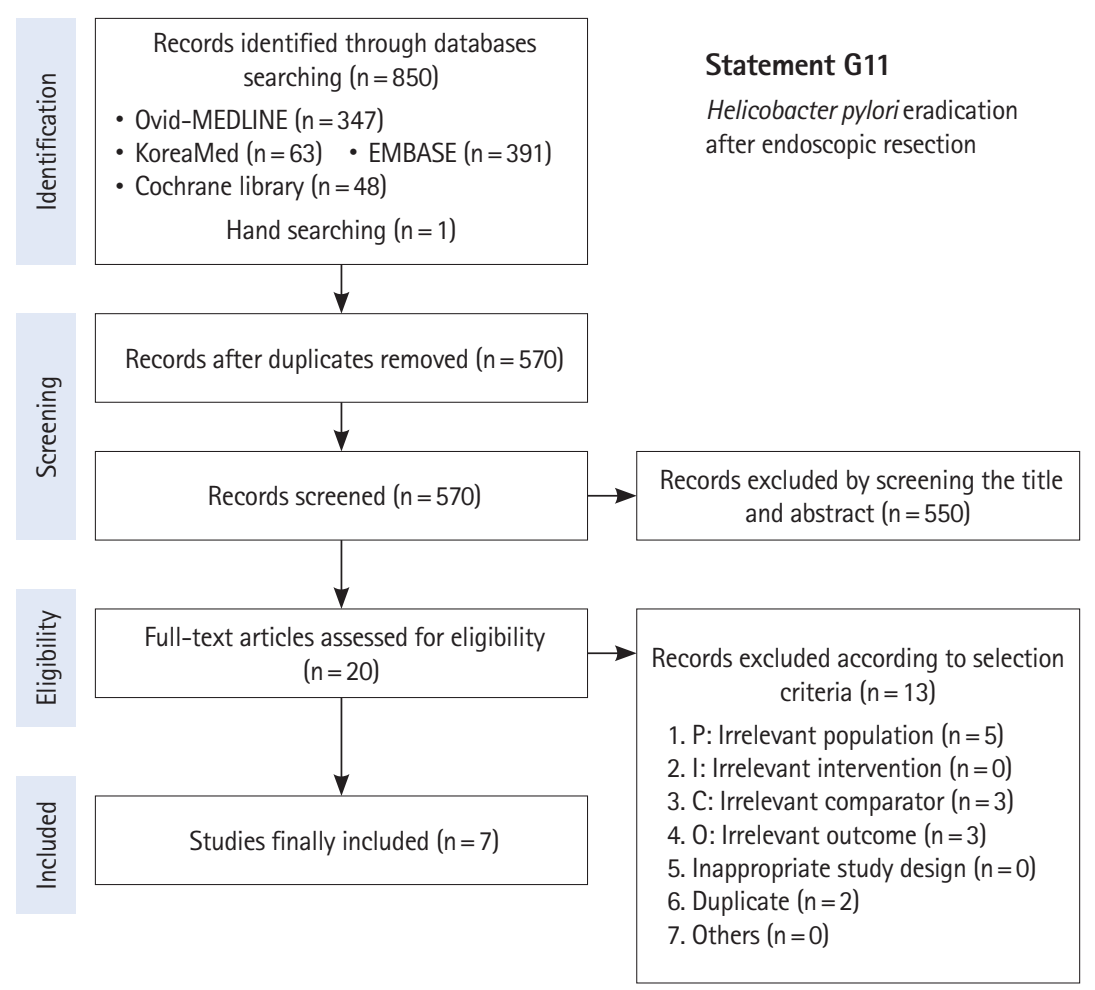




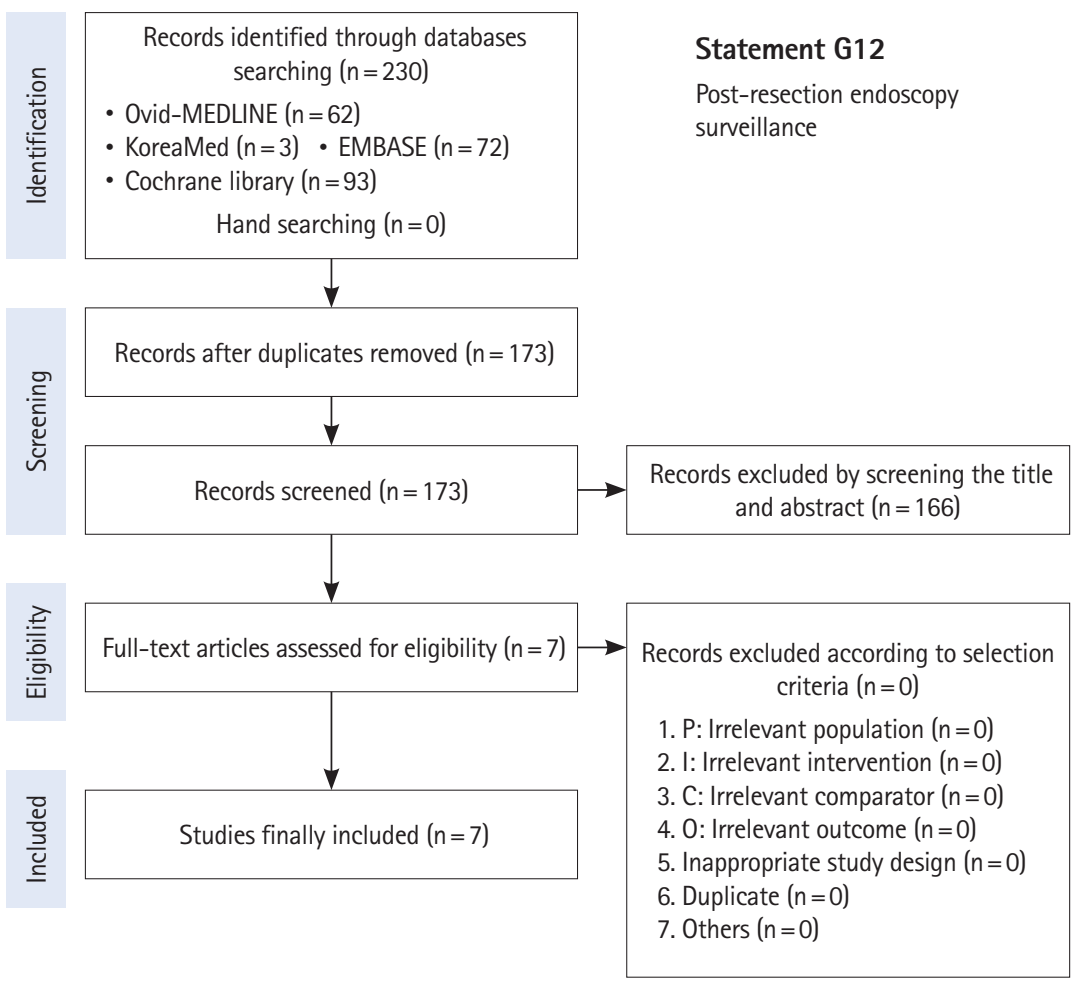




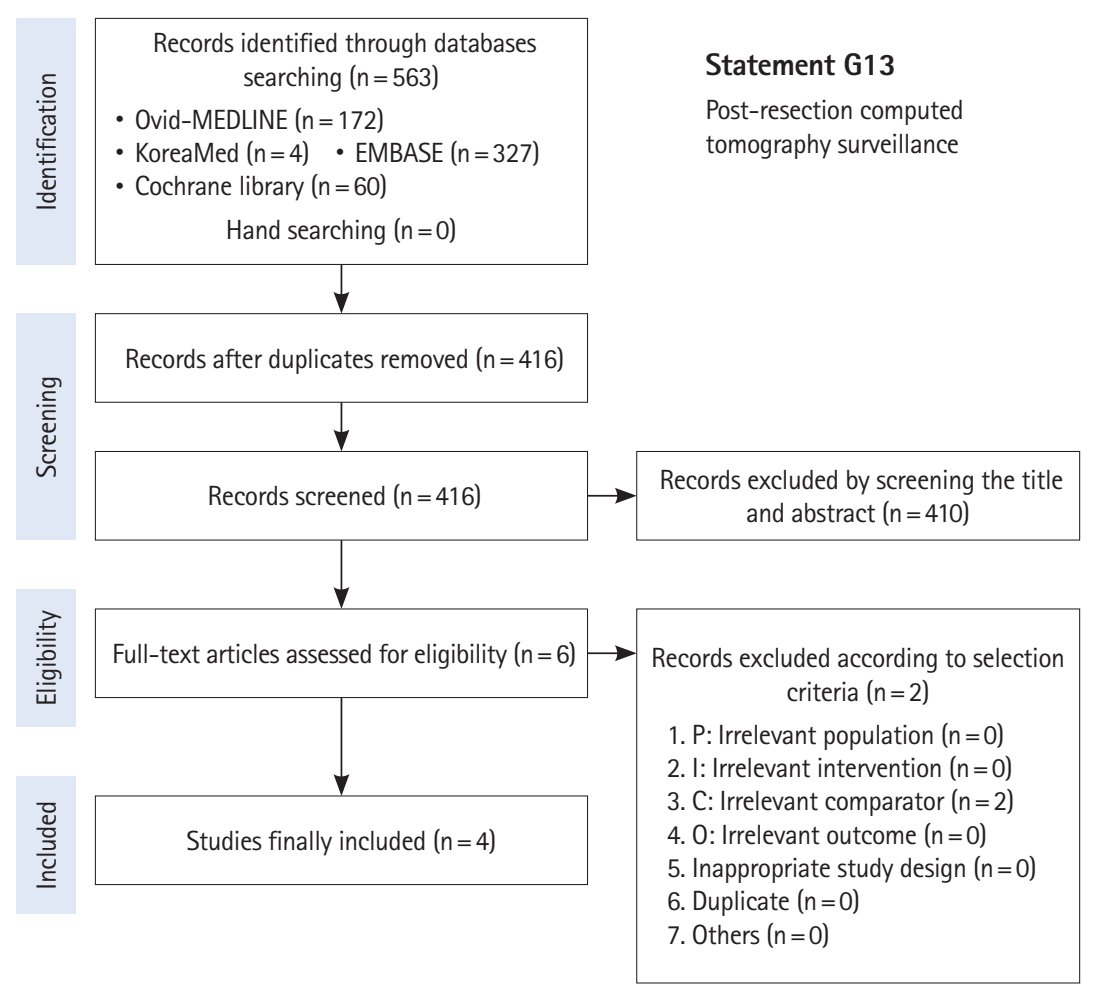




\section{Early Colorectal Cancer}

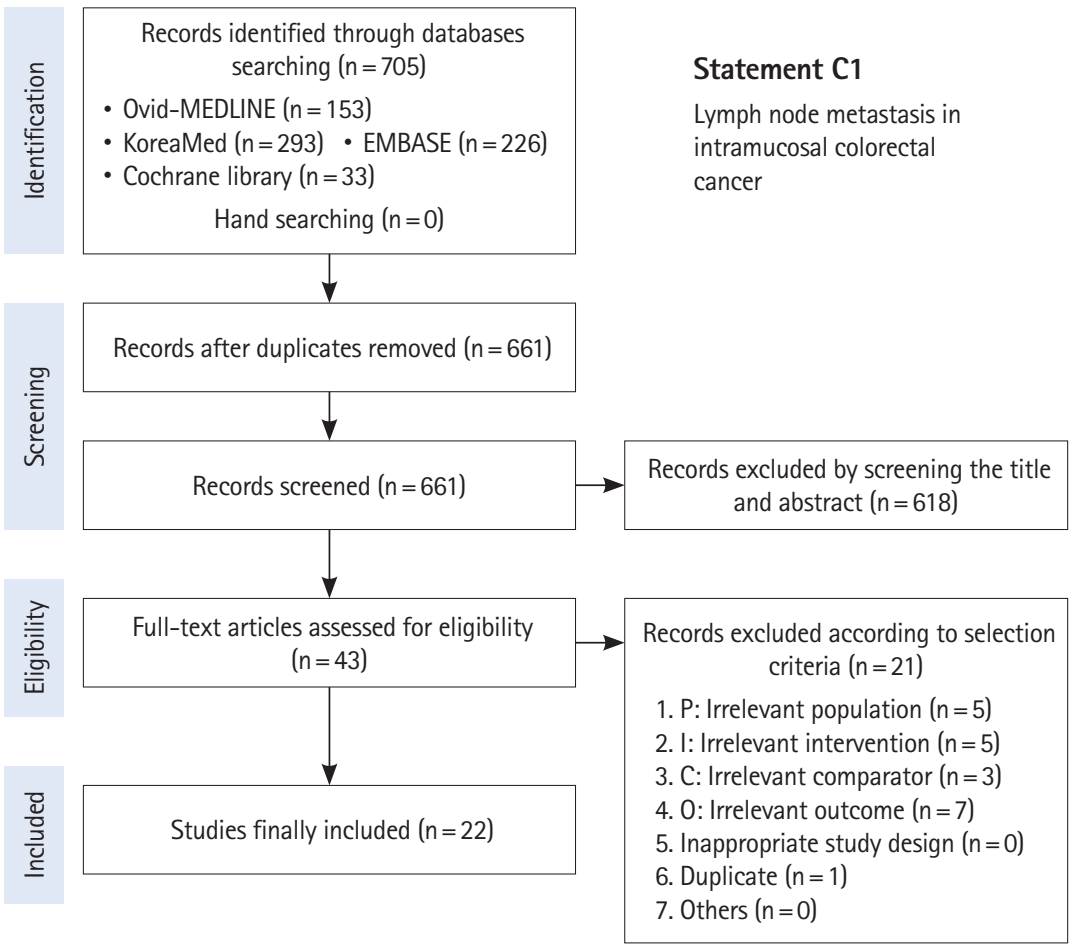




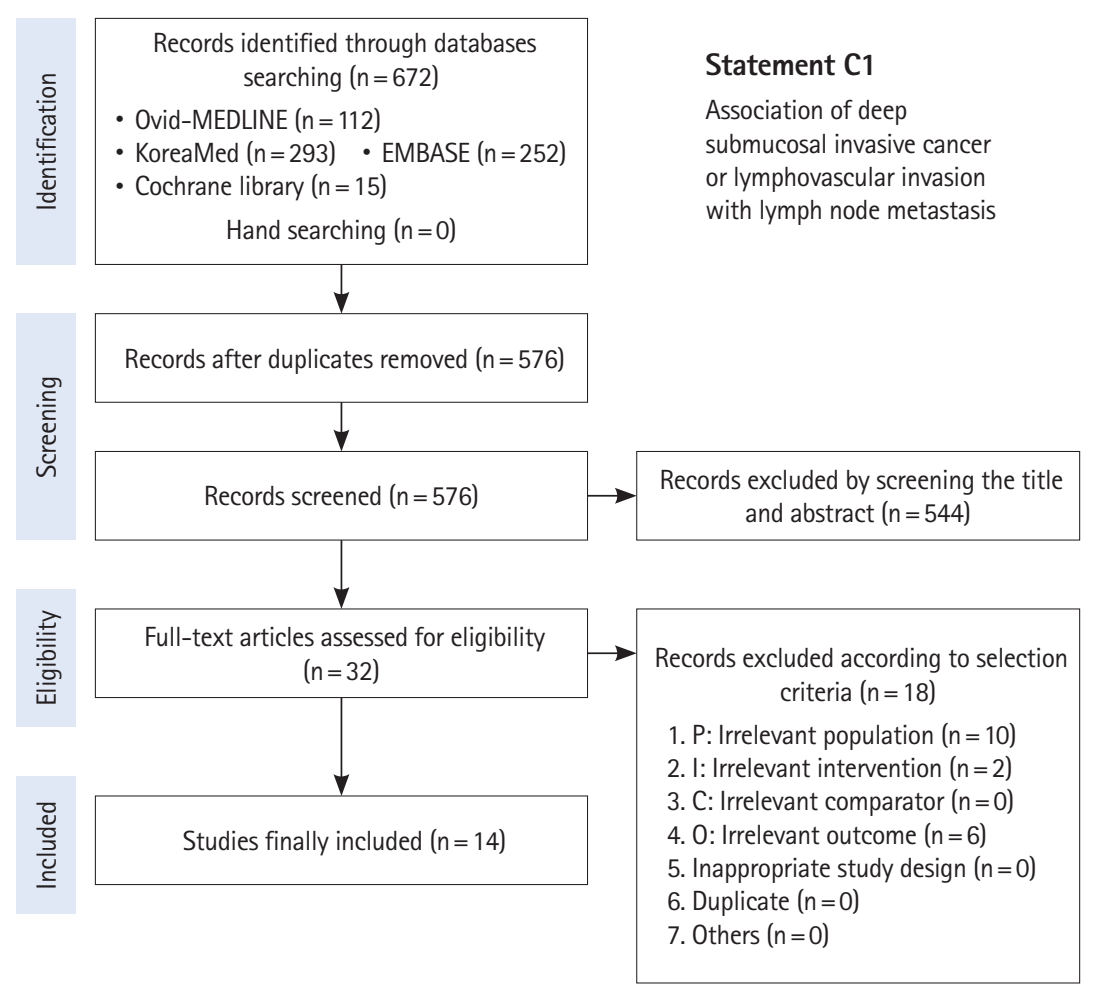




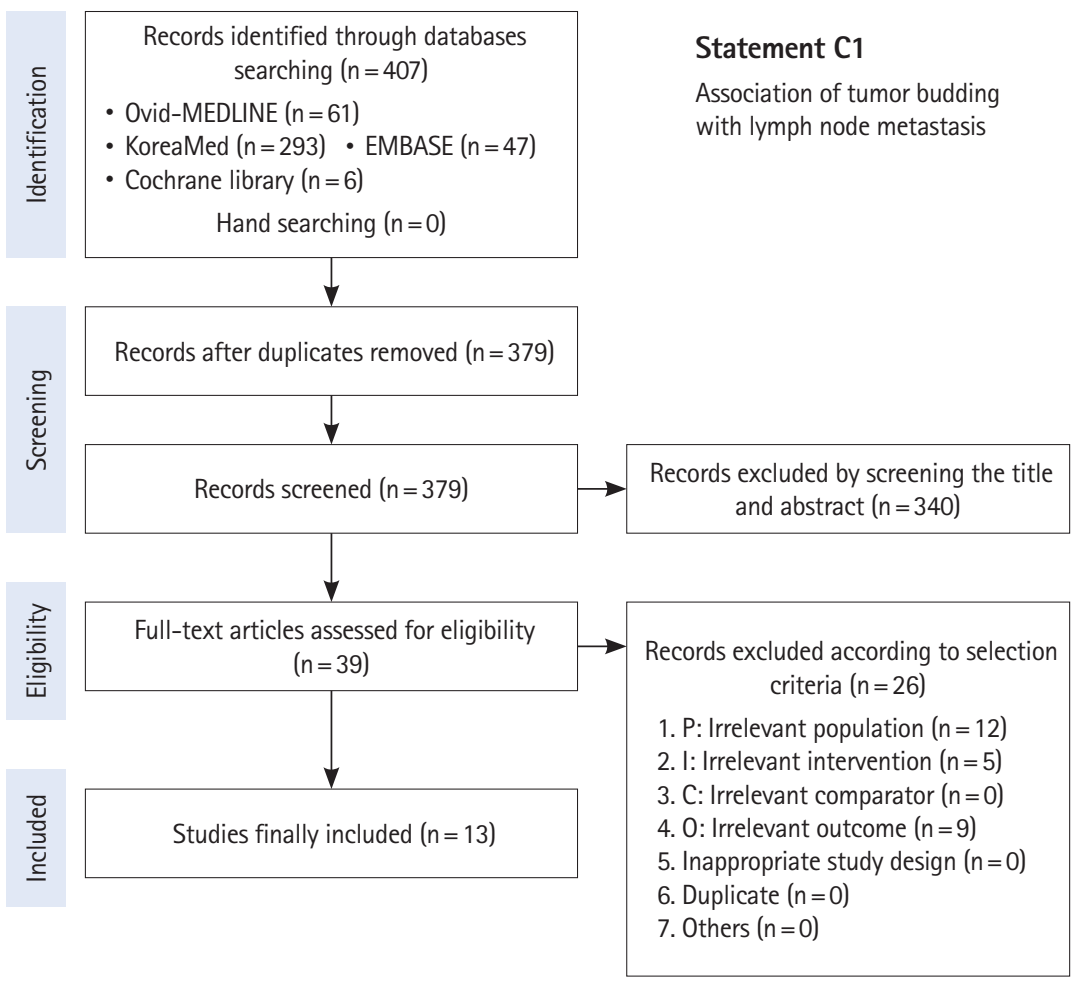




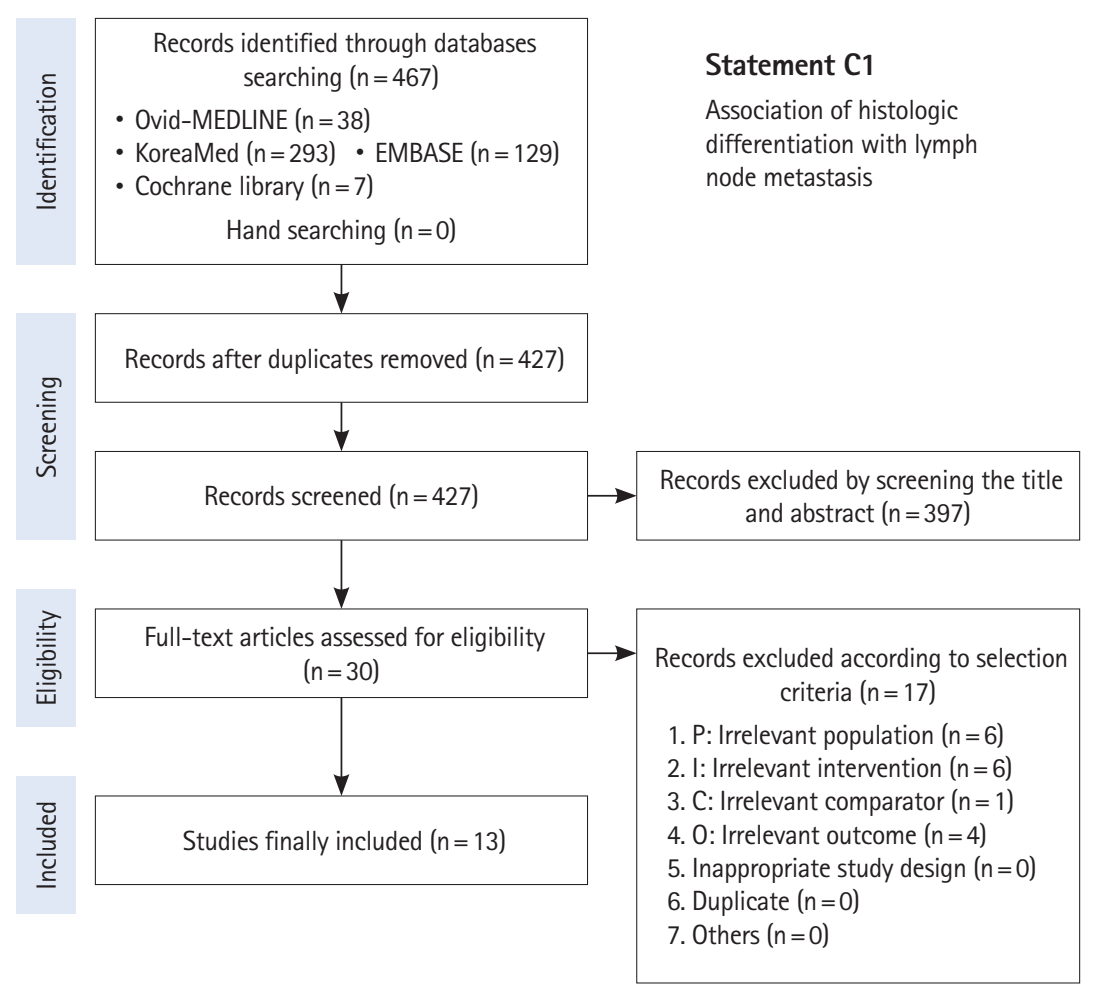




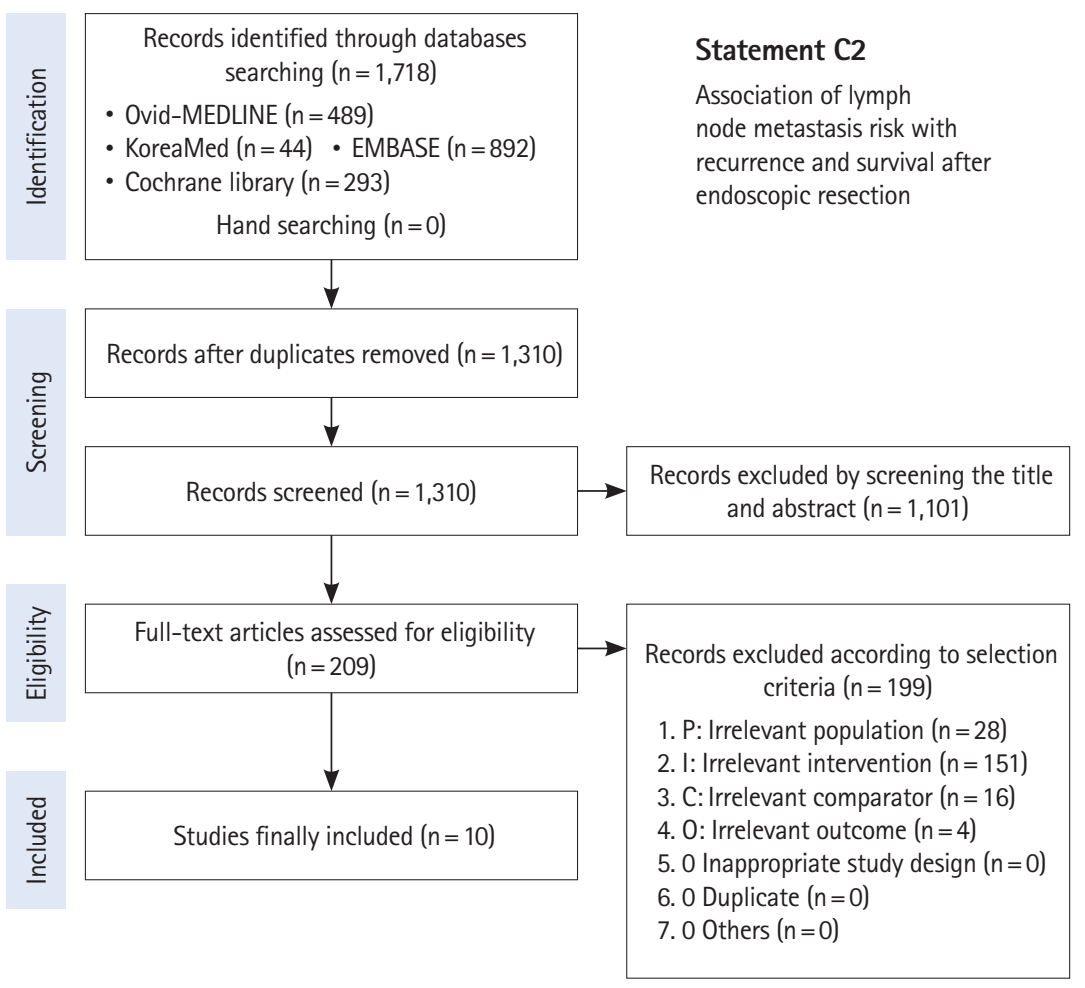




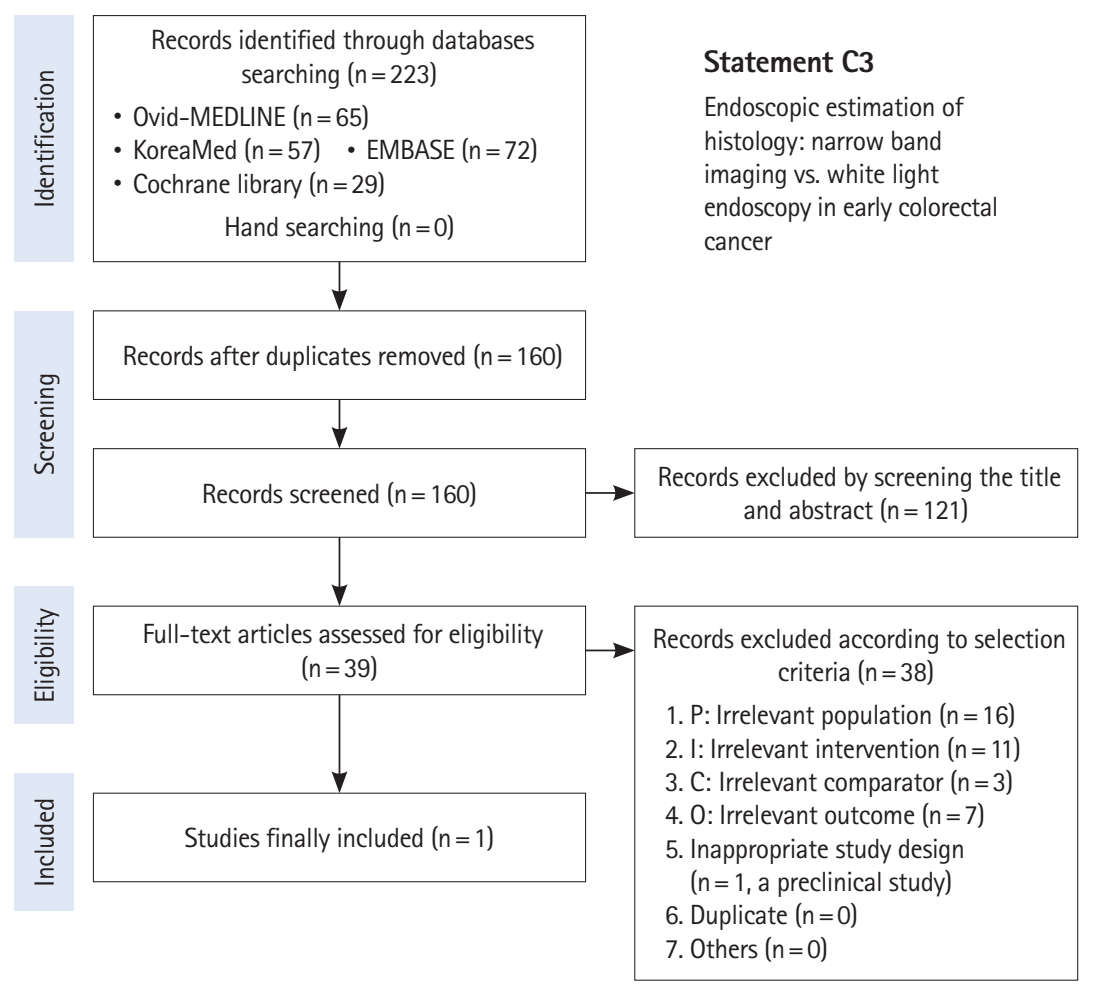




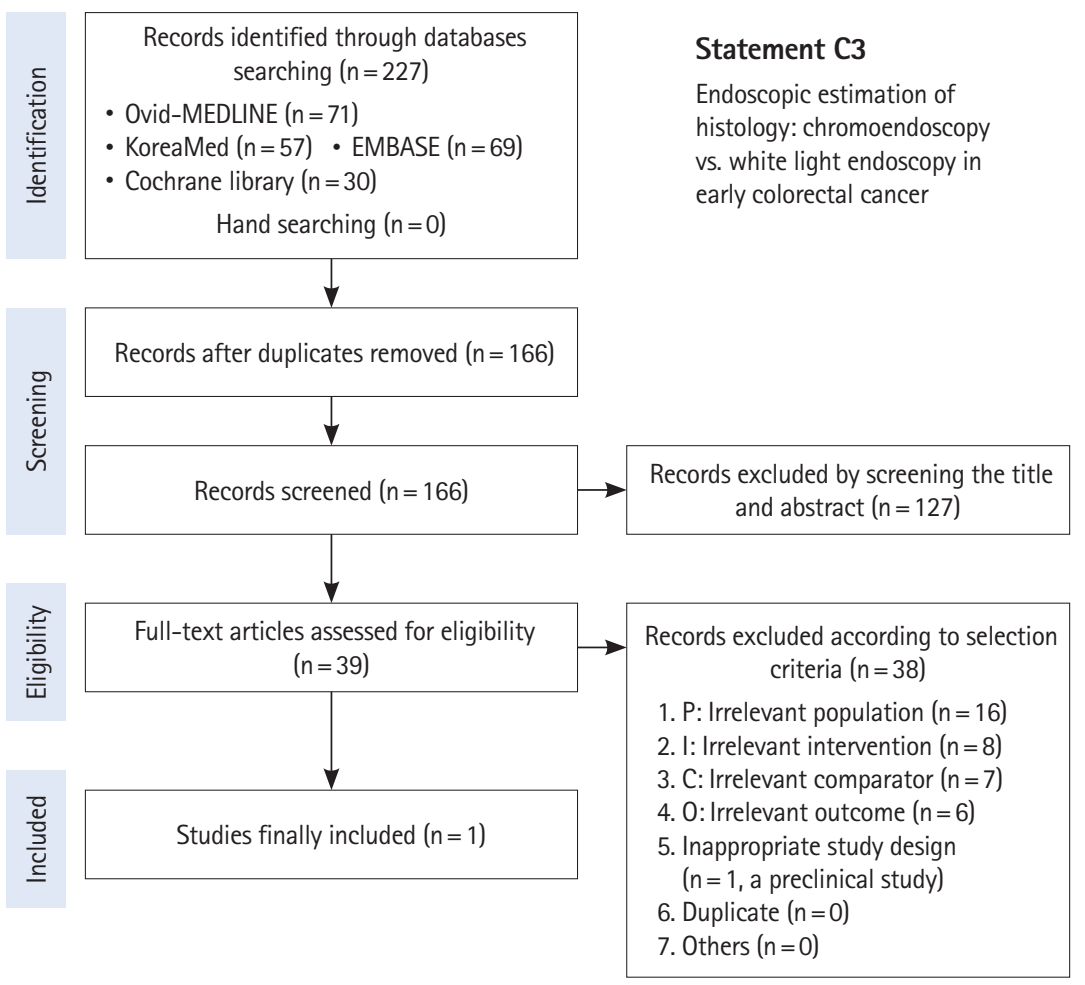




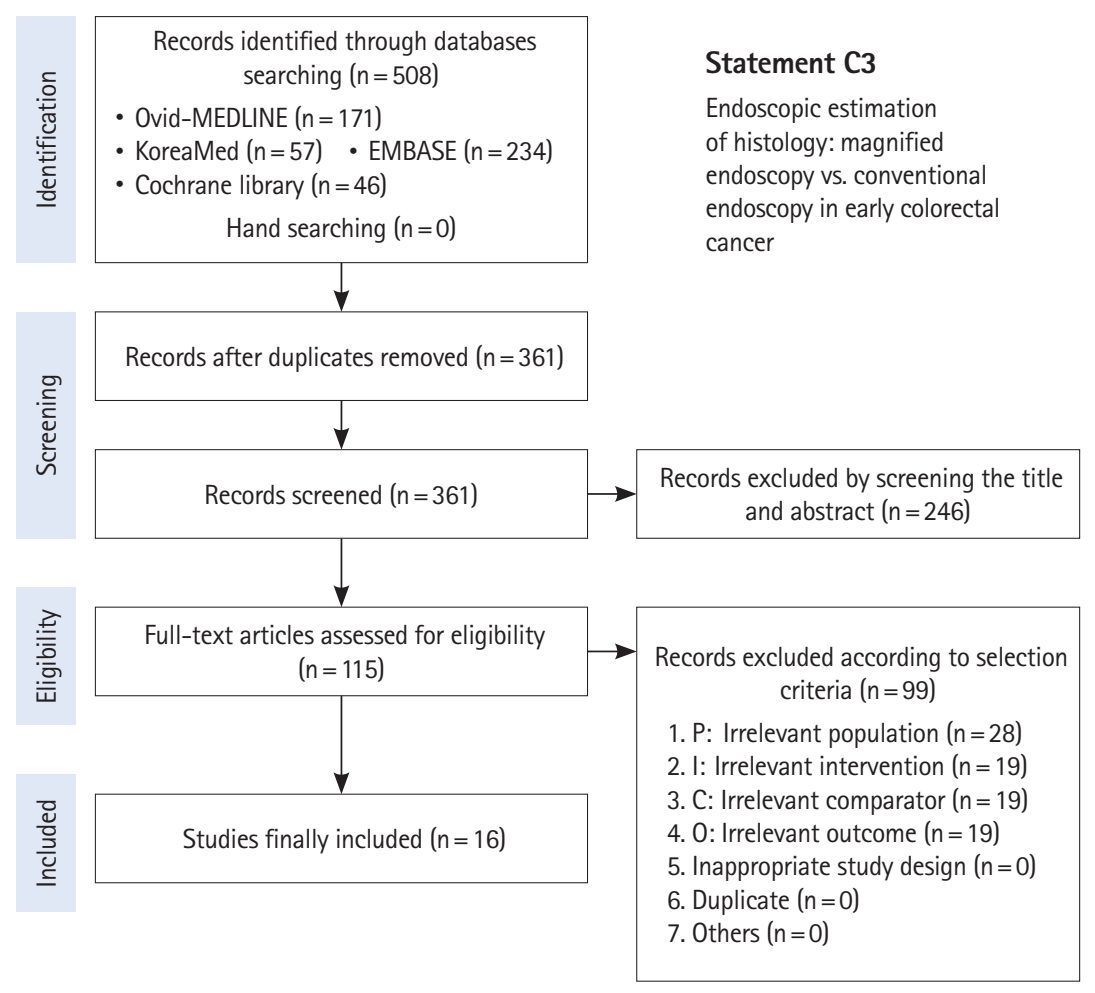




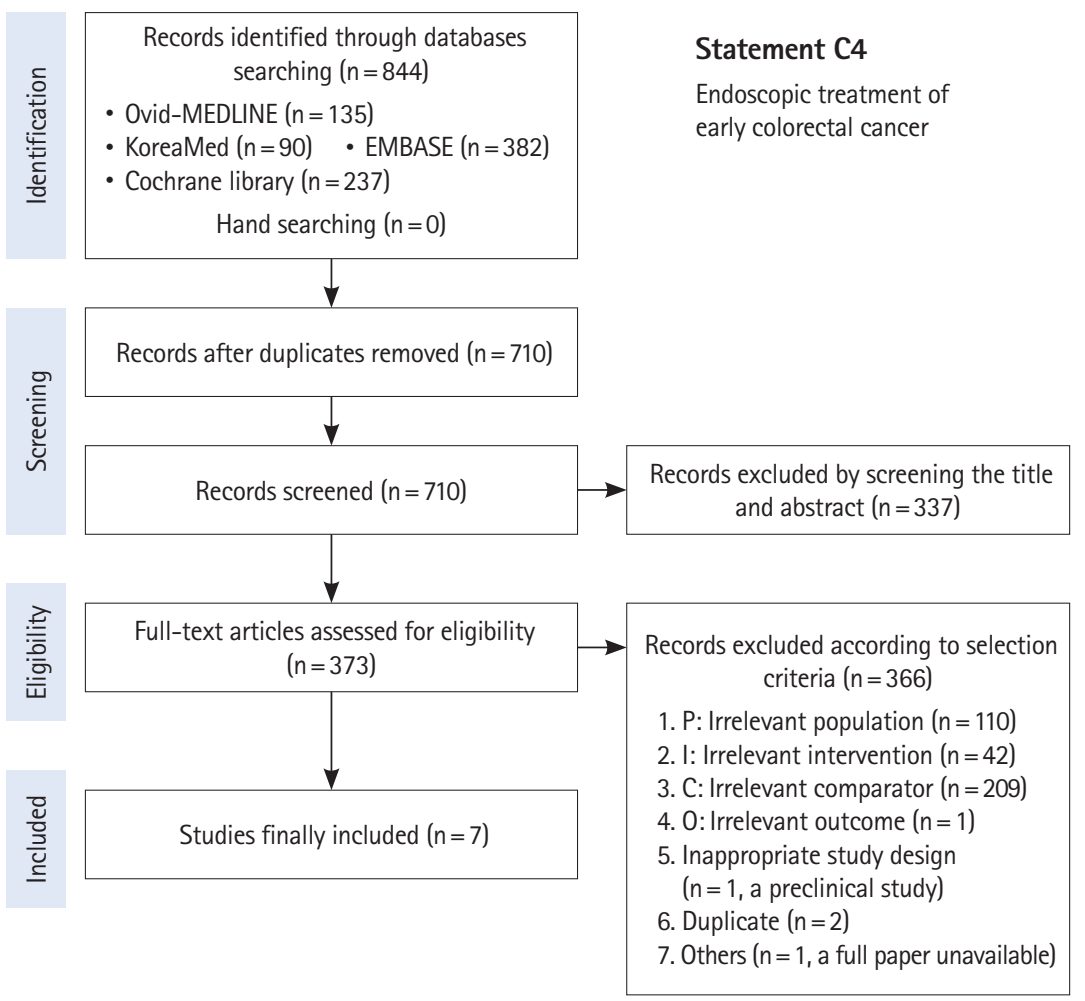

